\title{
Manifestation of Pathological States of Numerous Diseases in the Largest Organ of the Human Body: (I) Basics and the Diseases of Tendon
}

\author{
Peter Chin Wan Fung ${ }^{*}$, Regina Kit Chee Kong² \\ ${ }^{1}$ Division of Medical Physics, Department of Medicine, University of Hong Kong, Hong Kong, China \\ ${ }^{2}$ School of Traditional Chinese Medicine, Southern Medical University, Guangzhou, China \\ Email: *peterallegro333@gmail.com, *hrspfcw@hku.hk
}

How to cite this paper: Fung, P.C.W. and Kong, R.K.C. (2019) Manifestation of Pathological States of Numerous Diseases in the Largest Organ of the Human Body: (I) Basics and the Diseases of Tendon. International Journal of Clinical Medicine, 10, 183-249.

https://doi.org/10.4236/ijcm.2019.103018

Received: January 21, 2019

Accepted: March 15, 2019

Published: March 18, 2019

Copyright $\odot 2019$ by author(s) and Scientific Research Publishing Inc. This work is licensed under the Creative Commons Attribution-NonCommercial International License (CC BY-NC 4.0). http://creativecommons.org/licenses/by-nc/4.0/ (c) (i) \&) Open Access

\begin{abstract}
We analyze the crucial biochemical and biophysical properties of the basic constituents-connective tissues (CT), and interstitial fluid (IF) constituting the non-cellular part of the fascia. We provide ample evidence that the resident cells and cells in transit in the fascia are continuously interacting with the non-cellular constituents to form an active organ with well-defined functions. We show evidence that pathological states of diseases of internal organs, as well as that of the constituents of the fascia itself, manifest in certain CTIF domains of the fascia. Numerous diseases originate from imbalance of the digestion and synthesis of the native collagen triple helices. Review on the scanning electron microscopy examination of cross-section of tendons indicates that micro-fibrils of collagen I form regular geometrical structures, supporting the hypothesis that the collagen fibrils assemble like liquid crystals. Information on the age of Achilles tendons has been reported, based on dating of the ${ }^{14} \mathrm{C}$ atoms generated from the nuclear bomb tests in 1955-1963. The causes of spontaneous tendon rupture and tendinopathy are analyzed. Plausible clinical measures to treat tendinopathy are briefly discussed, including the application of synthetic mechano-growth factor, glyceryl trinitrate patch (to supply nitric oxide), platelet rich plasma, proteomic profile analysis and microRNA 29a therapy.
\end{abstract}

\section{Keywords}

Fascia, Mechanotransduction, Collagen Degradation and Synthesis, Durotaxis of Cells, Self-Assembly of Tropocollagen, Thermal Stability of Collagen, Fibroblasts, Stem Cells, Proteoglycans, Glycoproteins, Interstitial Fluid, 
Achilles Tendon, Tendinopathy

\section{Introduction}

\subsection{Mechanotransduction through Organisms on Earth}

All living organisms on earth are inevitably subjected to (a) the gravitational force that continuously acts as a mechanical pull on all parts of the body, and (b) frequently occurring external mechanical stimuli/forces of various degrees from other objects. In the past twenty years, research on intra- and inter-cellular signaling with reference to cellular structure variation indicates that (i) external stimuli of mechanical or electrical nature control or trigger many fundamental biochemical interactions; (ii) tissues are composed of a network of proteins joining organs; (iii) the nucleus and other functional components inside individual cells are not floating in a fluid; rather many protein/peptides readily join up to communicate between the extracellular matrix and the nucleus; (iv) certain intact cells are migrating in the connective tissues to carry out important physiological functions.

Putting fourth these observations and recalling the two "disturbances" (a) and (b) on organisms on earth, one is inclined to consider that a special architecture system must be at work in each living entity particularly suitable for the transmission of mechanical signals, if the organism is to remain as that entity. Such an architectural system is one important basis for allowing physical and biochemical signals to be transmitted inter- and intra-cellularly to certain parts of the body. Mechanical signal, as one type of physical signal, is inferred to be transmitted through mechanotransduction to various parts of the body based on the hierarchy nature of the body [1] [2] [3].

\subsection{The Basic Components of the Largest Organ of the Human Body-The Fascia}

In a multi-cellular organism, after a (fermented) cell has completed its first mitosis into two and then more cells, a system of communication must have existed to cater for the coordination of the function of a group of cells in a controlled environment and morphogenic development, for the survival and growth of the organism. Such a communication system must allow the exchange of various forms of energy and materials (such as the exchange of biomolecules via osmosis, diffusion) for both biophysical and biochemical interactions. A system that consists of both solid and liquid components could serve these purposes. The connective-tissue system, which is developed from the mesoderm, is a natural solid platform for communication between organs; the embryonic water is a natural fluid to develop into a fluid for the transportation of both soluble and insoluble (via vehicles such as chylomicrons) [3]. The connective tissues include 28 types of (a) fibrous (including collagen fibers, 
elastic fibers and reticular fibers) and (b) non-fibrous collagen structures, plus (c) non-collagenous proteins to support integrity of various visceral organs and the body as a whole [3] [4] [5].

Part (c) contains two main classes of non-collagenous protein complexes (A) and (B). Classes (A) i.e. Proteoglycans (PG) has subclasses aggrecan, fibromodulin, heparan sulfate, decorin, perlecan, glycosaminoglycan (GAG, such as hyaluronan, keratan, heparin) and others. Note that hyaluronan, which is the most abundant and ubiquitous member of the GAGs, forms negatively charged long chains. The hydronium ions together with layers of water (originated from the blood stream) are then bound to the hyaluronan chains, forming a thick interstitial fluid (IF) in the interstitium; IF, also named the ground substance, is just the fluid for communication mentioned above. There is about 3 liters of interstitial fluid processed through the human body per day. The other non-collagenous protein complex (B), called Glycoproteins, have subclasses such as fibronectin, tenuscin, thrombospondins- 1 and -4 (as adhesive proteins), laminin. Members of (B), together with members of (A), provide a potential bridge between parts (a) and (b) and the cells adjacent/within the interstitium. The connective tissue proper (CT) includes parts (a), (b) and (c). Since blood vessels do not "connect" cells of organs in the body, all communications are transmitted through the connective tissue-interstitial fluid (CTIF) system. The fascia is meant to be the grand anatomical structure joining all the CTIF systems associated with different parts of the body.

This fascia frame, including the solid parts and special fluid mentioned above, has various types of linked, connective tissue layers which embed the neurovascular tracts, extending to form tunicae around the visceral organs. The frame also wraps around muscles (striations/spindles); the connective tissues of the frame grow deep to form the periosteum which supplies vascular structure to the bone [6] [7]. Since the bone is also built of collagen, it is not unreasonable even to define the skeletal bone as the very "hard part" of the CTIF system.

There are intact cells migrating in the fascia. These cells are called the resident cells. They are also called indigenous cells [8] and have a stable population; they are mainly responsible for the synthesis and maintenance of the heterogeneous extracellular matrices of CTIF associated with different organs; these cells are also serving some other physiological functions. There are also cells in transit when in need, to perform immunity duties. The "hard part" and "soft part", which are both non-cellular, together with the cells mentioned, constitute an integrated network to maintain the integrity of body shape against gravity, as well as to serve as a grand active communication network. Research in the past decade recognizes the fascia to be highly dynamic and versatile (see force transmission aspect in [9]). Since this grand communication platform with solid and fluid constituents, has anatomical structure and has well defined functions, it is rightful to call it an organ-in fact, the largest organ of the human body. Figure 1 summarizes the basic compositions of this organ. 


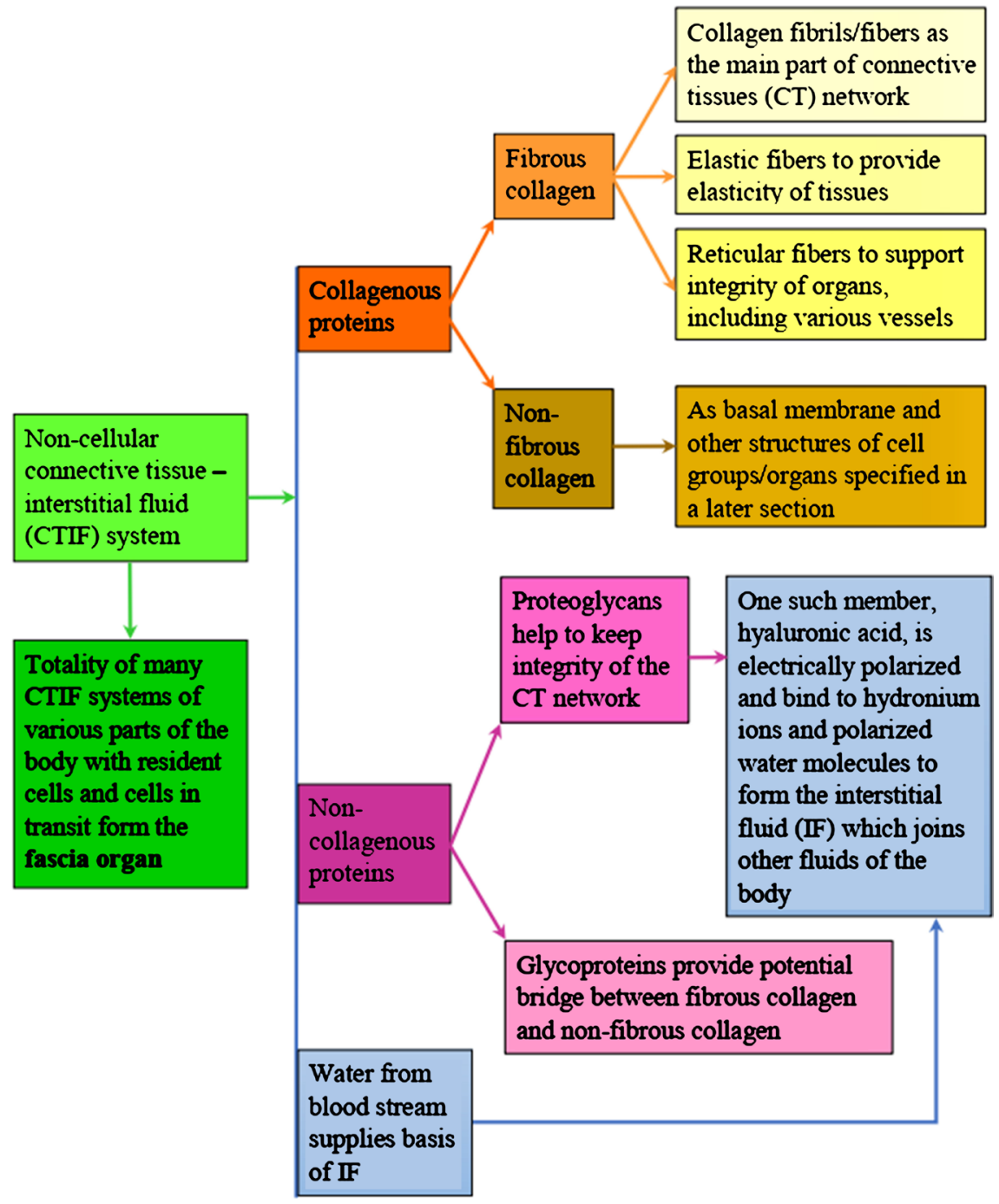

Figure 1. Basic structure of the largest organ of the body.

\subsection{Functions of the Circulation of Fluids in the Largest Organ of the Body}

We emphasize that as blood vessels do not "connect" cells of organs in the body, all communications between two organs pass through the connective tissue-interstitial fluid (CTIF) system. The stated communications include the transportation of molecules and various forms of energy signals (such as mechanical, sound, electrical signals). In particular, the IF is responsible for the following main processes: 1) Exchange of $\mathrm{O}_{2}$ and $\mathrm{CO}_{2}$ in muscles and organ cells; 2) Provision and re-absorption of nutrients to organ cells; 3) Transportation of metabolic debris and harmful cells to the peripheral lymphatic system via the flow of the IF to the lymphatic collecting ducts; 4) Supplying shear forces (acting as signals) during durotaxis/chemotaxis [10] of fibroblasts, chondrocytes, osteocytes, osteoblasts, mesenchymal stem cells and stem cells in the CT, including those in the hair-follicles, for tissue homeostasis as well as repairs/turnover of the CTIF system, cartilages and bones; 5) Provide a medium for the migration of 
leucocytes from the blood vessels to the CTIF during inflammation; 6) It has been discovered only in the recent few years that a lymphatic system in the brain exists-called glymphatic system and the fluid is named the glymphatic fluid (see review of [11]). This fluid is a mixture of the classical cerebrospinal fluid flowing in the subarachnoid space and the brain interstitial fluid in the brain parenchyma. One of the important functions of the IF flow is to provide a route for the glymphatic fluid to join the peripheral IF which flows into the peripheral lymphatic fluid system. 7) The IF, carrying debris and fragments of damaged cells in the CTIF system, joins the subclavian vein vessels. These vessels have branches flowing through the renal system; wastes are then discharged by urination [3] [11].

\subsection{Intracellular Mechanotransduction}

Integrins are cell membrane receptors, being composed of $\alpha$ - and $\beta$-subunits with various combinations. They can bind to proteins in the extra-cellular matrix (ECM) with specificity [12]. When the integrins are stimulated mechanically, they connect intracellular proteins such as focal adhesion kinase (FAK), src-family kinases. Activation of these kinases triggers off a series of pathways associated with cytoskeletal remodeling. In particular, in vitro experimental results show that the stress-induced mechanical strain stimulated conformational activation of $\alpha$ - and $\beta$-integrins of NIH3T3 cells [13].

Such activation is followed by new integrin ligand binding to ECM proteins; this process then mediates c-Jun NH2-terminal kinase (JNK), initiating a series of cellular responses without upsetting the existing integrin-ECM binding. Responding to mechanical stimulation, "focal adhesion" is said to be formed, leading to a stress-dependent increase in cytoskeletal (CSK) stiffness. The CSK stiffness changes because there is rearrangement of the microfilaments (MF), microtubules (MT) and intermediate filaments (IF), which are the three important elements to participate in mechanotransduction, intracellularly. These connecting structures, together with other components, eventually join the nucleus surface after such CSK remodeling [14].

Then expressions of different genes are affected to produce the relevant proteins to maintain the cell integrity and to initiate the necessary physiological processes [15]. There are different integrins for different cell types to trigger different functions in response to mechanotransduction. For example, the integrins of the endothelial cells of blood vessel are born to react sensitively to mechanical stimulus arising from fluid flow, in addition to "pull" from collagen fibers. Thus, mechanical signals at the cell membrane can cascade a series of signals reaching the cell nucleus with the integrin proteins, as mechanical sensors, starting the story.

\subsection{Intercellular Mechanotransduction}

Gap junction proteins, which are built by various connexin proteins, are "connection proteins" between adjacent cells [16]. It has already been known, based 
on analysis of synchronous contraction of myocardial cells, that the gap junction proteins participate in the transfer of mechanical stimulation, indicating that mechanotransduction can be "passed on" between adjacent cells of a tissue/organ [17]. It has also been shown that electrical synaptic transmission between nerve cells depends again on the function of gap junctions [17]. The connexin protein $\mathrm{Cx} 43$ has been found to bind directly or indirectly to some intracellular proteins like caveolin, 20- $\beta$-catenin, tubulin, src, which have various functions, providing evidence that gap junctions take part also in mechanotransduction [18].

\subsection{Objectives and Layout of This Paper}

As analyzed in Sections (1.2) and (1.3), all "ingredients" and signals for visceral organ cells pass through part of the fascia. It is thus important to learn the physiological conditions of various parts of this large organ. Now collagen is the main protein constituting the solid part of the fascia, and collagen forms loose connective fibers/fibrils in the skin and supporting tissues, integument layers of all organs, including even small blood vessels, nerve fibers, and lymphatic ducts. We review the key features of synthesis of the basic collagen molecules and their formation of fibrous morphology of different sizes, as well as some important structural characteristics in Sections (2.1) to (2.4). Relevant features of the residence cells are briefly outlined in Section (2.5). The hierarchy nature of the fibrous collagen constituents, together with roles played by resident cells and cells in transit will be briefly analyzed in Section (2.6). The crimp structure of collagen fibrils is important in absorbing force during movement of different parts of the body, and two examples are presented to illustrate the morphology of the crimps in Section (2.7). A living organism is a dynamical complex system. Homeostasis includes turnover procedures and repairing mechanisms of collagen. Therefore, we review the classification and functions of the degrading enzymes and the endogenously generated inhibitors of those enzymes in Sections (3.1) - (3.4). Based on the brief review presented in Sections (1) - (3), we can then analyze the first class of disease of our series-rupture and tendinopathy of the tendons which are parts of the fascia proper. Section (4) is devoted to the discussion of the interesting structural arrangement of the collagen fibrils that allows tendons to withhold tensile strength based on in vitro investigation of tendon specimens obtained from animal models. Thermal stability of collagen triple helices is a debatable key issue in maintaining the mechanical strength of tendons. We therefore present two types of contrasting experimental results in Section (5). Every triple helix is built of three peptide chains, and wrong combinations (due to genetic mutation or incomplete folding correction by heat shock proteins in the RER) lead to diseases of the fascia proper, which could trigger off pathological states of other organs. This issue is discussed in Section (6). It is difficult to predict tendon rupture, and tendinopathy is difficult to treat clinically. In Section (7), we present some updated information of the causes and introduce 
plausible treatments. Section (8) emphasizes the evidence of viewing the fascia to be the largest organ of the body and highlight the notion that pathological states of many diseases manifest in the fascia, paving the way for the next related paper. Section (9) gives concluding remarks. This paper is lengthy as a rather large amount of basic materials need to be introduced for meaningful discussion of any disease involved.

\section{Synthesis and Special Properties of Collagen Molecules in the Fascia}

\subsection{Collagen as the Most Abundant Protein in the Body}

Collagen fibrils have been supporting life of numerous species for over $600,000,000$ years, and collagen is now known to be the most prominent protein component of the hierarchy connective tissue systems of nearly all members of the animal kingdom. It is indeed amazing to find that the basic architecture of collagen fibrils is conserved across different animal species during evolution [19] [20] [21] [22].

In the human body, collagen constitutes about one third of the body mass [23]. The basic unit of collagen is composed of three helical structures of amino acids, with details specified later. According to different compositions of these helices, collagen can be classified, up to the present, into at least 28 types.

Types I, II, and III account for quantitatively over $70 \%$ by weight of the total connective tissues [24] which compose the biggest tissue system of the body. In particular, type I collagen makes up $80 \%-90 \%$ by weight of the collagenous proteins.

\subsection{Types of Collagen Molecules, Fibrous and Non-Fibrous}

Since both fibrous and non-fibrous collagen structures are involved in the pathogenesis of many diseases, we show Table 1 to summarize the classes of collagen so far found, their key characteristics and main locations in the human body. There can be more than one isoform for one type of collagen. For example, in the second column, $\left.\left[\alpha_{1}(\mathrm{I})\right]^{2} \alpha_{2}(\mathrm{I})\right]$ means that a type I collagen triple helix can be composed of two $\alpha_{1}$ chains and one $\alpha_{2}$ chain of collagen I; the second isoform is simply built of three $\alpha_{1}$ chains of collagen I. The super-script 3 of $\left[\alpha_{1}(\mathrm{I})\right]^{3}$ means that there are three $\alpha_{1}$ (I) chains in a type I tropocollagen molecule. The subscript 1 means that the chain is of class $\alpha_{1}$ (rather than the $\alpha_{2}$ chain). The former structure is called a heterotrimer and the latter structure is called a homotrimer. These two classes of structure respond differently to enzyme degradation, as will be explained later in Section (6). The other symbols for other types of collagen follow the same way. There are totally 28 types of collagen found up to now. We show only 14 types out of 28 here as they are relevant to our discussion on the physiological/pathological aspects involved in this paper. When we come to some other diseases involving other types of collagen, they will be specified in other papers to follow. 
Table 1. Types of collagen [25].

\begin{tabular}{|c|c|c|c|}
\hline Type of collagen & Chains & Basic structural characteristics & Distribution in body \\
\hline I & $\begin{array}{l}{\left[\alpha_{1}(\mathrm{I})\right] \cdot{ }^{2} \alpha_{2}(\mathrm{I}) ;\left[\alpha_{1}(\mathrm{I})\right]^{3}} \\
(\text { not native })\end{array}$ & fibrous & $\begin{array}{l}\text { skin, tendon, ligament, bone, cornea, general } \\
\text { connective tissues }\end{array}$ \\
\hline II & {$\left[\alpha_{1}(\mathrm{II})\right]^{3}$} & fibrous & $\begin{array}{l}\text { cartilage, vitreous humour, inner core of vertebral } \\
\text { disc-nucleus pulposus, less organized-meshwork }\end{array}$ \\
\hline III & {$\left[\alpha_{1}(\mathrm{III})\right]^{3}$} & fibrous & $\begin{array}{l}\text { co-distributes with type I in smaller amount, } \\
\text { endotenon }\end{array}$ \\
\hline IV & $\begin{array}{l}{\left[\alpha_{1}(\mathrm{IV})\right] \cdot{ }^{2} \alpha_{2}(\mathrm{IV})} \\
\alpha_{3}(\mathrm{IV}) \cdot \alpha_{4}(\mathrm{IV}) \cdot \alpha_{5}(\mathrm{IV}) \\
{\left[\alpha_{5}(\mathrm{IV})\right]^{2} \cdot \alpha_{6}(\mathrm{IV})}\end{array}$ & forming network & basement membrane of organs \\
\hline $\mathrm{V}$ & $\begin{array}{l}{\left[\alpha_{1}(\mathrm{~V})\right] \cdot{ }^{2} \alpha_{2}(\mathrm{~V})} \\
\alpha_{1}(\mathrm{~V}) \cdot \alpha_{2}(\mathrm{~V}) \cdot \alpha_{3}(\mathrm{~V}) \\
{\left[\alpha_{1}(\mathrm{~V})\right]^{3}}\end{array}$ & fibrous & co-distributes with type I in smaller amount \\
\hline VI & $\alpha_{1}(\mathrm{VI}) \cdot \alpha_{2}(\mathrm{VI}) \cdot \alpha_{3}(\mathrm{VI})$ & with beaded-filament structure & around muscles, in "cross-structure between fibrils" \\
\hline VII & {$\left[\alpha_{1}(\mathrm{VII})\right]^{3}$} & forming anchoring fibrils & epidermal-dermal boundary \\
\hline VIII & {$\left[\alpha_{1}(\mathrm{VIII})\right]^{2} \cdot \alpha_{2}(\mathrm{VIII})$} & forming network & $\begin{array}{l}\text { basement membrane between corneal proper and } \\
\text { endothelial-Descement's membrane }\end{array}$ \\
\hline IX & {$\left[\alpha_{1}(\mathrm{IX})\right] \cdot \alpha_{2}(\mathrm{IX}) \cdot \alpha_{3}(\mathrm{IX})$} & $\begin{array}{l}\text { fibril associated collagens with interrupted triple } \\
\text { helices (FACIT) }\end{array}$ & co-distributes with type II \\
\hline $\mathrm{X}$ & {$\left[\alpha_{1}(\mathrm{X})\right]^{3}$} & forming network & hypertrophic structure of cartilage \\
\hline XI & $\alpha_{1}(\mathrm{XI}) \cdot \alpha_{2}(\mathrm{XI}) \cdot \alpha_{3}(\mathrm{XI})$ & fibrous & co-distributes with type II \\
\hline XII & {$\left[\alpha_{1}(\mathrm{XII})\right]^{3}$} & FACIT & co-distributes with type I in small amount \\
\hline XIII & {$\left[\alpha_{1}(\mathrm{XIII})\right]^{3}$} & transmembrane protein & $\begin{array}{l}\text { cell-matrix and cell-cell adhesion, neuromuscular } \\
\text { junctions }\end{array}$ \\
\hline XIV & {$\left[\alpha_{1}(\mathrm{XIV})\right]^{3}$} & FACIT & co-distributes with type I in small amount \\
\hline
\end{tabular}

\subsection{Procollagen Molecules Are Synthesized, with Folding Checked by Heat Shock Proteins and Exit to the Extra-Cellular Domain via Exocytosis}

Interstitial collagens consist of three $\alpha$ chains of approximately 1000 residues with repeating Gly-X-Y triplets, where $\mathrm{X}$ and $\mathrm{Y}$ are often proline and hydroxyproline, respectively. Because of the high imino-acid content and the tripeptide unit repeats, the $\alpha$-chain adopts a left-handed poly-Pro II-like helix, and three left-handed $\alpha$-chains intertwine with each other to form a righthanded superhelix [25]. It is the occurrence of amino acid glycine as every third residue throughout $95 \%$ of the $\alpha$ chains as well as the presence of large amounts of proline and hydroxyproline (which together amount to approximately $22 \%$ of the amino acid residues) that would allow each (alpha) polypeptide chain to be arranged in a stretched polyproline helix. In other words, collagen triple helices are said to be packed into a "quarter-staggered" pattern so that the nearest neighbor molecules are staggered longitudinally by about $22 \%$ of their molecular 
lengths with a space gap between the $\mathrm{N}$-terminal of one molecule and the C-terminal of the next [25].

Each peptide chain of collagen is encoded by one gene in general. However, many of the collagen types have two, or even three peptide chains of the same class. In Figure 2, suppose three different collagen genes, $\alpha_{1}, \alpha_{2}, \alpha_{3}$ are triggered to synthesize a collagen molecule. In the nucleus, the double helical gene structure is broken to form RNAs. Each RNA works as an mRNA and one associated peptide is synthesized in the usual way in the ribosome; and the peptide is fed into the (rough) endoplasmic reticulum (ER or RER) and then the Golgi apparatus, as shown schematically in Figure 2. The three raw peptides assemble, and the resulting structure is quality checked for proper folding by heat shock proteins in the RER and Golgi apparatus (see [26]), with nucleation taking place at the $\mathrm{C}$ terminal [27]. A number of sugars are added to the peptides in the RERGorgi apparatus "factory" too. The "tentative collagen molecule", called "procollagen" of $\sim 325 \mathrm{~nm}$ in length, is then excreted from the cell by the usual exocytosis process, with the help of the Golgi apparatus. The dotted arrow represents the fact that the last synthesis processes are carried out in the RER and Golgi apparatus, not in the cytosol.

It was already known that HSP 47 is an ER-resident stress inducible glycoprotein that specifically and transiently binds to newly synthesized procollagens [28].

\section{Synthesis and exocytosis of procollagen}

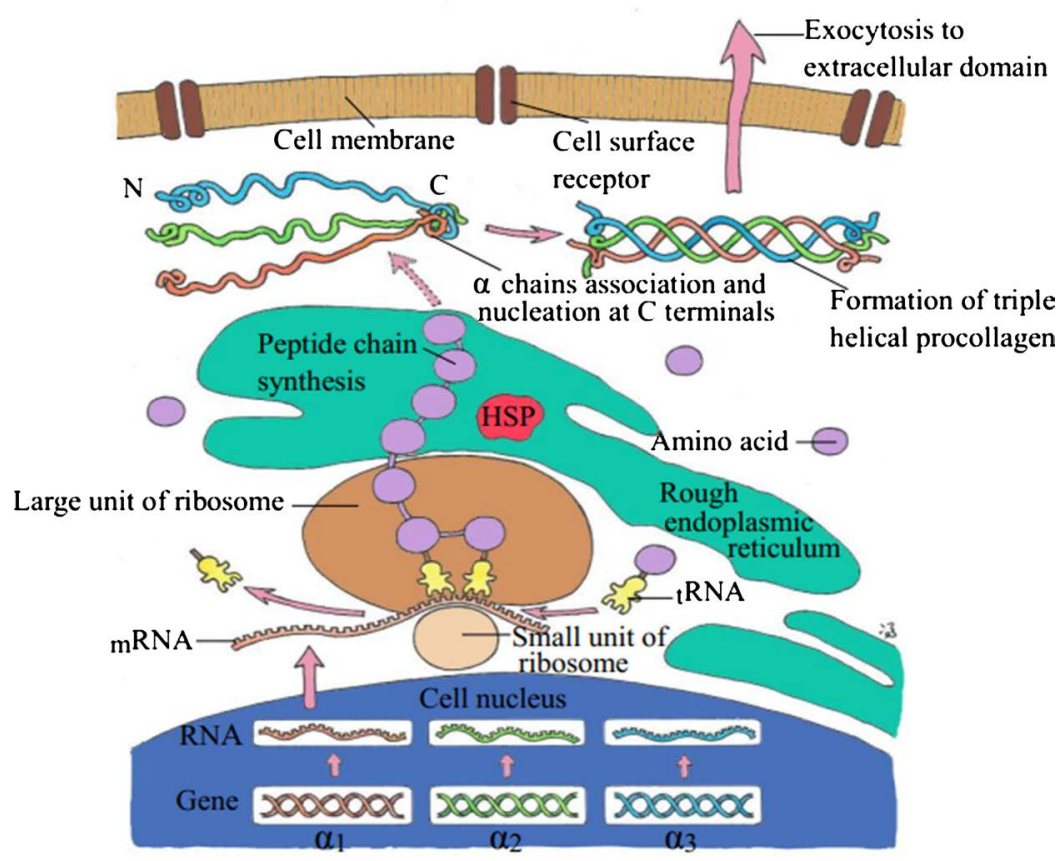

Figure 2. Schematic representation of the synthesis of collagen peptide chains, which may be called pre-procollagen chains, in the Ribosomes close to the Rough Endoplasmic Reticulum (RER). These peptide chains are secreted into the lumen of the RER where they are coiled to form a relatively loose triple helix, starting with nucleation [25] [26] [28]. A procollagen molecule is secreted from the cell. This figure was hand-painted by author PCWF. 


\subsection{Exocytosis of the Procollagen Molecules to Form Tropocollagen Molecules and the Formation of Micro-Fibrils and Fibrils in the Extra-Cellular Domain}

A procollagen has a typical length of $325 \mathrm{~nm}$, including a rod-like, tightly-packed triple helix of $300 \mathrm{~nm}$, plus loosely-structured $\mathrm{N}$ terminal $(15 \mathrm{~nm})$ and $\mathrm{C}$ terminal $(10 \mathrm{~nm})$ (Figure 3$)$. When a procollagen molecule is secreted via the secretory vacuole originating from the Golgi apparatus into the extra-cellular space, the $\mathrm{N}$ and $\mathrm{C}$ terminals are respectively cleaved by procollagen amino-protease and procollagen carboxy-protease, leaving a regular helical structure called tropocollagen molecule [25] [29]. That five triple helices build up a micro-fibril is generally accepted as the highly likely model based on the observed values of the cross-section of a triple helix and the length of a helix, but there are other alternatives; for example, it was long ago that another 5-strand model, with four helices in the cross-section, forming tetragonal stacking, plus another one helix attached to any side of the tetragonal (see Figure 2 of [30]) was proposed. For our analysis, the specific geometrical arrangement is not important at this stage. Five tropocollagen molecules can self-assemble to build up a micro-fibril, whose cross-section shows five helical structure in the over-lapped region, but the cross-section shows only four helical structure in the cross-section cutting across a gap. These two cross-sections are shown on the upper left part of the above figure. Micro-fibrils build up a fibril with different configurations. The one shown on the upper right of Figure 3 is just one possibility with radial symmetry in the cross-section. This tight-pack model shows a quasi-hexagonal boundary. The four-strand model of micro-fibril, built by four tropocollagen molecules is another model structure of a micro-fibril, which is not shown here because the structure is very simple-with four molecules arranged to form a quasi-rectangular shape. A three-strand model is also proposed based on fractal nature of the hierarchy [31]. These micro-fibrils, with effective diameter around several $\mathrm{nm}$, build up fibrils with effective diameter in the range around a few tens of $\mathrm{nm}$ to around $1 \mu$-meter.

\subsection{Resident Cells of the Fascia}

\section{Fibroblasts, reticular cells and stem cells}

Fibroblasts are derived from primitive mesenchymal cells which develop from the mesoderm of the embryo; they are called fibrocytes in general. In the dormant state, a fibroblast appears as an ellipsoid or said to have a spindle shape. An active fibroblast has branches, crawling on collagen fibers so that the fibers attain a certain degree of mechanical tension. The fibroblasts can be connected among themselves, via inter-cellular gap-junction and desmosome proteins, lining up along collagen fibers. The main function of fibroblasts is to secrete precursors of collagen, elastic, fibers, proteoglycans (PG), glycosminoglycans (GAG), together with glycoproteins [3]. Reticular fibers are synthesized by reticular cells [5]. 


\section{Self-assembly of tropocollagen molecules to form micro-fibril and fiber in extracellular domain}

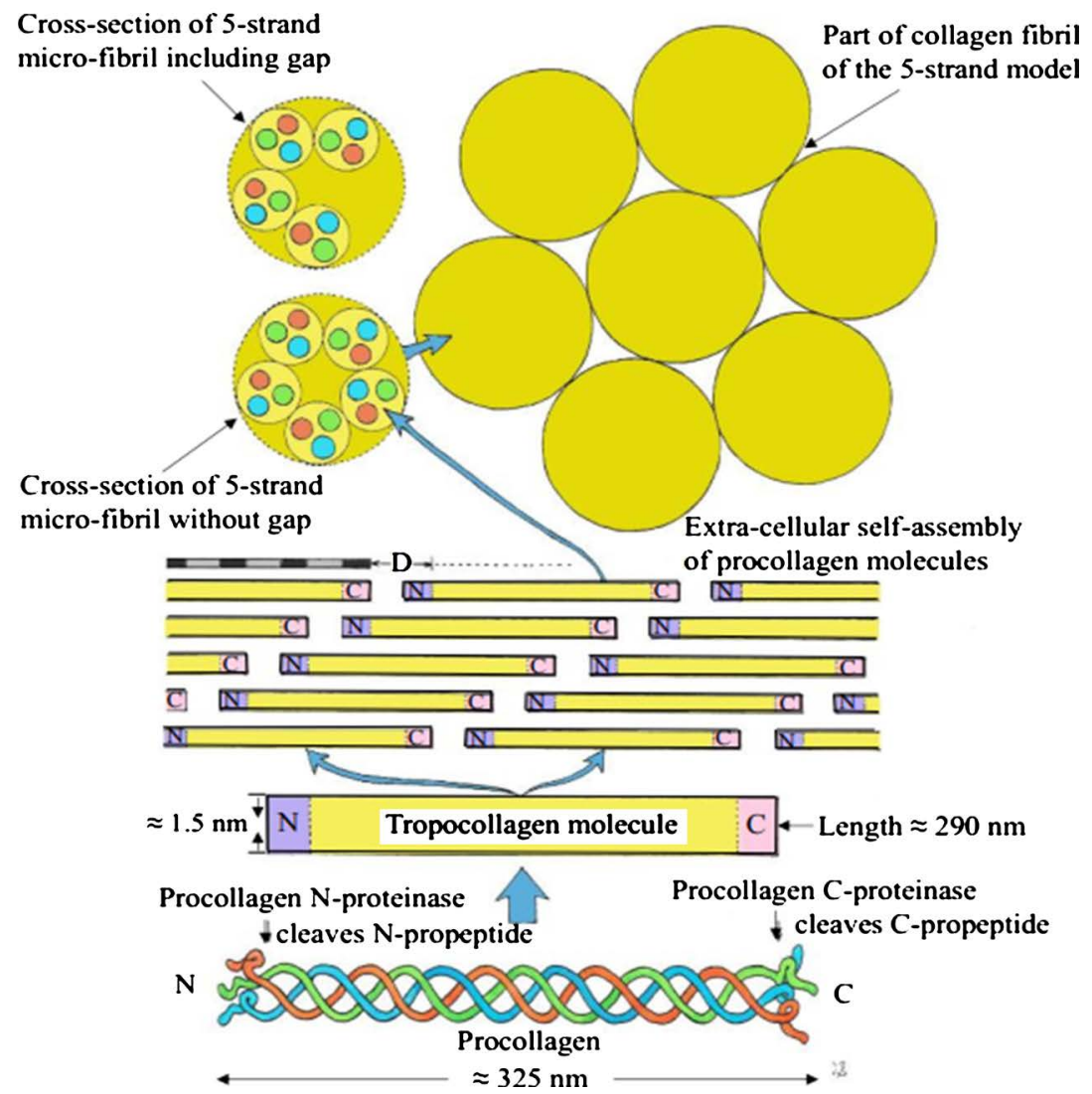

Figure 3. When a procollagen molecule is exocytosed from the fibroblast, the $\mathrm{N}$ and $\mathrm{C}$ terminals are respectively cleaved by procollagen amino-protease and procollagen carboxy-protease, leaving a regular helical structure called tropocollagen molecule, of length about $300 \mathrm{~nm}$ [25]. Micro-fibrils build up a fibril/sub-fibril with different configurations [29]. The one shown on the upper right is just one possibility. This figure was painted by author PCWF.

GAG with binding water molecules builds a jelly-like IF as the ground substance of the fascia, and the IF, together with other fluids forms an integrative five-fluid system [11]. The fibroblasts are the most important, and most abundant cells in the largest organ of the body. Fibroblasts migrate to many parts of the body, and they can change their phenotyping to become other cells. There is evidence that gradient of the mechanical tension of collagen fibers controls the direction along which cells would crawl-a process called durotaxis, which is the key factor for the stated change in phenotyping. In that respect, fibroblasts function like stem cells, in response to mechanical clue. Stimulated by cytokines, fibroblasts can also migrate (chemotaxis) to participate in wound healing [32]; they become myo-fibroblasts which may be involved in carcinogenesis if not properly regulated, as explained in the next related paper.

Mesenchymal stem cells (MSCs) also originate from the mesoderm of the embryo and are bone-marrow-derived. There is evidence that MSCs could pro- 
mote synthesis of collagen type I and collagen type III in tissue-engineered ligaments [33]. It is not surprising that a certain number of stem cells, which are reside in many locations of the fascia, would differentiate into fibroblasts and other fibroblast-like cells, participating in repair and growth when in need [33]. In addition to MSCs, there are stems cells found in the hair follicles [34] in the dermis and the fasica [3] [35]. These stem cells are interacting actively with the collagen molecules of the fascia.

\section{Chondroblasts, chondrocytes and cartilages}

A chondroblast or cartilage cell, like a fibroblast, originates from a mesenchymal stem cell. The extracellular matrix of cartilage is secreted by these chondroblasts, which reside in the outer covering layer of the cartilage. As the chondroblasts secrete matrix and fibers, they become trapped inside it, and mature into cells called chondrocytes. The active chondrocytes are large secretory cells with basophilic cytoplasm, containing many rough endoplasmic reticula. Older chondrocytes contain fat droplets [36].

The cartilage also contains a mixture of collagen and elastic fibers plus other non-fibrous protein components, of which there is $10 \%$ aggrecan (formed by aggregating chondroitin sulfate) and hyaluronic acid. Cartilage is avascular and can only be nourished (oxygen and nutrients) by long range diffusion from nearby capillaries in the perichondrium. Therefore, cartilage is a layer which does not grow to become thick. The ECM of cartilage entraps the PG (aggrecan) molecules to form a sponge-like structure to soak up water, producing high water content $\sim 75 \%$. The water combines with the hyaluronic acid in the matrix to form a gelatinous ground substance [37] [38].

The cartilage matrix, together with the thick fluid, is flexible, yet very durable, has strong resistance to compression forces. The disorders of this intriguing structure lead to the known diseases of the knee and other joints [38].

\section{Osteoblasts and osteoclasts}

Being mesenchymal in origin, osteoblasts are mononucleate, specialized fibroblasts which express bone sialoprotein and osteocalcin as well as other fibroblasts products. Osteoblasts are responsible for bone formation [37] [39]. First, osteoblasts produce a matrix of osteoid, composed mainly of Type I collagen, completely extra-cellular. To form a bone, osteoblasts are also responsible for the mineralization of this matrix, with Zinc, Copper, Sodium plus other minerals in this process. Osteoblasts separate bone from the IF by tight junctions [40]. Note that bone is a dynamic tissue: it is broken down by another specialized fibroblasts-osteoclasts, and is constantly being reshaped by osteoblasts [41]. The number of osteoblasts decrease with age, leading to osteoporosis [39].

\section{Mast cells}

It is known that mast cells (MC) develop, like other leukocytes, from haematopoietic stem cells but do not mature before exiting the bone marrow and circulate as committed progenitors [42]. It has been demonstrated that these undifferentiated but committed progenitors do not develop into mature MC but 
traverse the vascular space and complete their maturation after migrating into diverse peripheral tissues of the CTIF regions, such as skin, submucosa of stomach and intestine, breast parenchyma, myocardium, lymph nodes, conjunctiva and synovium and other CTIF domains of the fascia [43]. The sizes of mast cells in CT range from $20-30 \mu \mathrm{m}$; these cells are filled with deeply basophilic granules [44]. Human MC are conventionally divided mainly into two types, depending on the expression of different proteases in their granules. Mast cells are not only responsible for allergy reactions, but are also responsible for numerous physiological functions [3] [44], of which the relevant one in our study is that mast cells are sources and inducers of fibroblasts synthesis, at least in the skin [45].

\section{Macrophages}

Macrophages, very well known, also called histiocytes, are phagocytic cells derived from monocytes in the blood stream. They migrate in most loose CT, as one of the major lines of defense against infection.

\section{Adipocytes}

These cells, distributed throughout the subcutaneous connective tissue layer of the fascia, serve to aggregate a reserve store of energy and as a shock cushion, as well as heat insulator for internal organs. They are long-lived, and do not divide. Apart from the basic function mentioned above, they are involved in other important pathological states. We will discuss their special properties associated with different diseases in later papers.

\section{Melanocytes}

These cells are pigment cells found in the skin and choroid of the eye. Melanocytes produce melanin, a pigment in the skin, eye, and hair via a process called melanogenesis, protecting the hypodermis from the ultra violet B light that causes photodamage to the DNA.

During inflammations or injuries of organs, leukocytes extravasate from the blood stream and enter the CTIF system to carry out their immunity duties. They are well-known, and we will only discuss their interaction with the constituents of the fascia when we analyze pathogenesis of various diseases. In our nomenclature, we define leukocytes as cells in transit of the largest organ of the body.

\subsection{The Hierarchy Structure of the Fibrous Collagen}

The micro-fibril has a very stable structure. In Figure 3, we have shown the 5 -strand micro-fibril model. Based on the fractal and spectral dimension analysis of 26 biopsy samples from fibrotic livers of patients, regular crystalline structure of the collagen has been reported and confirmed [46]. Whatever geometric model is used to describe the cross-section of collagen fibril, there is evidence that the boundary of a fibril is a polygon. In Figure 4, at the lower right corner, four tropocollagen molecules may form a tetragon, which can also be squashed to become a squashed-4-strand model, with one tropocollagen molecule as one 
The hierarchy structure of fibrous collagen, taking Achille tendon as an example

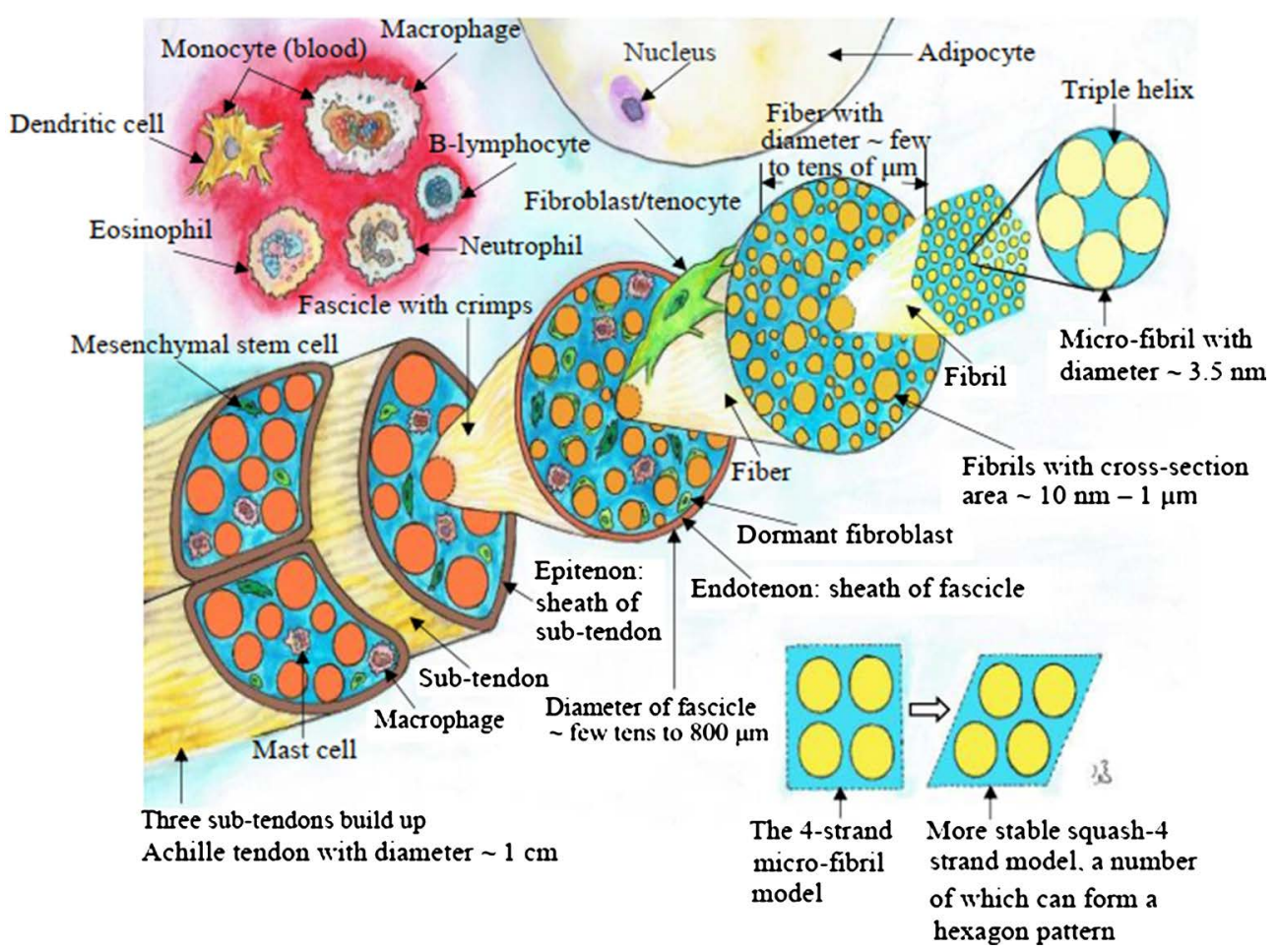

Figure 4. The right-hand corner at the bottom indicates that the quasi-square strand of four micro-fibrils would become the "squashed 4-strand model", which is more stable. We propose that many of these units form the hexagon or hexagonal like polygons observed in the cross-sections of animal fibrils, as confirmed in [46]. The resident cells-fibroblast/tenocytes, (mesenchymal) stem cells, mast cells, macrophages are painted in the ground substance of the CTIF system. The red patch are immunity cells from the blood stream during inflammation. We present three sub-tendons for an Achille tendon in human, and the tendon is closed by a layer called a paratenon (not painted here). The bright green tenocyte crawls on a fiber, giving the fiber a tensile force. A dormant or inactive fibroblast/tenocyte becomes ellipsoid like in shape and is not attached to a collagen fiber; an inactive fibroblast/tenocyte is marked in the figure. Note that the endotenon, epitenon, paratenon form extrinsic compartments consisting synovium-like tissues where some cells and signals (such as cytokines) of the immune, vascular, nervous systems can migrate/pass through [54] [55] [56]. This diagram is hand-painted by author PCWF.

basic unit. In view of the fractal nature mentioned, the basic unit can also be a microfibril (instead of a tropocollagen). At this point, we do not specify which strand model is the correct one; we take the squashed-4-strand model to show that with 64 tropocollagen molecules, the cross-section can become a hexagon, as shown in the figure. In Section (4.2), scanning electron microscopy (SEM) examination of human Achille tendon shows that the cross-sections of many fibrils in a tendon are polygons - in fact, quite a number are quasi-hexagon within the resolution of revelation (see e.g. Figure 1 of [47]). When the number of sides of a polygon is large, the cross-section becomes like a circle. The effective cross-section diameters (diameter of a circle having an area equal to that of the polygon) of fibrils vary from about $\sim 10 \mathrm{~nm}$ to $1 \mu-\mathrm{m}$ in human. Each fibril is composed of parallel tropocollagens shown in Figure 4, bound by hydrogen and 
other chemical bonds, depending on the class of collagen involved. However, due to the very specific chemical composition of a tropocollagen (Section (2.3)), there are always gaps and overlapping regions as shown in Figure 4. Thus the "white and black" bands with D values within a narrow range of $(64-67 \mathrm{~nm})$ appear in the optical/SEM micrographs of the fibrils. Many fibrils form a fiber; the blue background of the "second circumference" from the right of Figure 4 represent some proteins (proteoglycans and glycoproteins) plus the viscous interstitial fluid (IF); it is basically the inter-tropocollagen bonds that keep the integrity of a fibril. Collagen fibrils would self-assemble in physiological fluid [48], and there is evidence that the collagen fibrils are in fact liquid crystals-that is where the regular structure comes from [49] [50]. Many fibrils constitute a collagen fiber, having diameters in the range of $\sim$ few to tens of micro-m. This size scale is important because the cells in the human body have diameters/length size starting from $\sim 7 \mu-\mathrm{m}$ to $35 \mu-\mathrm{m}$. Therefore cells, the living units, are only interacting with fibers (or fibrils) around the same order of magnitude. Collagen fibers must have the benefit of the service of repair by the cells-the fibroblasts-which synthesize them. When some parts of the fiber or fibrils are damaged, enzymes called matrix metalloproteinases (MMPs) are secreted by fibroblasts to degrade the fragments/damaged portions, starting from very specific sites inside a fibril. When a fibroblast is activated, it stretches out with pseudopodia, crawling along a fiber with force. A string of fibroblasts line-up by cell-cell-interaction (see Fig.6 of [51]), subjecting the fibers to a certain amount of mechanical tension. The active sites for MMP degradation are then hidden, protecting the good fibers. A fibroblast (bright green) was painted to crawl on a fiber in Figure 4. The whole solid body structure of the connective tissues between two organs (even the small blood/lymphatic vessels, nerve fibers) is embedded in the viscous interstitial fluid as mentioned in Section (1). Since the connective tissue is developed from the mesoderm, evolution leaves some number of stem cells (deep green) around in the CTIF system [52], including some in the hair follicles [53]. They can change the phenotyping and become cells performing specific functions, such as wound healing. There are also some macrophages (one is labeled in the Figure 4) residing always in the CTIF system for surveillance. There are also mast cells which carry "bags of biochemical treasures"; a mast cell can secret one or more such bags by exocytosis to carry out physiological functions, including response to allergy [3] [44]. We have taken the environment of an Achille tendon as an example. In many parts of the body, there are adipocytes in the sub-cutaneous layer of the CTIF system. As the fat cell also plays important roles in physiology (details to be discussed in a future paper on obesity), a part of fat cell has been painted in the upper part of the figure. The fascicle (with diameter $\sim$ few tens to $\sim 800 \mu-\mathrm{m}$, even up to $1 \mathrm{~mm}$ [51]) is formed by fibers. These fascicles are bounded by a sheath/layer also of collagen in origin, called endotenon. The fascicles have crimp structure to absorb tensile force, as required during locomotion, because they form the (macroscopic) force enduring units of a sub-tendon. The little curvy lines on the fascicle in 
Figure 4 represent the crimp structure. A crimp structure automatically develops in a fibrous collagen structure which endures tensile force during daily life. In fact, one can find fibers (of various sizes) having crimps in different parts of animal models. Several fascicles build up the sub-tendon (with size $\sim$ several $\mathrm{mm}$ in human), bounded by a sheath called epitenon. Several (three are shown in the figure) sub-tendons form an Achille tendon, having diameter $\sim 1 \mathrm{~cm}$.

During inflammation, the white blood cells extravasate to the CTIF domain. The basophils become the mast cells which cannot reverse their identity and remain as resident cells there. In order to enforce immunity power, monocytes develop into dendritic cells (as antigen presenting cells) and macrophages. The B-lymphocytes, the neutrophils, and eosinophils can also extravasate to the tissues. These cells, called cells in transit in our nomenclature, are schematically painted within the "red patch", indicating that they originate from the blood circulation, and enter the CTIF during inflammation. We would emphasize that in different parts of the body, other cells are actively interacting with the CTIF to perform their physiological functions. For example, the chondrocyte, chondroblasts interact with the CTIF in the knee region; we would discuss activities of these cells elsewhere. Note that the endotenon, epitenon, paratenon form extrinsic compartments consisting of synovium-like tissues where some cells and biomedical signals (such as cytokines) of the immune, vascular, nervous systems can migrate/pass through [54] [55] [56].

\subsection{Crimp Structure of Collagen Structure Observed in Animal Models and Humans-Presenting Two Examples}

\section{Crimps observed in the Achille tendon of rat}

Polarized light micrograph of a relaxed Achille tendon of the rat model after dehydration is obtained in Fig.3 of [57]. The crimps look like flat sheets bent into triangular-like structures, (instead of a wavy pattern) as shown in Figure 5(A), a simplified representation by a hand-painted picture of the discovery in [57]. From Figure 4, we have learned that the cross-sections of fibrils are polygons in general, and many appear circular when the orders of the polygons are high. Due to inter-fibrillar chemical binding force, the fibrils can form flat structures. In a later study, highly regular planar crimps of Achille, flexor digitorum profundus tendons, collateral ligament of knee (of animal models) were also revealed [58].

When similar Achille tendon specimens were stretched, the bending became flattened, showing some "wrinkles" which are the small parts that were not stretched, as shown by the polarized light micrograph in Fig. 3 of [57]. Based on such micrograph, another water color painting was done and presented as Figure 5(B) here. Below we shall present an example of wavy crimps, rather planar ones.

Crimps revealed in the chordae tendineae of the mitral valve, as a miniature tendon, of humans

The chordae tendineae of the human mitral valve shows orderly, wavy crimps in the scanning electron microscopy (SEM) micrograph of [59]. The effective 
(A) Hand-painted, simplified interpretation of the polarized light micrograph of relaxed achilles tendon of rat model, after dehydration as reported in [57]. The crimps look like flat sheets bent into triangular-like structures, instead of smooth wavy pattern.

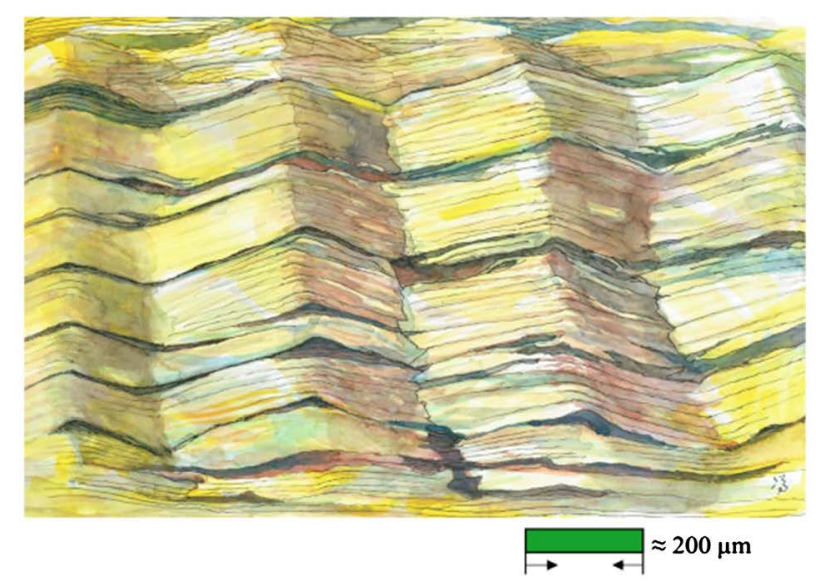

(B) Hand-painted schematic representation of the polarized light micrograph of rat achille tendon after tensile load as reported in [57]. The vertical "shades" represent the parts of the tendon that are not "stretched flat", so that some wrinkles appear.

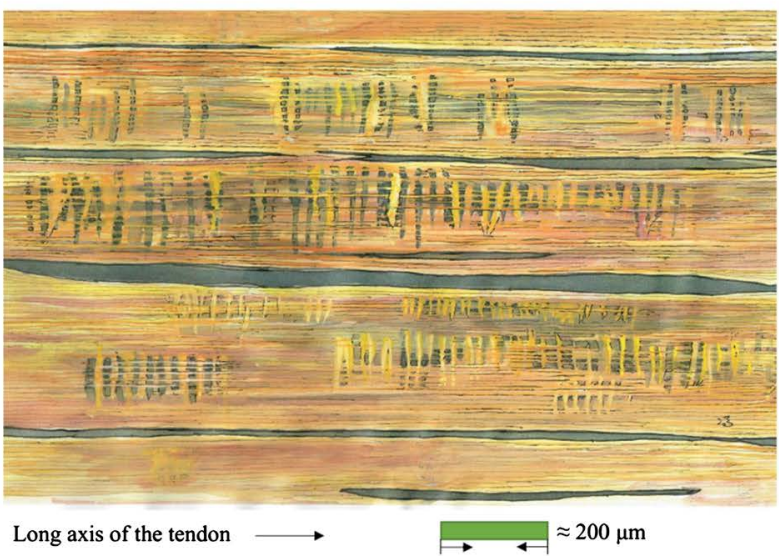

Figure 5. (A) Polarized light micrograph of a relaxed Achille tendon of the rat model after dehydration is obtained in [57]. The crimps look like flat sheets bent into triangular-like structures. This is a simplified, hand-painted representation of their micrograph in the above reference by author PCWF; (B) When the rat Achille tendon specimens of [57] were pulled by tensile force, the "triangular structures" disappeared, leaving some wrinkles, indicating certain small parts were not stretched. This is a hand-painting adaptation, simplified, following the work of [57].

diameters are around ten to several tens of $\mathrm{nm}$, being equal to the smallest fibrils in the Achille tendon of humans to be discussed in Section (4.2). Degenerative disease of the mitral valve is known to be always accompanied by lengthening and/or rupture of chordae tendineae, as shown in Figure 8(b) to (d) of [59]. In Figure 6(A), we present a hand-painted interpretation of the SEM micrograph of Fig. 8(a) of [59], showing clearly crimps of normal human chordae tendineae. The magnification is about 2400 times. Three green spindle-shaped cells are fibroblasts. Therefore, crimps can be found in fibrils and fibers in the collagen hierarchy; we have not indicated crimps of fibers and fibrils in Figure 4 for the 
(A) Hand-painted simplified interpretation of the SEM micrograph in Fig. 8(a) of [59] showing crimps in normal chordae tendineae of the human mitral value

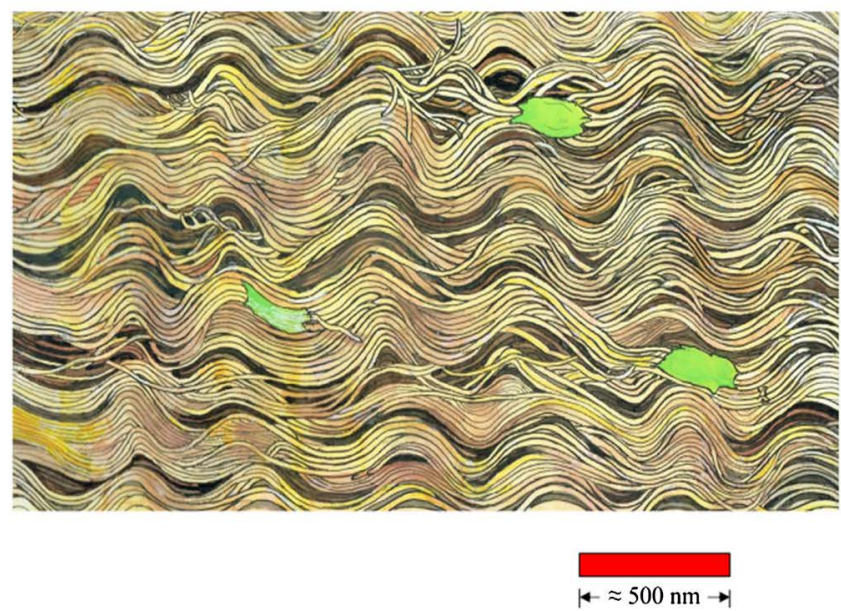

(B) Definition of crimp angle $\Theta$, crimp height $h$ and crimp base length $I$

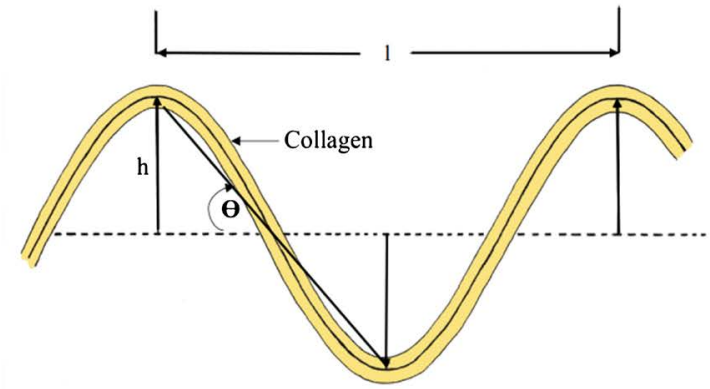

Figure 6. (A) In a healthy human mitral valve of the heart, the wavy crimps are rather ordered and very few ruptures are found. During the diseased state, the crimps disappear, and the fibrils are ruptured. The organization of the fibrils becomes disordered. We present only a simplified hand-painted interpretation (by PCWF) of the discovery of the healthy chordae tendineae of the mitral valve in [59]. The green spindle-shaped cells are fibroblasts, already "pressed" during the preparation of the SEM sample. The reader is referred to Figure 8(b)-(d) of [59] for the morphology of the diseased chordate; (B) Definitions of the crimp angle $\theta$, crimp hight $\mathrm{h}$, and crimp length 1 .

Achille tendon. In fact, the existence of crimp in fibrous collagen structure is well established. It is intuitively true that any heavy-duty tendon or ligament would have developed such a structure to absorb force. Only after the tendon is straightened, the collagen fiber/fascicles would experience force to unwind the helices.

Collagen crimps are developed to absorb tensile force and protect the host organism. To estimate the degree of such "protection", normally the parameters of crimp angle $\theta$, crimp height $\mathrm{h}$ and crimp base length $\mathrm{l}$ are used in literature. The definitions of these terms are depicted in Figure 6(B) for convenience of discussion.

\section{Degradation of Collagen by Metalloproteinases (MMPs) and Inhibition of Such Degradation by Tissue Inhibitors Metalloproteinases (TIMPs) in the CTIF Regions}

We already know that collagens are the major structural proteins of connective 
tissues such as skin, tendon, bone, cartilage, blood vessels and basement membranes of all organs, irrespective to their size. The scaffoldings of various types of collagen provide the most important communication network and integrity of these organs. The degradation of these collagen macromolecules, with various fibrous and non-fibrous structures, is naturally an integral part of many physiopathological processes such as embryogenesis, organ morphogenesis, tissue remodelling in tissue homeostasis, wound healing, angiogenesis, arthritis, atherosclerosis, aneurysm, fibrosis and carcinogenesis. A group of degrading enzymes, the matrix metalloproteinases (MMPs) feature to digest collagen molecules in various very specific ways in the above processes; on the other hand, inhibitors, called TIMPs regulate the degradation until a physiological balance is reached. Upsetting the balance either way could lead to important consequences-various kinds of diseases manifest themselves in certain CTIF domains of the fascia. We shall summarize below some characteristics of MMPs and TIMPs; much research on the balance of these classes of enzymes is going on.

\subsection{Types of Digestive Enzymes for Degradation of Collagen in Humans}

The triple-helical conformation makes interstitial collagens resistant to most proteinases because the MMPs, produced by many cell types such as epithelial cells, macrophages and other leukocytes, fibroblasts, marrow stromal cells have to bind to specific sites of the collagen macromolecules (for interaction) and these sites are "hidden" inside the triple helix structure (see evidence of collagen IV, as an example in [60]). Likewise, specific sites for MMP degradation are also hidden in the triple helix in general, an aspect mentioned in many papers on collagen degradation. In Table 2, we list some characteristics of the MMPs discussed in this paper. Briefly, MMP-1, 3, 8 are the endogenous digestive enzymes for the ECM collagen fibrils, and MMP-2 and -9 are more relevant to degrade basal membranes in the ECM of cell-groups/organs, whereas MMP-10 digests some important proteoglycans and some other collagen molecules, the types of which are yet to be confirmed. MMP-14, 15, 16 are anchored on the external side of the cell membrane in their dormant states. When activated by ECM proteinases, they can digest some collagen and noncollagenous molecules and regulate the activity of MMP-2, which is a powerful digestive enzyme to break the basal membrane of organ; for this reason, if these MT-MMPs are not regulated, they are involved in cancer invasion, as will be discussed in another paper.

\subsection{Atomic Force Microscopy Investigation of the Action during Collagen II (Obtained from Cartilage, Rather than Tendon) Degradation by MMP-9, as an Example}

Technically, by now, there is ample evidence that other members of the MMP family, cooperatively degrade a variety of extracellular proteins, including collagens which are resistant to other proteases due to their tightly packed structure 
[71] [72]. As an example, native human collagen type-II can be cleaved by the collagenases MMP-1, MMP-8, and MMP-13. These MMPs will cleave all three $\alpha$-chains of interstitial collagens by a single scission at a specific site, located $3 / 4$ from the $\mathrm{N}$ terminal and $1 / 4$ from the $\mathrm{C}$ terminal, leaving two fragments of the collagen molecule [73]. In fact, a more recent study [74] provides a direct visualization of MMP-9 action on the triple helical structure of intact collagen II molecule, using AFM observation. It is interesting to note that their single molecule imaging techniques provide direct evidence that during the initial state of the degradation process, the protease diffused laterally along the collagen type II fragment (to find and) to bind the relatively loose tail. During this process, the MMP-9 molecule changed its elongated conformation in the free state to a more globular conformation upon binding to the tail of the collagen fragment.

As the reaction progressed, and before collagen degradation, gelatin-like morphology arising from the denaturation of the triple helical collagen was observed [74]. Following the first cleavage, other MMPs, like MT1-MMP [75], MMP-1, MMP-8, MMP-13 (mainly gelatinases and stromelysins) can collectively further degrade the collagen fragments. Thus, the MMPs work collectively to cleave some collagen molecules, meaning that to inhibit "over-digestion" (such

Table 2. Characteristics of some relevant metalloproteinases (MMPs) and tissue inhibitors of MMPs discussed in this paper.

\begin{tabular}{|c|c|c|}
\hline MMP member & $\begin{array}{l}\text { Collagen types of the proteins being } \\
\text { substrates }\end{array}$ & Remarks \\
\hline MMP-1 & I, II, III & $\begin{array}{l}\text { when gene is mutated, member is associated with obstructive pulmonary disease (COPD) } \\
\text { [61] }\end{array}$ \\
\hline MMP-2 & IV, $\mathrm{V}$, elastin & $\begin{array}{l}\text { when gene is mutated, member is associated with Winchester syndrome, } \\
\text { Nodulosis-Arthropathy-Osteolysis (NAO) syndrome [62] }\end{array}$ \\
\hline MMP-3 & III, IV, IX, X & involved in wound healing, progression of atherosclerosis, tumor initiation [63] \\
\hline MMP-8 & I, II, III & $\begin{array}{l}\text { involved in embryonic development, reproduction, tissue remodelling, arthritis, metastasis } \\
\text { [64] }\end{array}$ \\
\hline MMP-9 & IV, $\mathrm{V}$ & animal studies suggest member is involved in tumor associated tissue remodelling [65] \\
\hline MMP-10 & $\begin{array}{l}\text { fibronectin, elastin, proteoglycan } \\
\text { core protein, laminin and some } \\
\text { collagen types to be confirmed }\end{array}$ & involved in tissue remodelling, arthritis, metastasis [66] \\
\hline MMP-13 & I, II, III & involved in articular cartilage turnover and its pathology [67] \\
\hline MMP-14 & I, II, III, fibronectin, vitronectin & $\begin{array}{l}\text { also known as membrane type MMP (MT-MMP); expressed at the cell membrane and is } \\
\text { activated when cleaved by ECM proteinase. This member also activates MMP-2 and is } \\
\text { suggested to be involved in tumor invasion [68] [69] }\end{array}$ \\
\hline MMP-15 & $\begin{array}{l}\text { ProMMP-2, fibronectin, laminin, } \\
\text { very small amount of I }\end{array}$ & $\begin{array}{l}\text { this member is also an MT-MMP; suggested to be involved in tissue remodelling, } \\
\text { development, reproduction, arthritis and metastasis [69] [70] }\end{array}$ \\
\hline MMP-16 & $\begin{array}{l}\text { III, ProMMP-2, gelatin, fibronectin, } \\
\text { laminin }\end{array}$ & $\begin{array}{l}\text { this member is also an MT-MMP; suggested to be also involved in tissue remodelling, } \\
\text { development, reproduction, arthritis and metastasis [69] }\end{array}$ \\
\hline
\end{tabular}


as during cancer invasion), we might need to break off one of the processes in the progressive cleavage phenomenon.

Normally, the proteolytic activities of MMPs are regulated precisely by endogenous tissue inhibitors of metalloproteinases (TIMPs). Recent research in the past few years have shed light on the complexity of the functions and activities of these MMP and MT-MMP as they can be "re-absorbed" back into the cells that synthesize them, and the processes are not fully understood up to now.

\subsection{Another Example: Two Domains in MMP-1 Work Together to Cleave Collagen II in Three Steps}

MMP-1 consists of an N-terminal catalytic (Cat) domain containing an active-site zinc ion and a C-terminal hemopexin ( $\mathrm{Hpx}$, the plasma protein with the highest binding affinity to heme and is mainly expressed in liver) domain comprised of a four-bladed $\beta$-propeller, which are connected by a "linker region" [76]. Although the Cat domain can cleave some non-collagenous proteins plus heat-denatured collagen (gelatin), its activity on native triple helical collagen is negligible. However, experimentally, the combination of the Cat and Hpx domains is required for MMP-1 to degrade native collagen. The statement holds true also for MMP-2, MMP-8, MMP-13, and MMP-14 [77]. It has been demonstrated that MMP-1 first unwinds triple-helical collagen locally before peptide bond hydrolysis. Employing combined biochemical experiments and crystallographic structure analysis (i.e. screening of a triple-helical peptide library of collagen II with MMP-1, (see Fig.2 of [78]) the authors of [78] discovered that extensive interaction of all three chains (of a collagen II triple helix) with the two stated domains of MMP-1 was required for collagenolysis in three steps: (i) positioning of the scissile bond (i.e. a covalent chemical bond that could be broken by the MMP enzyme) near the active site; (ii) locally unwinding the triple helix; (iii) chemical interaction of the enzymatic action; (iv) the Cat and Hpx domains worked cooperatively in a temperature-dependent manner, up to $37^{\circ} \mathrm{C}$ for degrading collagen II, and the interaction (of degradation process) decreased sharply, indicating that MMP-1 prefered a looser triple helix but not denatured collagen. This result is very interesting, as it implies, at least for collagen II, that degradation is insignificant above core body temperature. Above core body temperature, there are supposedly more triple helices being denatured (gelatin-like). We interpret such a result as: at least for collagen II, MMP-1 degrades the injured triple helices below and up to body temperature. Since the fibroblasts would synthesize collagen molecules as explained in previous sections, a natural healing process is at work if the activities of MMPs are being regulated. The very subtle problem on folding and refolding of triple helices will be followed up in Sections (5) and (8.5).

\subsection{There Are Only Four Types of Endogenous Inhibitors of MMPs Found So Far to Regulate the Digestion of Collagen in Humans}

On the other hand, the proteolysis of the collagen molecules, whatever their 
forms, must be regulated. So far, four members of the tissue inhibitors of metalloproteinases (TIMPs) have been identified. The N-terminal domain of a TIMP interacts with the active site of the associated MMP, resulting in inhibition of catalytic activity. Table 3 presents some characteristics of these TIMPs only, because such inhibitors participate in many other functions, and are candidates of rather intensive research, and they have been applied to treat various cancers. Both Table 2 and Table 3 are by no means comprehensive but show special features of those versatile proteins.

\section{Probing the Reasons for Tendons Having the Ability to Sustain Lengthy Periods of Mechanical Tensile Loading}

Tendons in many parts of the body are prone to sustain heavy mechanical loading duties, though we have learned that the crimp structure can absorb some tensile loading in Section (2.7). Clinically, there are many cases of spontaneous tendons ruptures, without alarming pre-rupture symptoms [94]. To prevent tendon rupture and to design treatments when rupture does occur, it is important to understand the physiological process of tendons' response to tensile loading. The following sub-sections serve this purpose.

\subsection{Distribution of Kinks in Overload Bovine Tail Tendon}

Specimens of tendons from the tails of steers were employed to analyze the response of the collagen fibrils to tensile force in [95]. The bundle of collagen fibrils was anchored in the manner specified in Figure 2 of [95]. We show schematically in Figure $7(\mathrm{~A})$ such a bundle following their SEM micrographwithout showing crimps in the length scale of the experiment; it is difficult to distinguish the difference between fibrils and fibers. Collagen tubes having diameters within a range of a few hundreds of nm are called fibrils by many authors-e.g. authors of [95]. We follow such nomenclature here. Tensile force

Table 3. Some characteristics of tissue inhibitors of metalloproteinases (TIMP).

\begin{tabular}{llll}
\hline TIMP member Source of TIMP member & Types of MMPs inhibited & Remarks \\
\hline TIMP-1 & $\begin{array}{l}\text { human skin [79] fibroblast; } \\
\text { tendons [80]; many other cells }\end{array}$ & most of the known MMPs & $\begin{array}{l}\text { in addition to tissue remodelling, it promotes proliferation of a } \\
\text { wide range of cells; it has anti-apoptotic function; involved in } \\
\text { pancreatic cancer, melanoma, and glioblastoma [81] }\end{array}$ \\
TIMP-2 & endothelial and other cells [82] & $\begin{array}{l}\text { forms a complex with } \\
\text { collagen IV, but inhibits also } \\
\text { other MMPs in tissues }\end{array}$ & $\begin{array}{l}\text { suppresses proliferation of endothelial cells; involved in cardiac } \\
\text { fibroblast ECM remodelling; osteoarthritis in Chinese Han }\end{array}$ \\
& population [83]
\end{tabular}


(A) Before tensile overload was applied, the fibrils of bovine tail tendon under SEM examination showed clear $D$ bands in ref. [95]

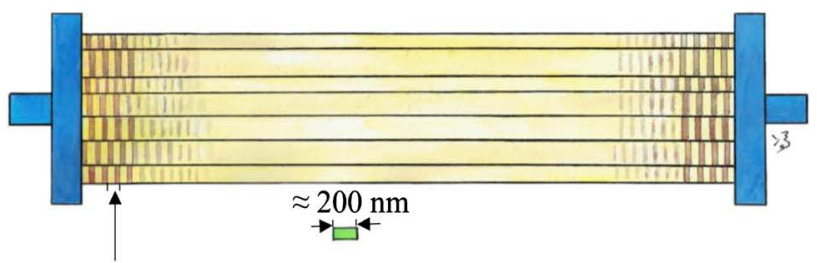

$\mathrm{D}$ bands are revealed in SEM micrographs of the tendon fibrils published in ref. [95]

(B) Interpretation of the experiment of reference [95] rupture of the tendon specimen by tensile force

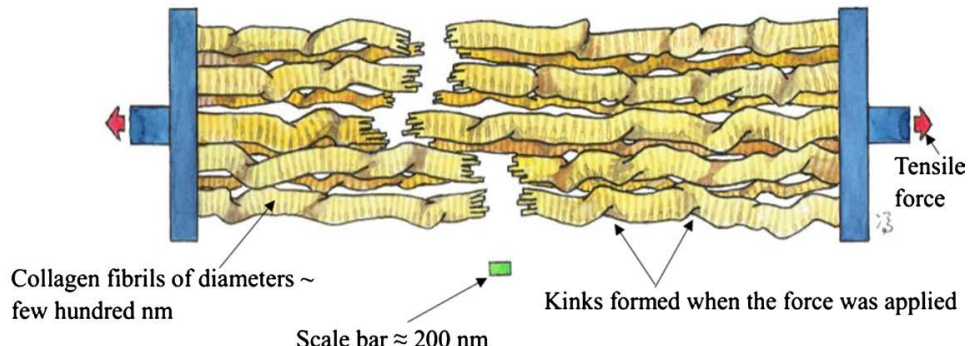

(C) After the application of tensile force which caused rupture eventually there were changes in structure of the collagen fibrils according to the micrograph of [95]

Examples of sites showing blurring of the fibril band of $D(\approx 67 \mathrm{Da})$

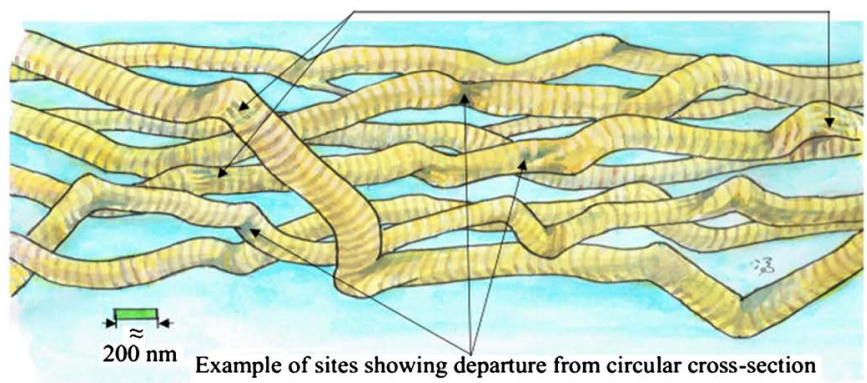

(D) Interpretation of the structure of the ruptured fibrils after digestion of the denatured collagen molecules according to the micrograph of [95]

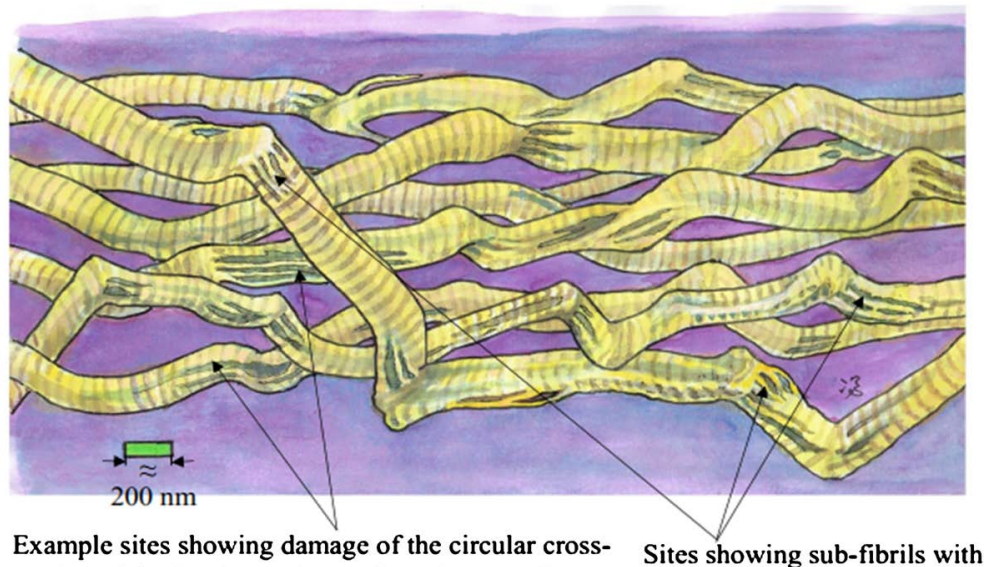

Example sites showing damage of the circular cross- Sites showing sub-fibrils with section of fibrils, due to denaturing of tropocollagen molecules directly by mechanical force diameters $\sim \mathrm{a}$ few tens of $\mathrm{nm}$ 
(E) When the tendon sample was subjected to pre-rupture cyclic overload, the density of kinks along a fibril increased significantly according to ref. [96]

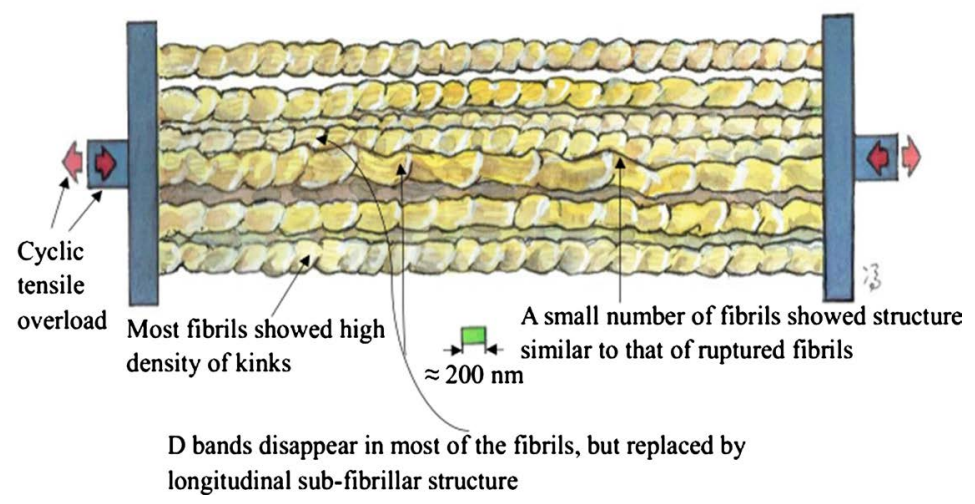

Figure 7. (A) Schematic representation of the bovine tail tendon specimen of [95] before overload tensile force was applied. The $\mathrm{D}$ bands showed up clearly in the collagen fibrils. The rough scale is for the effective diameters (ranging around one to three nm roughly) of the fibrils only, as the length of the sample is $1.2 \mathrm{~mm}$, much longer than that shown in the painting. (B) Overload tensile force was applied at both ends of the tendon specimen of (A), causing it to rupture, and kinks were found along the collagen fibrils as shown in the SEM micrograph in Figure 3(A) of [95]. (B) was a hand-painted interpretation of such kinks in the gauge length of the fibrils. In their experiment, about half of the whole cross-section of the tendon was ruptured. (C) SEM micrographs of [95] indicate that at the kinks of the ruptured tendon fibrils, the cross-sections became irregular in shape, and the D bands became a little blurred. Instead, longitudinal small tubes appeared; these tubes are obviously sub-fibrils. However, other parts of the fibrils still showed clear D bands. This hand-painted picture is interpreted based on Figure 3(C) of [95]. (D) Hand-painted interpretation of the SEM micrograph of Figure 3(D) in [95], showing the sub-fibrils with effective diameters around a few tens of $\mathrm{nm}$ after the specimen was treated with digestive enzyme which dissolved the uncoiled/damaged triple helices. Many portions of the fibrils showed irregular cross-sectional shape. (E) Now refer to the work of reference [96]. After 5 cyclic tensile overloaded with strength below rupture as described in the text, a hand-painted, simplified interpretation of Figure (1B) of [96] is presented here. Special features of the damaged tendon are described in the text. The pictures were painted by author PCWF.

was then applied to the tendon specimen until rupture occurred. The SEM mircrographs indicate that many kinks occurred along the ruptured fibrils. The distance between two consecutive kinks along a fibril was reported to vary between about 300 to $800 \mathrm{~nm}$, though some samples showed values up to $1100 \mathrm{~nm} \mathrm{ac}$ cording to their Figure 5. Interpretation (of Figure 2 of [95]) of the present authors on the rupturing process is shown schematically in Figure 7 (B) by a painting. The two red arrows indicated that tensile forces were applied at both ends of the sample. Kinks formed along fibrils before rupture, after tensile force was applied. The green bar scale is about $200 \mathrm{~nm}$ on the vertical scale, as the length of the specimen is out of the scale here. Figure $7(\mathrm{C})$ is the simplified interpretation of the present authors with a painting, based on their SEM micrograph (i.e. Figure 2 of [95]), highlighting the few main features only. In Figure $7(\mathrm{C})$, while kinks were formed, there were sites indicative of "blurring of the D-band of 67 Dalton"; a few are marked in this figure. At these sites, tubes with 
diameters around a few tens of $\mathrm{nm}$ appeared vaguely, indicative of sub-fibrillar structure. There are also many regions along the fibrils suggesting that the "close to circular" cross-sections of the fibrils were altered. In their original experiment, the digestive enzyme trysin (an enzyme stronger than the human MMPs) was applied to the ruptured fibrils specimens, dissolving the denatured tropocollagen molecules. We should remark that denature is defined here to be uncoiling of the triple helical structure of a tropocollagen molecule. Note that the fibrils have a range of sizes, depending on the anatomical sites of the body. In order just to point out only the main features, we present a picture in Figure $7(D)$ to represent the structure of the ruptured fibrils after the denatured triple helices have been digested by the degrading enzyme based on the SEM micrographs published in [95]. We highlight the clear appearance of the sub-fibrils with diameters around a few tens of $\mathrm{nm}$ after the specimen is treated with digestive enzyme. Many portions of the fibrils showed irregular cross-sectional shape, because quite a number of sub-fibrils were uncoiled during the rupturing process. We would like to emphasize that despite the fibrils being ruptured, the appearance of the D bands between kinks of the fragments implies that the ordered molecular packing of micro-fibrils in the fragments of the fibrils was still retained. This property is important. Following up, the researchers applied a cyclic overload tensile force to similar bovine tail tendon specimens [96]. Before proceeding, the displacement (effectively the extension) versus load graph was plotted, in order to find out at what load the sample would rupture. When the data points reached a plateau region, further increase of load would not cause any extension, and the sample would rupture. The rupture force was found to be 25 Newton. In the "cyclic experiment", a similar sample was stretched using a strain rate of $0.5 \%$ per second. Before rupture occurred, the force was decreased at the same strain rate of $-0.5 \%$ per second, until the tendon resumed its original length. After 5 sub-rupture overload cycles (pertaining to the SEM micrograph discussed; 5 - 15 cycles of overloading were carried out in other parts of their experiment), the specimen was examined by SEM as before. Based on the SEM micrographs published in [96], the authors present here a painting of the structure of the tendon after overloading below the rupture threshold in Figure 7(E). Note that (a) Only a small number of fibrils show a structure similar to that of the ruptured fibrils (i.e. Figure 7(C)), with smaller kinks. (b) The D bands disappeared in most of the fibrils, and longitudinal sub-fibrillar structure appearred instead. (c) Most fibrils demonstrated high density of kinks (with distance between consecutive kinks around 200-400 nm). (d) In some parts of overloaded fibrils, D bands still appeared in the regions between kinks, again implying that ordered molecular packing of micro-fibrils in these regions was retained. Interpretations (a)-(d) of the present authors are marked in Figure 7(E). After digestive action of trysin, the micrographs of [96] show that the outer layers of the fibrils were dissolved, leaving fibrils with smaller diameters, with some sub-fibrillar "fragments" attached to the host fibril. These smaller fibrils showed the D bands again, as expected, because they were triple helices with definite order of ar- 
rangement. While in real life, the fibrils would remain stable, many of the damaged fibrils should be dissolved and repaired by new tropocollagen molecules, if the tendon is to keep its physiological state. As emphasized in [95], the damaged sites were spread out so that no crowding of big kinks occurred in a small spatial region. The failure to sustain the strength of the fibril group, i.e. the tendon, occurred in many parts which were spaced apart. This is an important aspect, enabling the tendon to endure tensile forces within a rather wide range. In fact, the rupture process is like the rupture of a rope [97] in our daily life during a tug-of-war game. We would emphasize that the tendons of the tail of a bovine is not normally subjected to strong tensile force. Tendons in some other parts of the body, e.g. the Achille tendons of the ankle, would have to endure strong tensile force in exercise. Nature has allowed this to happen by synthesizing fibrils with crimp structure in many of our tendons. This important aspect has already been mentioned in Section (2.7). Note that the loaded Collagen I fibrils as elements of the ECM would promote cell adhesion, accompanied with reorganization of the actin cytoskeleton inside the fibroblasts. The fibroblasts, therefore, are in their active states, stretching out to form a network-like structure among themselves; repair work can be carried out readily [3] [98].

\subsection{Evidence of Ruptured Human Achille Tendons Have Fewer Number of Larger Fibrils, Smaller Crimp Angle, and the Oc- currence of Disrupted Crimp Continuity}

Achille tendon tissues were obtained at the central core/central plus the posterior peripheral/distal superficial as well as the proximally intact (proximal superficial) part of the of the Achille tendons of subjects who suffered from complete rupture core [47]. These specimens of Achilles tendons were taken during routine forensic autopsy. The cross-sectional area density and diameter distribution of fibrils were analyzed using stereological techniques of digitized SEM biopsy cross-sections. It is interesting to note that the "fibrils" are polygons, and some displayed "quasi-hexagonal" shape or even rectangular shape. We notice that sizes of these fibrils cover a wide range. Notice also that the fibrils are separated-the space is occupied by the interstitial fluid and some non-collagenous proteins.

We present the finding of the SEM micrograph in Fig.1(a) of [47] by a schematic painting in Figure 8. As the collagen fibrils are liquid crystals, it is not difficult to understand that such orderly geometrical shapes appear, as briefly discussed in Section (2.7) with Figure 4.

Clearly, there is variation of the cross-sectional areas of the fibrils. The "diameter", strictly speaking, can only be defined as the "effective circular diameter" of the fibril/fiber. The magnitude of the effective diameter is in the range of $250 \mathrm{~nm}$ down to $10-20 \mathrm{~nm}$. Revelation of such patterns of the cross-sections of fibers/fibrils is not surprising, as there are different possible ways of forming the micro-fibril and bigger basic regular collagen units (Section (2.6)). There is clear evidence, using optical interferometry measurement, that liquid crystalline 


\section{Interpretation of the SEM cross-section of human achilles tendon of [47] showing polygon structure of most collagen fibrils}

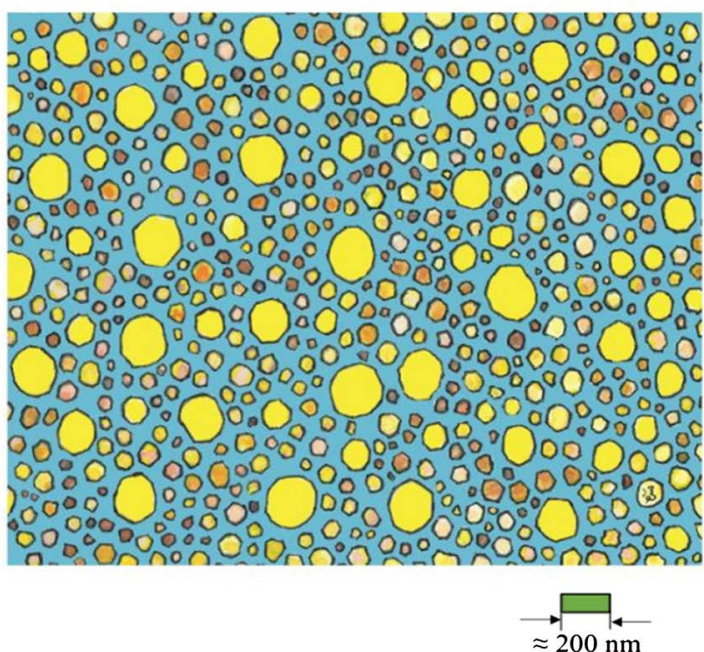

Figure 8. Schematic representation of the scanning electron microscopy result of the cross-section of a typical Achille tendon of ten subjects under study reported in Fig.1 of [47]. We observe that most of the cross-sections of the collagen fibrils have polygonal shapes of various types. See also Figure 4 of the present paper. The scale bar is painted in green. The painting was done by PCWF.

mesophases exist in living organisms [49]. Later, other studies also indicate that collagen molecules (and other polypeptides of living organisms) behave like liquid crystals with self-assembly ability [50] [99] [100] [101]; they can assemble into regular geometrical shapes. The longitudinal, tube-like structure is maintained by the special tropocollagen molecules with "quarter-staggered" pattern (Section (2.3)), a well-established aspect in collagen studies. By analyzing the distribution of the effective diameters of these fibers/fibrils, we observe from Figure 2(a) of [47], that there were clearly fewer comparative larger fibers (effective diameter in the range from 70 to $190 \mathrm{~nm}$ ) in the ruptured tendon. We show the schematic representation of their discovery in Figure 9, where the first graph (histogram) of Fig.1(a) of [47] is approximated by two continuous functions (solid line for the intact tendon, and dotted line for the ruptured tendon); the vertical axis gives the number of fibrils per micrometer squared and the horizontal axis indicates the effective averaged diameter as defined above. It is sufficient to show qualitatively that the ruptured Achille tendons of the 10 subjects had fewer relatively large fibrils (represented by the deep red region), and had a higher number of smaller fibrils (represented by the pink region) as compared to the intact tendon.

Since the variation of the crimp angle plays a role on the absorption of force, it was also measured in [47]. In short, the periodic banding pattern of collagen fibers was revealed to be changed when it was rotated between crossed optical polaroids. When the transmission direction of a fiber coincided with one of the polarizers, a dark extinction band became visible. When the sample was rotated with respect to the polaroids, the extinction band moved continuously along the 

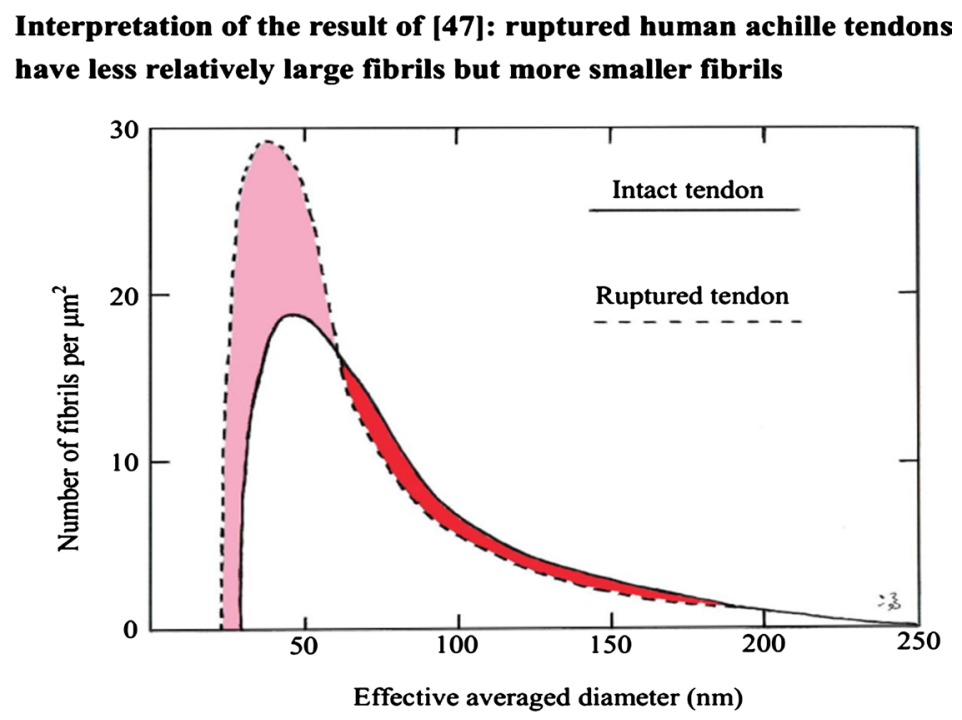

Figure 9. A rough estimation of the variation of the number of fibrils per micro-meter squared with respect to variation of effective averaged diameters in the distal core region of the tendon samples, where the histograms are approximated by two continuous functions here-solid line for the intact Achille tendon and dotted line for the ruptured tendon, according to the data of [47]. The ruptured tendon has fewer relative large fibrils (read portion) and more smaller fibrils (pink portion). The graph was painted by PCWF.

tendon; from the data on the variation of the extinction band, the crimp angle could be calculated according to a method established long ago [102]. The averaged crimp angle was found to be smaller in the ruptured tendons [47].

In another study, 66 spontaneously human ruptured tendons, including those in Achilles, quadriceps, biceps brachii and extensor pollicis longus, were studied. Even though the size distribution of the crimp angle and effective averaged diameters varied a lot in these samples, the measured effective averaged diameter (using SEM) and crimp angle were found to be smaller in the localized raptured sites, showing also disrupted crimp continuity [103].

\subsection{Evidence of Tendons under a Certain Degree of Mechanical Tension Resist Degradation by MMPs}

Types I, II, III, V and XI form fibrils, fibers which are the predominant tensile load-bearing proteins in the connective tissue of various parts of the body such as skin, blood vessels, corneal stroma, tendon, ligaments, cartilage, intervertebral disc and bone. The load-bearing fibrils persist to adapt to applied strain during daily life, including the early growth period. During adaptive matrix remodelling under load, mechanically-activated fibroblasts synthesize both procollagen and MMPs; the detailed mechanism of removal of (damaged) collagen and repairing them by the new collagen molecules is still under research, but we know that such repair must have happened. Also, there is evidence to suggest that the collagen molecules are stabilized by mechanical strain against both thermal denaturation [104] and enzymatic degradation [105] [106] [107]. We will review briefly below the work of [108], relevant to proceeding with our analysis. 
A "differential interference contrast (DIC)/edge detector" has been built to take optical image of the kinetics and pattern of the samples of collagen micro-networks during enzymatic degradation (see Figure 1 of [108]). A pepsin-extracted, commercial bovine sclera type I sample of atelo-collagen monomers (the outer collagen layer that protects the eye) at a concentration of $3.0 \mathrm{mg}$ $\mathrm{ml}^{-1}$ was obtained commercially for the experiment. The collagen specimen was strained gently between micro-pipettes; the intensity of the CID recording indicated the strained sample was significantly persistent to degradation by the established bacterial enzyme Clostridium histolyticum as compared to the unstrained one.

Following up, the same CID technique was applied to measure the resistance of reconstituted bovine type I collagen (at $\mathrm{Ph} 7.4$ ) to digestion by MMP8, which is rather specific to degradation of collagen I [109]. In more detail, there is evidence that MMP-8 cleaves the native type I collagen triple helix preferentially at a site located between Gly775 and Ile776 [110]. This experiment is one step ahead (of those using bacterial degradation enzymes) because MMP- 8 is physiological encountered.

Intuition tells us that MMPs cannot cleave all three alpha chains simultaneously due to size restrictions at the catalytic cleft. With the above background, we proceed to review briefly the experiment of [111], leading to hysteresis loops discussed in many papers. A single fibril mechanochemical erosion assay with $\mathrm{nN}$ force resolution was developed to detect the loss of a few layers of monomer from the surface of single native bovine sclera collagen specimen. The specimens were subjected to zero or finite tensile loads. When the unstrained specimens were subjected to digestion by Clostridium histolyticum collagenase A, they were degraded rapidly in $20 \mathrm{~min}$. When a tensile force of $1.8 \mathrm{pN} /$ monomer was applied, the fibrils were degraded in a longer time of 35 - $55 \mathrm{~min}$. Moreover, if the load was increased to $23.9 \mathrm{pN} /$ monomer, the fibrils were not degraded at all. The enzymatic degradation of collagen follows two steps; (i) binding; (ii) cleavage. This process as a whole is called the "Michaelis-Menten reaction process", discovered long ago [112]. The amount of monomer being cleaved is estimated by the binding and cleavage rates. For insoluble monomers, as in this case, only the cleavage rate $k_{c}$ is nonzero. Analysing the decrease of diameter of the monomer in time, the strain-stress relation, the $k_{c}$ values, the authors concluded that the result strongly supports the hypothesis of "mechanical tension stabilizes collagen monomers against enzymatic degradation" [111] [113]. The action of such degradation was called a mechanochemical switch. Therefore, there is evidence that the collagen monomer has an intrinsic protection against enzymatic digestion. Using the data of [111], incorporating mathematical model analysis (which is omitted here) the effective diameter (of the collagen monomer) versus time graphs for the zero load, a load of $46 \mathrm{nN}$, and a large load of $1054 \mathrm{nN}$ was plotted with discrete points in [114]. To show the idea of their discoveries, in Figure 10 we show three lines of best fit (roughly) based on the data presented in Fig. 2 of [114]. 
Such data suggest that tension may generally pull the collagen alpha chains into a tighter apposition, limiting enzyme access all along the molecule.

In view of the experimental investigations analysed above, we consider that the healthy tendons, ligaments, skin collagen fibrils/fibers, cartilages, bones must be under certain, but various degrees of tension to sustain homeostasis, avoiding over degradation. It will be fruitful if there is a way in future to quantify the tensions needed for each collagen structure of a subject.

\subsection{While Repair Work of Degradation and Neo-Synthesis of Tropocollagen Is Going on Through Life, Cores of Tendons Are Not Turned over Since the Age of 17, Based on Radioactive Examination of Specimens of Humans during the Period of Atomic Bob Tests}

From the rupture and pre-rupture overload experiments on bovine tail tendon discussed in Section (4.1), we have learned that when the tail tendon was overused, the damaged sites spread over a vast domain all over the tendon. If the tensile force is below the threshold of rupture, after degradation by a strong bacterial degrading enzyme to digest the damaged fragments, the tendon is still intact (see Figures 7(A)-(D)). In a human body, the digestive enzymes (MMP-1, $3,8)$ employed to degrade collagen I are not so strong as the bacterial enzyme. Moreover, there are stringent conditions under which collagen fibrils can be degraded - the enzyme has to interact to a full length to detect the site of interaction; the enzyme has to unfold the deformed portion (i.e. the kinks) of the fibrils, and then chemical reaction takes place to degrade. There is evidence, as presented in Section (4.3) with Figure 10 that when a tendon is under stretched,

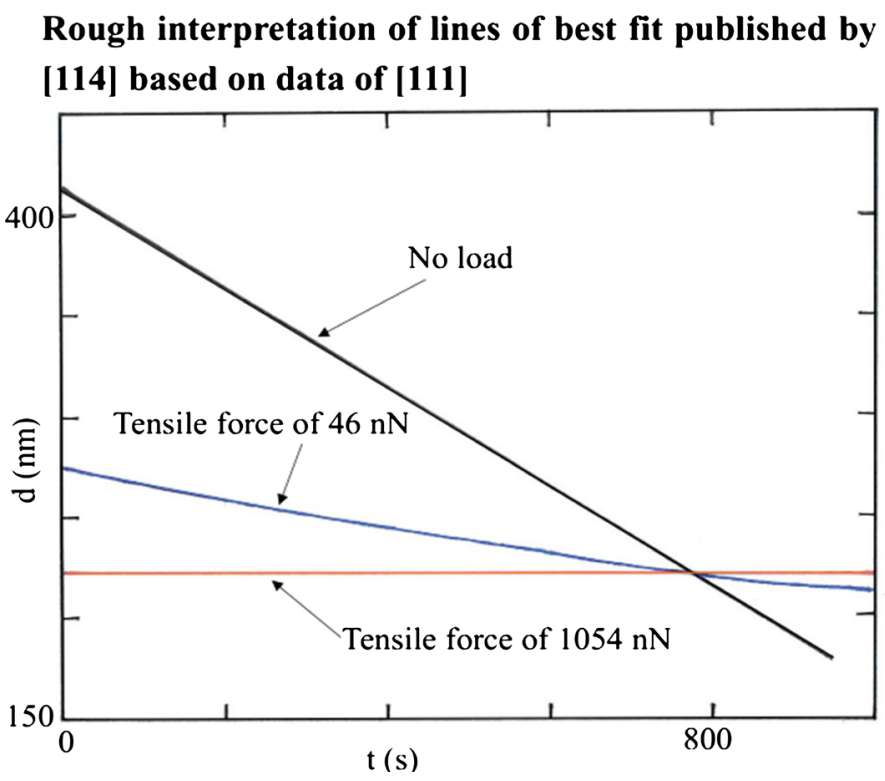

Figure 10. Effective diameter $\mathrm{d}(\mathrm{nm})$ of collagen monomer versus time (s). Three lines of best fit are shown, based on the data presented in Fig.2 in [114] with reference to the data obtained in [111]. The red line with a longer time scale substantiates the previous result presented in Fig.4 of [111]. 
the activation site of degradation is "hidden" inside so that tension on the tendon actually protects it from degradation. Moreover, in the experiments reported in [95] and [96], the repair process of synthesis of new collagen was excluded. In real life, when a tendon is stretched, the fibroblasts are activated, with their pseudopodia stretched out. Procollagen molecules are synthezised and their exocytosis would bring them to an extra-cellular domain where they are trimmed at both ends by enzymes as described in Figure 3. The resulting tropocollagen molecules can self-assemble and repair the damaged regions. During wound healing, collagen III molecules are produced first and are replaced by collagen I molecules on completion of healing [115]. The tendons are very heavy-duty structures of the body. It might be expected, at first thought, that tendon turnover should be fast to enable the tendons to carry out their heavy duties. However, measurement/estimates of the lives of tendons of the past few decades give rather controversial results: a wide range from 2 months to 200 years have been reported [116]. In order to give a precise answer to the turnover time accurately, it was noted that there were nuclear bomb tests in the time period 1955-1963, releasing the isotope $\mathrm{C}^{14}$ which can be distinguished from the common isotope of $\mathrm{C}^{12}$, according to accelerator mass spectrometry (AMS) analysis. Levels of $\mathrm{C}^{14}$ were measured using AMS in 28 forensic samples of Achilles tendon core and 4 skeletal muscle samples (donors were born in the period 1945-1983). Such investigation indicates that the tendon core is formed at about 17 years of age (during height growth) and is essentially not renewed thereafter. The accurate experimental result explains why Achille tendon tear is so common and difficult to treat. For similar results, the diseases of other tendons, due to overuse in many cases, are also difficult to treat clinically, an issue to be followed up in this paper.

\section{On the Controversial Issue of Thermal Stability of Collagen Triple Helices below and above Body Temperature}

There have been controversial results on the thermal stability of collagen triple helices for decades. It started off in the work [117] in which collagen samples from human lungs were heated and differential scanning calorimetry as well as circular dichroism experiments were conducted on the samples. Their analysis led to the conclusion that collagen fibrils are unstable even at body temperature. Note that the magnitude of the heating rate is one decisive factor, and debates went on for over one decade. We will not review the pros and cons but describe two sets of controversial results below and draw our conclusion based on common experience in daily life, together with the ability of self-assembly of collagen molecules in the discussion section.

\subsection{Newly Synthesized Peptide Chains of Collagen I in Chick Tendon Fibrobasts Fold Faster to Form Triple Helices as Temperature Was Increased, Up to $40^{\circ} \mathrm{C}$}

Chick embryo metatarsal tendon cells were cultured and collagen I peptides were synthesized as a natural process [118]. These cells were pulse-labelled for 4 
- $10 \mathrm{~min}$. with ${ }^{14} \mathrm{C}$ proline which is the amino acid that would preferentially label collagen, so that the synthesized collagen peptides would contain radioactive ${ }^{14} \mathrm{C}$. As the synthesis of the peptide begins with the N-terminal, and the labelling occurred in time series, the young peptides were labelled near the N-terminals, whereas the oldest peptides were labelled near the C-terminals. The peptides with intermediate ages were labelled throughout sites of the chain. The experiment was carried out at different temperature steps. Once the peptides were synthesized, they began to fold. Note that the chromotography technique was used in order that the constituents (folded helices and peptides/loose coils) could be separated due to difference of their mobilities. In that way, the relative amounts of folded helices and procollagen peptides were determined at specific temperature points.

Based on the briefly reviewed experimental steps, the authors demonstrated that the rate of triple-helix formation increased with increasing temperature. Roughly, at $33^{\circ} \mathrm{C}$, it took $14 \mathrm{~min}$. for the newly synthesized peptides to form triple helices; it took only $6 \mathrm{~min}$. for such folding at $40^{\circ} \mathrm{C}$. The fast folding rate was explained by the occurrence of a series of cis-tran isomerization of peptide bonds; in short, such a process means a rotation of the interactive part of the peptide (from a "cis" orientation to a "tran" direction) favorable to the elongation of the folding, governed by chemical force. It was also found that the triple helices resisted the action of collagen digestive enzyme within the temperature range studied.

It was noted that the temperature-dependence of rates of proteins synthesis, being conserved during evolution, are similar in all organisms known so far; such rates are characterized by an approximate activation energy of $125 \mathrm{~kJ} / \mathrm{mol}$. Taking that value to estimate the rate of elongation/production of procollagen molecules at $37^{\circ} \mathrm{C}$, a general equation expressing the time of elongation as a function of temperature was derived. The derived results on kinetics was found to be consistent to the time of folding found experimentally.

In a follow-up study along the line of [118], it was noted that (cyclosporin A)-bind protein (cyclophilin) is chemically identical to peptidyl-prolyl cis-transisomerase. Using chick leg tenocytes as specimens, it was demonstrated that cyclosporin A would slow down collagen triple helix formation, as an indirect support for the cis-trans-isomerization process for folding mentioned above [119].

\subsection{Investigation on Folding of Procollagen Derived from Human Skin, with the N-Terminal Cleaved, to Form Fibrils in the Temperature Range of $29^{\circ} \mathrm{C}-41^{\circ} \mathrm{C}$}

${ }^{14} \mathrm{C}$-labelled type I procollagen was purified from cultured fibroblasts of human skin in [120]. We have noted in Figure 2 that the procollagen includes loosely-structured $\mathrm{N}$ terminal (about $15 \mathrm{~nm}$ ) and $\mathrm{C}$ terminal (about $10 \mathrm{~nm}$ ). The typical sample was digested by $\mathrm{N}$-proteinase, leaving a specimen called $\mathrm{pC}$-collagen with the C-terminal still attached. In our terminology, it is the intermediate form from the propagation from procollagen to tropocollagen (Figure 2 and Figure 
3) with one "surplus C-terminal". The $\mathrm{pC}$-collagen specimen and the C-proteinase solution was heated in the temperature range of $29^{\circ} \mathrm{C}-41^{\circ} \mathrm{C}$. When the C-terminal was cleaved, the $\mathrm{pC}$-collagen became a tropocollagen (Figure 3 ). Tropocollagen molecules, once formed, would fold and form triple helices, and the solution would become turbid. The amount of turbidity, representing the amount of folded collagen, was measured by recording the absorbance of light at a wave length of $313 \mathrm{~nm}$ by a spectrophotometer fitted with a temperature recorder. Fluorography (or photofluorography) is the technique of photographing an image produced by light emitted from a fluorescent screen on collagen solution. Light is produced by the excitation of a fluorescent material by ionizing radiation which is produced when charged particles (electrons from the ${ }^{14} \mathrm{C}$-labelled collagen) can interact with the fluorescent material. In the experiment, the amount of soluble collagen ("unfolded collagen") was assayed by the stated technique of "fluorography". In fact, the fluorograms revealed the $\alpha_{1}(\mathrm{I})$ band, confirming the identity of the soluble collagen I in the buffer. The (supposed) collagen fibrils were centrifuged out and the effective diameters of the fibrils were measured using specimens from SEM examination (to justify that the folded protein molecules were triple helices) and the authors reported (without showing micrographs) that the effective diameter was inversely proportional to temperature. Based on the turbidity measurement as a function of temperature, Fig.3 of [120] shows effectively that the folding of tropocollagen molecules to form triple helices increased with temperature until $37^{\circ} \mathrm{C}$. This result contrasts that using collagen III as reviewed briefly in Section (5.3) below. At a higher temperature range of $37^{\circ} \mathrm{C}-41^{\circ} \mathrm{C}$, the assembly rate decreased. The authors interpreted that result is due to the formation of micro-unfolded monomer states, i.e., a collagen monomer has some portions of unfolded $\alpha$ chains along the monomer. It was also noted that fibronectin binded readily to denatured collagen, and that the resulting unfolded collagen chains would have a better chance of self-assembling to form fibrils according to the relevant authors in their later paper, in line with an earlier study of [121]. We interpret that the rate of triple helices assembled is proportional to the degree of turbidity in the experiment of [120], though the relationship may not be linear. To show the basic idea qualitatively, we present the schematic representation of the rate of tropocollagen folding versus temperature in Figure 11, showing positive slope up to body temperature, and negative slope when $\mathrm{T}$ was higher than $37^{\circ} \mathrm{C}$.

This result is supporting the experiment described in Section (5.1), contrasting to another typical in vitro experimental result reviewed below.

\subsection{Heating Bovine Fetal Skin beyond Body Temperature Will Cause Denaturing of Triple Helical Collagen Molecules, but the Resulting Molecules Will Refold during Cooling to Resume Their Intrinsic Helical Structure-An Example of Results Contrasting that Presented in $\mathbf{5 . 1}$ and $\mathbf{5 . 2}$}

The skin is built up of molecules of collagen I and III, and collagen I was studied 
Schematic interpretation of the folding rate of tropocollagen I derived from human skin to form fibrils based on the turbidity propagation rate reported in [120]

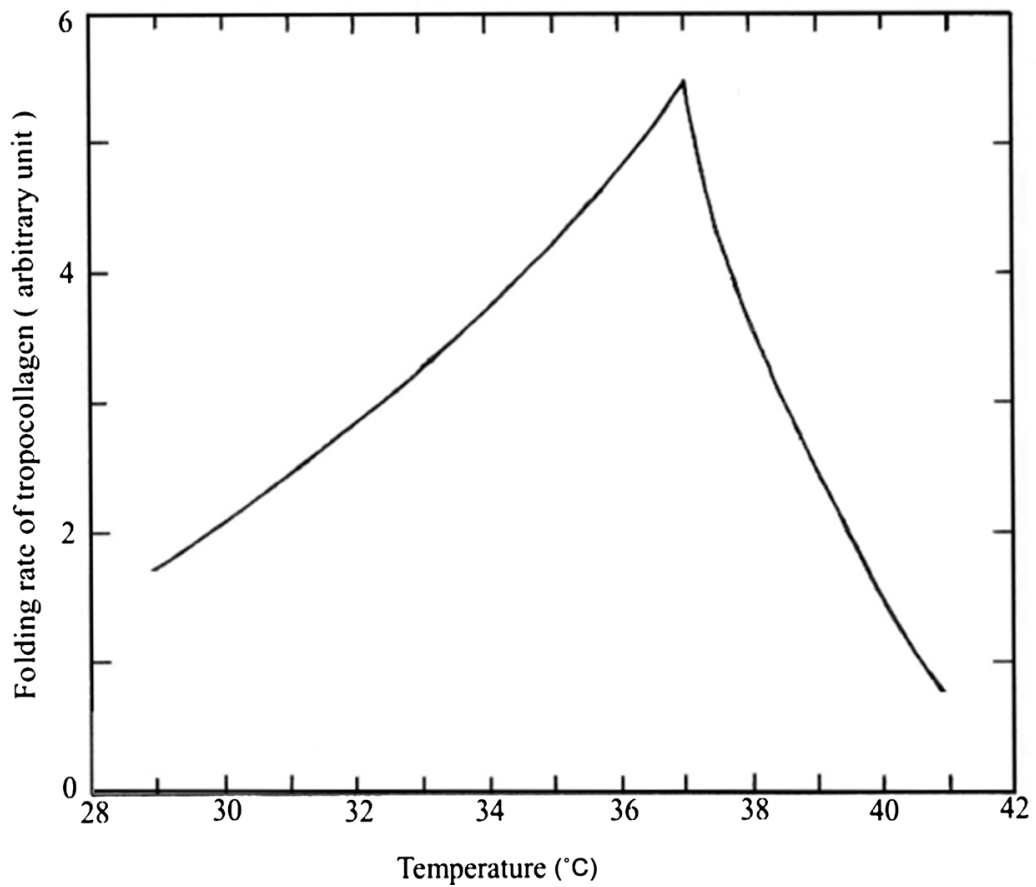

Figure 11. ${ }^{14} \mathrm{C}$-labelled type I procollagen was purified from cultured fibroblasts of human skin [120]. The typical sample was first digested by $\mathrm{N}$-proteinase, leaving a specimen called pC-collagen with the C-terminal attached. The specimen was put in buffer composition and temperature close to the physiological conditions with the presence of $\mathrm{C}$-proteinase enzyme, so that the $\mathrm{pC}$-collagen molecules became tropocollagen molecules in our terminology (see Figure 2 and Figure 3). We plot the schematic representation of the rate of tropocollagen folding versus temperature in the above figure based on data of [120], obtained by measuring the turbidity as described in the text. Notice that the slope is positive up to body temperature.

rather extensively. Some groups therefore used collagen III to investigate the thermal stability problem.

A tropocollagen III of bovine, like that of human, consists of three identical $\alpha_{1}$ (III) chains containing 342 tripeptide units or 1026 amino acids each, extending to a length of about $300 \mathrm{~nm}$ (see Figure 3).

Type III collagen contains interchain disulfide bonds in its mature processed form, holding the chains at the carboxyl-terminal end. Some pioneering works were done in the 1980s for the stated purpose, applying the Circular Dichroism (CD) or Optical Rotatory Dispersion technique (ORD) [122] [123] to measure the fraction of collagen molecules to be in the helical form. We will leave out the technicality details, and review very briefly a more recent experiment below.

In [124], bovine fetal skin was extracted and denatured by heating at a rate of $1^{\circ} \mathrm{C}$ per hour, to a temperature of $45^{\circ} \mathrm{C}$. The sample was then cooled and the (ORD) method was used to measure the fraction of the protein sample that was in the $\alpha$-helix conformation. The reading of the ORD signal was found to remain stable at the points indicated by the triangles in the original Figure 1 of [124]. 
We roughly estimate the five temperature points to be at $39^{\circ} \mathrm{C}, 35.5^{\circ} \mathrm{C}, 34.5^{\circ} \mathrm{C}$, $33.5^{\circ} \mathrm{C}$ and $25^{\circ} \mathrm{C}$. In Figure 12 we followed their heating curve and joined the stated five points in the cooling part, obtaining a hysteresis loop (painted with deep orange color). We interpret the appearance of this loop using the energy concept. In fact, we can draw an analogy to the action of a piston in a car engine. During one cycle of the piston action, the pressure of the gas inside the cylinder compresses and expands in cycles (by the chemical reaction of the burning fuel) and the volume of the cylinder changes from zero to a maximum as limited by the structure. When the piston resumes its original volume, some energy is wasted in friction. This loss of energy also happens in the refolding of the collagen molecules. The larger the area enclosed by the hysteresis loop, the more energy is wasted/stored in refolding, and in general, more time is needed to refold. There are similar results published showing hysteresis loops, but we shall not repeat to review these works. The key issue we point out is that, in these sets of experiment, as temperature increases, the folding rate is not increasing up to body temperature, as found by experiments stated in Sections (5.1) and (5.2); rather, it is negative (unfolding) all the way to the highest temperature designed for the experiment (in Figure 12, it is $45^{\circ} \mathrm{C}$ ). The hysteresis area is not zero, meaning energy is wasted/stored in refolding and it takes hours for the refolding process to complete during cooling in results where time period was recorded. The contradictory issue, which is very important in medicine, will be followed up in the discussion section.

Thermal unfolding and refolding of fetal bovine skin collagen III according to [124]

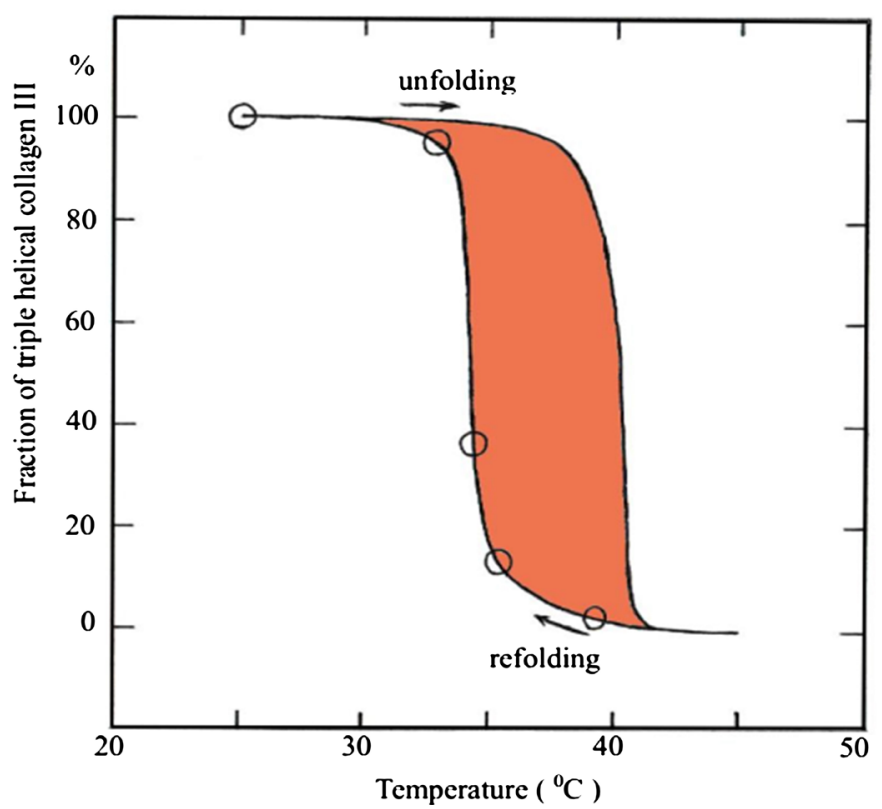

Figure 12. Bovine fetal skin was extracted and denatured by heating at a rate of $1^{\circ} \mathrm{C}$ per hour, to a temperature of $45^{\circ} \mathrm{C}$. The sample was then cooled and the ORD method was used to measure the fraction of the protein sample that was in the $\alpha$-helix conformation. We roughly estimate the data of Fig.1 in [124], and plot their result, showing a hysteresis loop in the fraction of triple helix III-temperature plot. 


\section{The Presence of Homotrimers in Collagen Types I, II and III and Related Diseases}

MMP degradation of damaged domains of collagen molecules is a physiological process, leading to tissue remodeling, homeostasis, and to allow for wound repair. The basic unit, i.e., tropocollagen of collagen I which is the most abundant type in humans, consists of two $\alpha_{1}(\mathrm{I})$ chains and one $\alpha_{2}(\mathrm{I})$ chain (Table 1 ). To digest a portion of a collagen fibril, the MMP first unwinds the collagenous cleavage site, so that the individual $\alpha$ chains can be placed (by chemical force) inside the catalytic cleft of the enzyme. The unwinding process is rate limiting. The presence of the $\alpha_{2}(\mathrm{I})$ chain is to allow efficient unwinding for digestion to take place. Due to genetic mutation or disorders in the folding process at the RER by heat shock proteins/chaperones, the isoform of three $\alpha_{1}(\mathrm{I})$ chains, forming the homotrimers, is also present in collagen I of various unhealthy tissues of the human body. Investigation of the difference in reactions of the homotrimers and the (native) heterotrimers of collagen I to MMP-1 and other MMPs enzymatic processes during the past three decades indicate that it is the structure of the homotrimers that hinders the exposure of the cleavage sites of such collagen fibrils [125], leading to the phenomenon that type I homotrimers resist cleavage of all tissue MMPs [126] [127] [128]. Accelerated degradation of dermal collagen matrix plus decrease in collagen synthesis lead to skin aging [129], correlated with other diseases such as rheumatoid arthritis [130], hypertensive cardiac [131], hypertrophic cardiomyopathy [132] (both are caused by the predominance of synthesis over degradation), and others. On the other hand, resistance to physiological digestion also leads to many diseases, such as osteogenesis imperfecta (brittle bone disease in mice model) [133] (interpreted to be due to disordered alignment of mineralized collagen fibrils in the bone), weakening in tail tendon of mice model [134]. A type of glomerulopathy was detected in tissues of mouse model with homozygous null for $\alpha_{2}(\mathrm{I})$ gene [135]. Note that not all the diseases mentioned are analyzed with respect to the presence of homotrimers. There are other factors involved, but for collagen I, the correlation of the progression of the diseases mentioned with the resistance to digestion (because of the presence of homotrimers) is more clearly established. Note that collagen III is a homotrimer in its native form; it is established that during wound healing, the collagen structure is synthesized by stem cells in the injured CTIF site during the earliest phase of wound healing, followed by synthesis of collagen I by the matured fibroblasts [136]. Since collagen III is observed to be replaced by collagen I, MMPs 1, 3, 8 must be able to digest collagen III far more readily than collagen I due to the difference in their structures. Collagen II is also a homotrimer (Table 1). The cartilages (with some amount of collagen IX) are turned over very slowly during live time after adulthood, and the common degenerative disorder is arthritis when one ages (see e.g. [137] [138]). We consider the homotrimer structure of the vertebral discs is one factor that causes fibrosis; the loss of gela- 
tinous characters of the nucleus pulosus is another important factor that leads to degenerative disorder. The other types of collagen having homotrimer compositions are found in small amounts only, and present in a small part of the fascia.

\section{Causes of Tendinopathy and Some Plausible Clinical Treatments}

\subsection{Manifestation of Tendinopathy in the Fascia}

Having explained the "longevity" of tendon cores, it has been a problem to understand the cause of tendinopathy. Tendinopathy is a complex multi-faceted tendon pathology, leading to decline in musculoskeletal function, not only limited to sports medicine. There is usually no symptom at the initial stage. When the disease is recognized, common pain is felt with stretching, together with a certain degree of localized swelling, and palpitation of the pathological area [139] [140]. Under clinical settings, rheumatologists commonly used the term tendonitis to describe painful symptoms as a result of tendon inflammation [141], whereas other clinical experts might consider the painful symptoms as disorders, called tendinosis, reflecting degenerative changes at the microscopic level [142]. The treatments are usually temporary, costing a lot of resources to the society. Tendinopathy refers to overuse tendon injury; the intrinsic pathogenetic mechanism of this disease has been under rather intense research and debate during the past ten years. One key issue is whether inflammation is involved during the pathological process. From the collagen view point, tendinopathy is characterized by the change of collagen production from type I to III, resulting in a decrease in tensile strength that explains the fact that tendinopathy has a higher risk of tendon rupture [143].

\subsection{The Evidence that Tendinopathy Starts with Inflammation and the Disease Progresses as a Complex Interplay between the Intrinsic and Extrinsic Compartments}

We have in the beginning remarked that there are cells migrating in the CTIF system and the collagen structures were interspersed with various non-collagenous proteins, predominantly proteoglycans and glycoproteins, as matrix molecules. Structural integrity is kept by collagen crosslinks at the molecular and sub-fibrillar levels. In the normal state, the fibroblasts attached to the tendons are called tenocytes, and are found to be residing in rows (via connection protein connexin 43) following the direction of the crimp of collagen fibers [144] [145] [146]. It is not surprising that the resident cells, cells in transit, fibrous collagen constituents, plus the above-mentioned "linkage proteins" are involved in the development of the pathological state, when a tendon is overused. In more details, the concept of complex interplay has been introduced. The progress of the disease is a complex interplay between two compartments: the intrinsic and extrinsic compartments as named in [51]. The intrinsic one is composed of: (i) The fibrous collagen core (mainly collagen I with small amounts 
of collagen III, V and VI) [147]. (ii) Fibril-associated collagen with interrupted triple helices (FACITs). (iii) The resident cells (mainly tenocytes, mast cells, some macrophages, plus some stem cells [148]). (iv) Some attached proteins (such as the small leucine-rich proteoglycans (SLRP) which regulate collagen self-assembly to form fibrils [149], plus some glycoproteins). (v) Resident stem cells in the CTIF system (one origin is from hair follicles, because there is no evidence that they migrate from the bone marrow when they are in need) [150] [151].

The extrinsic compartment is composed of: (i) Interstitial fluid. (ii) Nerve fibers/fibrils with various endings. (iii) Blood vessels. (iv) Lymphatic vessels. (v) Cells in transit (immunity cells which migrate to the target when inflammation occurs) as well as some stem cells migrating into the region of interest [148]. Here we emphasize the importance of including the interstitial fluid which is not commonly mentioned in other works in general. In particular, the tenocytes have mechanical sensors in the cell membrane. Tenocyte behaviour, including change of phenotyping, is much affected by all the mechanical forces experienced, including (a) shear force of the interstitial fluid flow, (b) collagen-structure-mediated integrin activity, leading to focal adhesion and other functions as described in Sections (1) and (3). The IF flow shear force is experienced by the known ion-channels as well as the prime cilia in the cell membrane of tenocytes which have only been found recently to be highly oriented along the collagen direction and the long axis of extensor tendon [152]. We postulate that similar structure could be found in other tendons too. Interaction (a) is an example of interaction between the extrinsic and intrinsic compartments. Interaction (b) is an example of interaction among members of the intrinsics compartment.

Since the collagen fibers have long turnover time, microstructure disorder among the fibers, fascicles, sub-tendons are accumulative, for instance, glycation in diabetic patients (details will be treated in another paper). Tendon repair is then a complex interaction between the intrinsic and extrinsic compartments, involving degradation of collagen fragments, synthesis of new procollagens for repair as experienced in wound healing. Overdoing healing leads to scarring, and even fibrosis.

Including the "accumulative factor" just mentioned, we consider that overuse of the tendons could trigger off the very complex interplay between the two mentioned compartments, with inflammation starting the pathological process. Table 4 lists some special features of typical examples of tendinopathy, suggesting strongly that the disease begins with inflammation. In fact, human tissue biopsy specimens obtained from small rotator cuff tears of 40 patients during surgery operation showed a significant inflammatory infiltrate of macrophages and mast cells in cases of more severe mechanical tears of the tendons [153], supporting the hypothesis that tendinopathy is associated with inflammation at the early stage. 
Table 4. Some typical examples of inflammatory response of injured tendons.

\begin{tabular}{|c|c|c|c|c|c|c|}
\hline Treatment & $\begin{array}{l}\text { Genes of cytokines expressed; } \\
\text { secreted cytokines detected }\end{array}$ & $\begin{array}{l}\text { Types of cells } \\
\text { examined }\end{array}$ & $\begin{array}{l}\text { Models of } \\
\text { in vitro study }\end{array}$ & mRNA or proteins found & $\begin{array}{l}\text { Expected biomedical } \\
\text { consequences }\end{array}$ & Reference \\
\hline $\begin{array}{l}\text { Cyclic mechanical } \\
\text { stretching }\end{array}$ & $\begin{array}{l}\text { Interleukin } \mathrm{IL}-1 \beta \text { over } \\
\text { production }-17 \text { times of } \\
\text { control }\end{array}$ & $\begin{array}{l}\text { Tenocytes of } \\
\text { Achille } \\
\text { tendon }\end{array}$ & Rabbit & $\begin{array}{l}\uparrow \text { of collagenase- } 1 \text { and } \\
\text { stormelysin- } 1 \text { genes }\end{array}$ & $\begin{array}{l}\text { Over degradation of } \\
\text { collagen I; } \\
\text { inflammation }\end{array}$ & [154] \\
\hline $\begin{array}{l}\text { IL- } 1 \beta \text { added to cell } \\
\text { culture }\end{array}$ & NIL & Tenocytes & Human & $\begin{array}{l}\text { mRNA of COX-1, } \\
\text { MMP-1, MMP-3 } \\
\text { expressed; prostaglandin } \\
\text { PGE }_{2} \text { secreted }\end{array}$ & $\begin{array}{l}\text { Over degradation of } \\
\text { collagen I; } \\
\text { inflammation }\end{array}$ & [155] \\
\hline $\begin{array}{l}\text { Torn edges of } \\
\text { supraspinatus } \\
\text { tendon }\end{array}$ & $\begin{array}{l}\text { Genes expressed: IL-18, IL-15, } \\
\text { IL-16, macrophage inhibitory } \\
\text { factor (MIF), tumor necrosis } \\
\text { factor } \alpha \text { (TNF- } \alpha \text { ) }\end{array}$ & $\begin{array}{l}\text { Tenocytes of } \\
\text { supraspinatus } \\
\text { tendon }\end{array}$ & Human & $\begin{array}{l}\text { Proteins of IL-18, IL-15, } \\
\text { IL-6, MIF, TNF- } \alpha \text {, } \\
\text { caspases } 3 \text { and } 8 \text { detected }\end{array}$ & $\begin{array}{l}\text { Apoptosis of } \\
\text { tenocytes via the } \\
\text { caspase pathway }\end{array}$ & [26] [156] \\
\hline
\end{tabular}

\subsection{The Very Recent Evidence that a Model System with Tenocytes Cultured on Aligned Biomaterial Scaffolds Would be Less Susceptible to a Catabolic Inflammatory Stimulus than the One with Tenocytes Seeded on Disorganized Topography-We Postulate that Well Aligned Collagen Fibers Have "Anti-Inflammatory Effect"}

The anterior cruciate ligament (ACL) and posterior cruciate ligament constitute a pair of cruciate ligaments in the human knee. The hamstring tendons form two groups of tendons at the back of the knee. In [157], fragments of healthy hamstring tendons were collected from patients who underwent surgical reconstruction of the anterior cruciate ligament. Tenocytes were stripped from surrounding tissues in the way described in [158]. Monocytes were differentiated towards the uncommitted macrophages called MO macrophages by stimulation with phorbol 12-myristate 13-acetate. These MO macrophages were chemically stimulated by Interferon-c and Lipopolysaccharide (LPS) to arrive at the M1 phenotype, which is known to be able to induce strong immune response and tumoricidal activity. When MO cells were activated with Interleukin-4 (IL-4), they acquire the M2-polarized phenotype, and they would shut down their TIMP1 gene expression, would also initiate the production of highly angiogenic TIMP-deficient proMMP-9 molecules [159]. All three types of macrophages (MO, M1- and M2-phenotypes) plus human tendon fibroblasts were seeded on two substrates; (i) electrospun polycaprolactone (PCL) mats with either highly aligned, or (ii) randomly oriented fiber structures. The mono-cultured tenocytes on aligned scaffolds served as control. Leaving out the technicality of the analysis, the main findings were: (a) There was crosstalk between the tenocytes with the immune cells (macrophages of two phenotypes) with results dependent on the mechanical conditions of the scaffolds they were seeding. When the substrate, which represented the ECM collagen fibril/fiber network, was well aligned (parallel), such cross-talk led to a result tending to downregulate the expression of MMPs. The result was aberrant collagen matrix turnover. (b) As expected with the result of (a), highly aligned tendon cell scaffolds would promote tendon 
matrix synthesis. (c) The tenocytes would be less sensitive to stimulation of immunity cells with substrate (i) because they were involved in the synthesis activity as a postulate. In other words, we infer that there is anti-inflammatory effect when the tenocytes are seeding on highly aligned scaffold [157].

\subsection{Application of Synthetic Mechano-Growth Factor to Cultured Rat Achille Tendon Tenocytes Would Lead to Enhancement of MMP-2 Activity, a Condition Necessary for Tendon Repair}

Directional migration is a fundamental cellular process essential for embryonic development, wound healing, immune response, and tissue development. We use the term pseudopodia for physiological migration to distinguish migration during cancer invasion (called invadosome, to be treated in the next paper).

To repair an injured tendon, tenocytes need to move to the repair site, require remodelling of the ECM, giving room/way for migration, to begin with. After that, synthesis of collagen and other proteins follow, which might be considered as the second stage of wound healing. The major part of collagen III is eventually replaced by collagen I in the tissue, and the healing is complete. Employing cultured tenocytes from rat's Achille tendon, it has been shown in [160] that treatment of these tenocytes with a new synthetic growth factor, called the mechano-growth factor (MGF), would lead to enhanced MMP-2 activity (but not the MMP-9 activity) via the activation of the FAK-ERK1/2 signalling pathway. Whereas both MMP-2 and 9 can degrade collagen IV, V (as constituents of the basal membrane), MMP-2 also degrades elastin. It has been found that elastic fibers are broadly distributed in tendon and localized around tenocytes [161], though the total amount is small [162]. It therefore makes sense that MGF would expedite tendon repair. However, we also note that elastin has an extremely slow turnover rate. It is therefore desirable to find out later whether tendon repair itself would cause elastin degeneration.

\subsection{Proteomic Profile Analysis in the Fascicle Matrix (FM) and Inter-Fascicle Matrix (IFM) and Its Relevance to Development of Future Clinical Treatment for Tendinopathy}

We have noted that the "core" of a tendon has a very slow turnover rate. This core of a tendon is referred to the collagen fibrils/fibers forming aligned (along the direction of force transmission) structure for obvious physical demand-to sustain tensile force. A fascicle is composed of many fibrils and enclosed by a sheath called endotenon as shown in Figure 4. The blue region inside a fascicle contains proteoglycans and glycoproteins of which only several of each class have been named in Section (1.2). These proteins are embedded in the interstitial fluid, and the blue region may be called a fascicle matrix (FM) in Figure 4. Likewise, in a hierarchy way, a sub-tendon contains fascicles embedded in a blue domain, enclosed by a layer called epitenon; this blue domain is called inter-fascicle matrix (IFM). Resident cells and cells in transit can reach both FM and IFM. The abundance of proteins in FM and IFM may differ according to 
functional demands. In a recent investigation, superficial digital flexor tendons (SDFT) of the forelimbs of horses, euthanased based on an incurable disease rather than that related to the tendons, were taken as samples [163]. Using laser-capture microdissection and mass spectrometry, it has been demonstrated that majority of the proteins found in FM were ECM proteins, such as collagen types I and XII, thrombospondins-1 and-4, COMP, fibromodulin and decorin. Both Thrombospondin 1 and 4 are adhesive glycoproteins that mediates cell-cell and cell-matrix interactions [164]. Thrombospondin-1 binds fibrinogen, fibronectin, laminin, type $\mathrm{V}$ collagen and integrins $\alpha_{\mathrm{v}} \beta_{1}$, and is inferred to participate in angiogenesis and platelet aggregation. Thrombospondin-4 binds heparin (a glycosaminoglycan having anti-coagulant property) and calcium. It is involved in local signaling in the nervous system. The protein COMP has been thought to be more involved in the cartilage structure, but it has other functions: binding to bone morphogenetic protein (BMP), binding to heparan sulfate proteoglycan, playing a role in collagen fibril organization, as an ECM structural constituent [165]. Fibromodulin is involved in collagen fibrillogenesis, keratan sulfate (major glycosaminoglycan in the cornea) biosynthesis, transforming growth factor $\beta$ receptor complex assembly [166]. Decorin is a leucine-rich proteoglycan mainly involved in collagen fibril assembly [167]. Thus from protein analysis, the FM's functions are mainly fibril synthesis and refolding.

The proteins found in higher abundance in the IFM were mainly cellular proteins. The IFM contains more protein fragments (neopeptides), implying that greater matrix degradation has happened in this compartment for homeostasis. This revelation is intuitively understandable because the fascicles, as basic units of the tendon (macroscopically), need to slide along the force direction to absorb external force, causing deformation of the IFM. In addition, the number of these neopeptides was found to reduce with ageing, implying that the turnover rate of the IFM decreases in aged tendons, offering less resistance to cyclic load. Collagen type III concentration, perlecan (a basement membrane-specific heparan sulfate proteoglycan core protein), and 5 glycoproteins ( 3 laminin subunits, transforming growth factor $\beta$-induced protein and adiponectin) are enriched in the IFM. The laminin is a major component of the basal lamina, a protein network. The transforming growth factor- $\beta$ (TGF- $\beta$ ) protein is involved in regulating and mediating processes at the cellular level, including cell proliferation, differentiation, motility, adhesion and apoptosis, as well as processes of tissue organism. The adiponectin protein, being secreted by adipocyte, is a novel adipocyte-specific protein. It is suggested to play a role in the development of insulin resistance and atherosclerosis.

Summing up, these data suggest that reduced turnover of the IFM with increasing age may result in damage accumulation and alterations in IFM mechanical properties, increasing the risk of tendon injury, and hence tendinopathy, in aged individuals [168]. Since the tendon inserts into the bone and joins the muscle, it will be a fruitful future project to study the functions of the FM 
and IFM proteins during the development of tendinopathy, including that due to aging. We might even consider the development of local application of deficient proteins when a pathological state emerges.

\subsection{Enhancement of Collagen Synthesis via Growth Factors Derived from Platelet-Rich Plasma: Can It Be a Therapeutic Measure to Treat Tendinopathy?}

Platelet-rich plasma (PRP), obtained simply by centrifugation of whole blood, is a portion of the plasma fraction that has a platelet concentration above that of whole blood. Being activated by activator such as thrombin, the PRP forms a gel. Platelets enclose different types of granules that can perform different functions. The three main types of granules are $\alpha$-granules, dense granules, and lysosomes. In particular, the $\alpha$-granules store up some grow factors such as platelet-derived growth factor (PDGF), transforming growth factor- (TGF-) $\beta$, insulin-like growth factor (IGF), vascular endothelial growth factor (VEGF), fibroblast growth factor (FGF), and epidermal growth factor (EGF) [169]. Analyzing the relevant growth factors, it was shown in [170] that intermediate concentration of platelet-rich plasma within the range of $\left(0.5 \times 10^{6}, 1 \times 10^{6} \mathrm{plt} / \mu \mathrm{L}\right)$ strongly enhanced the processes of proliferation, migration, collagen production, and MMPs production; these processes are needed for tendon repair. Such a result suggests that further experimentation is encouraged to apply an intermediate concentration of platelet-rich plasma locally to sites of tendon injury.

\subsection{A Balance between Reparation and Degeneration in Treating Tendinopathy: Sparing Inflammation-Induced Healing Moieties and Encouraging Robust and Rapid ECM Repair Treatment by Exploiting miRNA-29a}

Let us follow on from Table 4. Among the cytokines, IL-33, a member of the IL-1 family, plays a major role in innate and acquired immune responses. It is expressed in endothelial cells and fibroblasts, and is released after cellular damage and biomechanical overload; it has the nickname of "alarmin" [171].

On the other hand, we note that a microRNA (miRNA) is a small non-coding RNA molecule that functions in post-transcriptional regulation of gene expression [172]. Along this line the following specimens were obtained in the investigation of [173]: (i) Seventeen supraspinatus (torn) tendon specimens were obtained from 12 patients with rotator cuff tears undergoing shoulder surgery in [173]. (ii) Samples of both the subscapularis part of the tendon (thus representing the onset or early sample of tendinopathy) were also collected from the same patients. Arthroscopic repair, a minimally invasive surgical procedure of the rotator cuff was carried out. Human tenocyte cells were explanted from hamstring tendon tissues; a hamstring tendon is one of the three tendons from the three hamstring muscles in the back of the thigh. These tenocytes were transfected with synthetic mature miRNA for miR-29a and b. The tenocytes were the human in vitro cell cultured on two tendon tissues (i) and (ii) stated above. Ana- 
lyzing these cultured models, we leave out the details here, the authors reported that IL-33 was secreted from the tenocytes at the early stage of tendinopathy, leading to a transition of collagen I to III, the latter of which is well known to play a key role in collagen repair. The use of synthetic miRNA-29a provides information that miRNA-29a is a post-transcriptional regulator of matrix/inflamematory genes during tendon repair. It has been suggested [173] to exploit miRNA-29a as a future therapy for quick collagen repair in the presence of inflammation, to treat tendinopathy. The reader is referred to a very recent review [174] for the concept of balancing between reparation and degeneration in treating tendinopathy: sparing inflammation-induced healing moieties and encouraging robust and rapid ECM repair. While we have to wait for further experimental results adopting this miRNA-29a therapy, the present authors wish to draw an analogy discovered a few decades ago in treating pain: applying needle acupuncture to initiate a neurogenic inflammation, resulting in quick repair and analgesic effect; the reader is referred to [3] [175] for more details.

\subsection{Wound Healing of Tendon is Initiated by Endogenous Nitric Oxide Generation, with All the Three Isoforms iNOS, eNOS, nNOS of the Nitric Oxide Synthases Participating in Time Sequence, Suggesting the Usage of Glyceryl Trinitrate Patches to Treat Tendinopathy Might Be Useful}

When NOS catalyzes the substrate L-arginine to L-citrulline, nitric oxide (NO) is produced. Cofactors calmodulin, tetrahydrobiopterin (BH4), heme, flavin mononucleotide (FMN), and flavin adenine dinucleotide (FAD) are working to regulate the production. There are three isoforms of the nitric oxide synthase: eNOS is mainly expressed in endothelial cells; nNOS is expressed in neurons. The third, inducible, isoform iNOS is expressed in macrophages, and is induced by proinflammatory cytokines (such as interleukin-1 and tumor necrosis factor), and cytokines from alien cells. Normally, the amount of NO produced by iNOS is vast. For example, after transplantation of organ (liver, say), the huge amount of NO produced can react with super-oxide, a natural product in ATP generation in the mitochondria, to form peroxynitrite $(\mathrm{ONOO})^{-}$, a biochemical molecule being detrimental to all cells, and the transplanted organ will be readily damaged. The inhibitors of iNOS can be used as anti-rejection drug after organ transplantation, such as myco-phynolate mofetil, which was further developed to treat renal ischemia-reperfusion injury [176]. The enzyme iNOS is doing its immunity duties, some of which are involved in physiological processes, but the degree of activation has to be strictly regulated.

Using in vivo mouse models, it was demonstrated in [177] that nitric oxide is an important mediator of normal wound healing, resulting in collagen synthesis and accumulation at the wound site. Injection of S-methyl isothiouronium sulphate (S-Methyl-ITU), a potent inhibitor of nitric oxide synthase NOS, was shown to inhibit the healing process, as a check. 
Achilles tendon of rats [179]

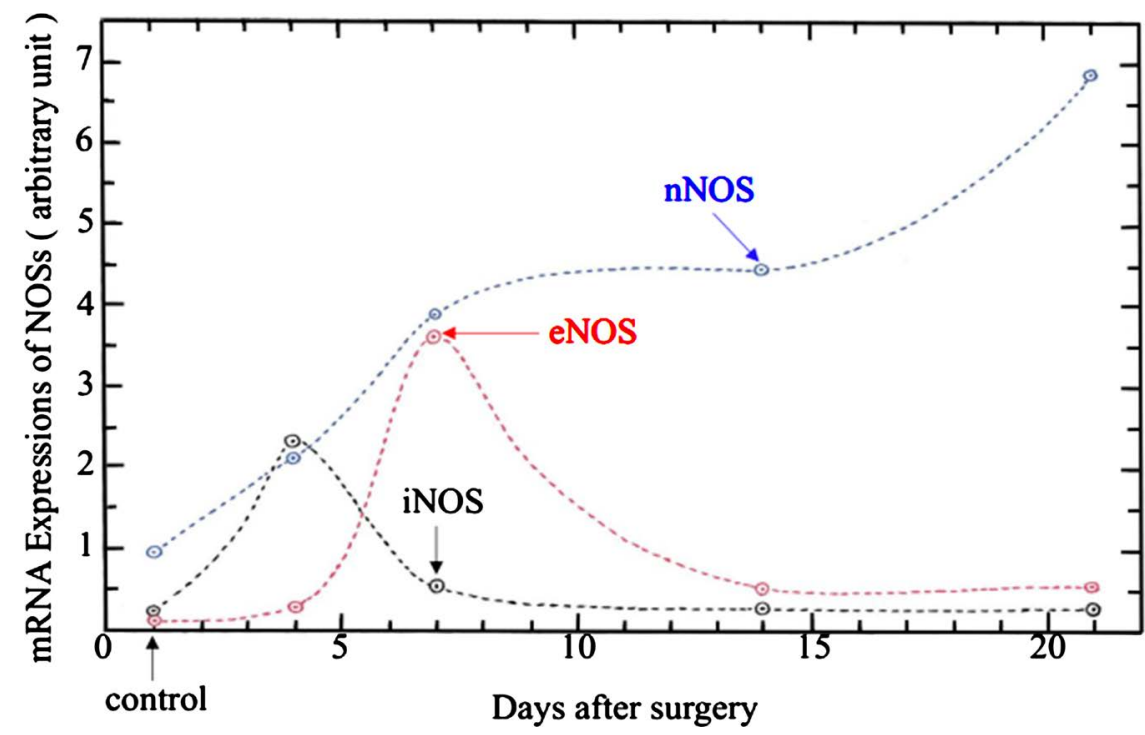

Figure 13. Surgery injury was introduced to the right Achille tendons of 44 rat models and the left Achille tendons were uninjured, as control specimens. The mRNA expressions of the inducible nitric oxide synthase iNOS, the endothelial NO synthase eNOS, the neuronal NO synthase nNOS were detected in the injured tendons. Taking the histogram values in Fig.2 of [179], we show that the wound healing process was initiated by iNOS, an immunity action, followed by enhanced expression of eNOS, causing blood vessel dilation. The neuronal NOS expression was activated from the beginning of injury, and was enhanced in general during the healing process.

Note that there is also evidence that NO induces collagen synthesis in cultured human tendon cells [178]. In another study [179], Achilles tendon and plantaris of the right hind limb (of the animal model with 44 rats) were dissected free from the surrounding fascia. The Achilles tendon was transected with a scalpel from its calcaneal insertion. The tendinous portion of the plantaris was removed to prevent any possible action as an internal splint. RNA expressions of eNOS, iNOS, nNOS were investigated at 4, 7, 14 and 21 days following the stated surgery by the usual RT-PCR procedure. Based on the values of the histogram published in Fig.2 of [179], we plot three lines in Figure 13, representing respectively the activity of the three stated enzymes, after the stated surgery operation was carried out to induce injury of the Achille tendon. The data points (circles in black, red and blue) at day 1 are the relative mRNA expressions of the control samples. The other circles with three different colors are taken from the maximum values of the histogram in Fig.2 of [179]. The dotted lines are only the speculated data points if more data of the expressions of mRNA had been measured. The purpose of this figure is to show, qualitatively, that iNOS (black dotted line) is responsible for initiating the healing process, substantiating the result of [177]. After the first 7 days, the expression of iNOS remained at a very low level. Such an initiation is not unreasonable, as the damaged tissues would have been broken down, and carried away (by the interstitial fluid). Significant expression of eNOS was observed at day 7 . We interpret that result as representing dilation 
of the blood vessel for better blood supply to the wound site occurred after the immunity act was about to complete. Here NO (from eNOS) acted purely as a vessel dilator. NO is also a potent neuro-transmitter. Right from the start, the neurons at the wound site were informed, and have been playing roles to regulate the healing process, all the way to over 21 days after injury. The uninjured Achille tendon was found not to express any significant isoform of nitric oxide synthase [179]. There are other studies published on the application of supplying NO to treat tendinopathy, and the reader is referred to the review of [180].

More recently, glyceryl trinitrate patches, which can release nitric oxide, have been developed to treat tendinopathy, but noting that an exercise program must accompany the patch treatment [181]. Such a consequence is in line with the analysis presented in Section (7.3). Without a certain amount of mechanical tension, the tenocytes are in the dormant state and would not synthesize much collagen. At this stage, we do not have quantified data as to the magnitude of tension required for the injured tendon for certain type of tendinopathy.

\subsection{Effects of Taking Antibiotic Ciprofloxacin on the Strength of Tendon Based on Explant Experiment According to Reference [182]}

Tendon fragments were obtained from 6 healthy subjects, undergoing surgical procedures to treat anterior cruciate ligament rupture, excluding cases of tendinopathy [182]. Ciprofloxacin (CPX), an antibiotic to treat possible infection (which might have been acquired during surgical operations), was applied with different dosages, to three groups of tenocyte cultures obtained from the mentioned tendon explants. The following measurements were carried out on the treated and untreated tenocytes: (i) MMP-1,2 protein expressions; (ii) mRNA expressions of collagen I; (iii) LH2b (protein for cross-linking of newly synthesized collagen); (iii) mRNA expressions of TIMP-1,2; (iv) mRNA expressions of Cx43 \& N-cadherin (as intercellular connexin proteins). The levels of these expressions of three groups associated with different dosage of the medicine, plus that of the control group receiving no treatment, were measured. Analyzing the difference of these levels, the authors of [182] conclude that application of CPX could lead to "toxicity" that weakens the regularity of the tendon structure, causes over degradation of collagen, and reduces the ability of the tenocytes to repair the tendon tissues. The result implies that the application of CPX may lead to failure of the tendon's resistance to mechanical loading in vivo. Such investigation suggests that the effects of medicines during the repairing process needs to be monitored with care.

\section{Discussion}

\subsection{The Fascia Is an Active Organ with Cells Interacting Continuously with the Protein Network via Mechanotransduction}

The fascia is not a passive organ. The resident cells and the cells in transit when inflammation occurs are continuously communicating with the collagenous and 
non-collagenous proteins (28 types, Table 1 ), the interstitial fluid via mechanotransduction. Characteristics of the communications are different in different CTIF domains that make up the whole fascia, because the constituents of the irregular-shaped fascia embed all internal organs, even as small as nerve fibers, lymphatic and the smallest blood vessels. The forces involved include fluid shear force exerted by the viscous IF on the cilia and mechano-sensors (integrins) at the cell membrane of the resident cells (such as fibroblast, mast cell), as well as organ cells (such as hepatocytes). Mechanical forces are also exerted by collagen fibers/fibrils/basal membranes, elastic fibers, reticular fibers on these sensors on any cell in contact. On reception of these forces, focal adhesion complexes are built, attached to the inner sides of the integrins. Cytoskeletal elements like F-actin, myocin-II, microfilaments, microtubules, intermediate filaments are induced to form "bridges" bringing the mechanical signals directly to the nucleus surface. Depending on the features of the signals, the associated genes are expressed, splitting into mRNA. The corresponding peptide chains are synthesized at the ribosomes which are attached to the surface of the RER. Passing through the RER-Gorgi apparatus "factory", sugars are added and the peptides are folded with the help of heat shock proteins (HSP). The misfolded proteins (beyond repair) are sent to apoptosis pathways [26]. For any type of collagen, three peptide chains with the proper combinations (Table 1) form the procollagen molecules which exit to the CTIF domain. Thus the types of proteins synthesized by the cells depend much on the type and intensity of the mechanotransduction signals received; these signals are transmitted through certain parts of the fascia. In short, the constituents of the fascia are communicating continuously with the cells in contact. Note that cells migrate according to the rule of durotaxis (towards collagen network of higher gradient of mechanical tension [10]) and chemotaxis (attracted by biochemicals released by other cells or from the stores in the associated CTIF domain, a rather well-known process). The migrating cells therefore react on the collagen fibers and other protein structure during their crawling action; at the same time the tension of the collagen structure is increased. The resident cells, cells in transit, and the non-cellular network form the largest active organ of the body. Moreover, the mechanical tension of the collagen network can change the fate of the stem cells and fibroblasts crawling via durotaxis [52]. The concept of the CTIF system being a dynamic microenvironment for stem cell niche has been introduced [35]. The six main functions of the ground substance, or interstitial fluid have been stated in Section (1.3), and also described in more details in our previous work [11]. This fascia organ therefore also forms the largest communication network of the body. In short, since all transport of materialistic constituents and energy signals pass back and forth between the blood circulation and organs, it is easy to understand that malfunctions of such transportation, in any form, are causes of the pathological states; and these states manifest with certain characteristics in the fascia. 
The fascia is also affecting the functions of internal organs. For example, during cyclic heart beating, the heart cells do the least amount of work for the same output (the best possible efficiency) if the heart cells and the ECM around the heart (which is part of the fascia) play the "push and pull" game in synchrony; details are described in [11].

\subsection{Homeostasis of the Fibrous and Non-Fibrous Collagen Structures is Maintained by a Balance of the Following Two Main Processes: (a) An Intricate Process of Degradation and Its Inhibition; (b) A Proper Rate of Synthesis of Collagen}

Let us consider three scenarios concerning the synthesis of collagen. (i) If the tension of the collagen network is low at a CTIF domain, the main resident cells, i.e., the fibroblasts, are in the dormant state, leading to low collagen output. (ii) If the mechanical tension of the collagen network is "properly high", the fibroblasts are in the activated state, stretching to form cell-cell connection, and there is a good communication network. The fibroblasts themselves form part of the collagen network, and the synthesis rate of collagen is proper. (iii) If the tension of the collagenous network is too high, the fibroblasts are over-activated, and would produce collagen at a rate which is too fast. However, we should note that scenario (i) would lead to the degeneration of the CT, but condition (iii) might not necessarily lead to fibrosis. The digestive enzymes MMPs, (23 classes, 15 are mentioned in Table 1) with specificity to types of collagen digested are secreted by the fibroblasts which digest the damaged fibrils after certain collagen structures, such as the tendons, have been loaded (exercise or injury). A clear explanation of degradation processes, with the example of the loading/overloading the bovine tail tendon, is reviewed in Section (4). Degradation actions of the MMPs are regulated by 4 inhibitors TIMP -1 to 4 (Table 3 ). The regulations are carried out in very subtle ways, as some MMPs are bound to the receptors of the cell membrane, whereas some are soluble. Normal physiological remodeling processes requires precise regulation of collagen degradation. We can use the concept of "net degradation rate" to simplify matters in our series. The overall ratio of (synthesis rate)/(net degradation rate) decides whether (A) fibrosis or (B) excessive breakdown occurs. So far, there are not enough parameters for us to quantify the stated ratio, which is specific for the type of collagen concerned.

A number of examples of (A) have been reported; to name a few: hypertensive myocardiac fibrosis [183], heart failure [184], spontaneous abnormal endochondral bone development in mice model [185], liver fibrosis [186]. Examples of (B) include rheumatoid arthritis [187], atherosclerotic heart disease [188], glomerulonephritis [189]. Also, Crohn's disease is a chronic inflammatory disease of the digestive tract, manifesting clinical symptoms such as pain and diarrhea. Recently, analysis of serological biomarkers (P1NP, Pro-C3, Pro-C5, Pro-C6) indicates that the active inflammation in Crohn's disease is characterized by increased formation of type $\mathrm{V}$ collagen and increased matrix metalloproteinase mediated breakdown of both type I and III collagen. The penetrating 
Crohn's disease is characterized by increased matrix metalloproteinase- 9 degraded type III collagen and formation of type V collagen [190].

\subsection{On Possible Treatment of Inherited Diseases Which Manifest Pathological States in the Fascia}

We have reviewed in Section (6) that collagen I, II, III built of homotrimers would resist the normal degradation by MMPs. In particular, the osteogenesis imperfecta (OI) disease is interpreted to be due to disordered alignment of mineralized collagen fibrils (particular collagen I) in the bone, leading to a brittle structure, as well as weakening of other tissues built of collagen I [113] [191]. In fact, more than 70 mutations in the two structural genes (COL1A1 and COL1A2) for type I procollagen have been found in probands in patients with Ehiers-Danlos syndromes, osteoarihritis, chondrodysplasias, (familial) intracranial aneurysms [192], in addition to OI [193]. The two common Ehiers-Danlos syndromes refer to loose/unstable joints which are prone to dislocations, and fragile skin that tears or bruises easily [194]. Intracranial aneurysms cause subarachnoid hemorrhage (SAH). Osteoarihritis is well-known. These diseases are usually found to have either abnormal collagen triple helices or abnormal (too much or shortage of) proteoglycans (or glycoproteins). We post the following questions: (i) Are all the peptides that are supposed to fold up to become the proper procollagen (or non-collagenous proteins) mutated? If the answer is positive, measures on genetic correction are needed, and would have been considered by genetic experts. (ii) If among the related peptides synthesized, some do have the correct sequences, but are not folded properly in the RER, can activation of the related heat shock proteins help to improve their intracellular refolding processes? We propose to investigate on whether heat shock proteins can help in the issue of folding correction intracellularly in the future.

\subsection{Pathological States of Inflammation Often Manifest as Edema in Certain Part of the Fascia}

We have already listed the seven key functions of the interstitial fluid in Section (1.3). In the experimental study of [195], fluid shifts were measured in eight subjects employing a "simultaneous, radionuclide dilution technique" for three postures: (a) seating (control), (b) supine, and (c) standing. Technically, radioiodinated serum fibrinogen, radiochromated crythrocytes, radiobromine and tritiated water were used to measure plasma volume, red cell volume, extracellular and total body water volumes. Vascular fluid lost during standing was found to be filtered into the interstitial compartment, while the extracellular and intracellular volumes remaining unaffected. The loss of intravascular fluid during standing was caused by the filtration of plasma into the fascia. On the other hand, in the supine position, intravascular volume was found to increase, indicating that there is IF fluid flow from the fascia back to the blood circulation. Although there is overall balance of fluid volumes in the fascia and blood circulation, since the geometrical structure of the fascia is so irregular, the IF pres- 
sures in different CTIF domains of the fascia are in general not equal [196]. It is the difference in pressure that drives the thick IF to flow from sites to sites. In the above statement, it has been assumed that the flow rate of IF into the lymphatic system remains constant. Moreover, it has recently been discovered that a lymphatic system inside the skull exists, and the "glymphatic lymph", which is a mixture of the classical cerebrospinal fluid and the interstitial fluid in the brain parenchyma, will flow from the brain via sheaths of nerve fibers, sheaths and inside the collagen layers of blood vessels to join the IF of the neck and peripheral lymphatic vessels (see Fig.3, 4, 6, 7, 8 and 10 of [11]). The fluids inside the body form a complicated circulation system. Many diseases manifest their pathological states in the fascia which includes properties of these fluids. For example, we infer that blockage of the glymphatic fluid to join the peripheral IF and hence the peripheral lymphatic system will naturally inibit the clearance of the debris of metabolism inside the brain, lead to the accumulation of proteins such as $\beta$-Amyloid and $\tau$-protein, which are highly correlated to neurodegenerative diseases such as Alzheimer disease. Peripheral edema, due to disorder of IF-lymph flow is associated with some well-known diseases, details of which will not be discussed in this paper. However, we would like to point out that due to overuse of muscle cells, intracellular edema of these cells is the cause of the exertional compartment syndrome. The largest organ which enclosed many muscle stripes/ striations, are partitioned into pulley systems including bones (and bone joints), tendons, ligaments, for efficient locomotion of different parts of the body. Each of these pulley systems is "protected" by sophisticated collagenous connective layers, which are stiffer than the common connective tissues (such as that in the skin). Readers are referred to Fig.2, 3, 4 of [197] for details in some anatomy structures. During the development of the exertion compartment syndrome, the IF pressure in the compartment concerned highly increases, resulting in the augmentation of lyses of the muscle cells (which have been overused). The only way, so far, is to release the IF pressure by surgery procedure, well known to orthopaedics surgeons. We may consider the exertional compartment syndrome as the failure of potent flow of IF from one compartment to another; this restriction is inevitable if we need efficient locomotion of certain muscle-joint systems. It is not out of the blue to say that treating the IF to release pressure, together with clinical measures to repair the overused muscle cells, might help to prevent certain excertion compartment syndromes.

On the other hand, to study the cause of inflammatory edema in the fasica, the in vivo burn model with rats was set up some decades ago [198]. The interstitial fluid pressure (IFP) was found to drop from $-1.3 \mathrm{~mm} \mathrm{Hg}$ (preburn) to $-5.5 \mathrm{~mm}$ $\mathrm{Hg}$ after $10 \%$ total body surface (BSA) burn. After a $40 \%$ BSA, the IFP dropped drastically to $-50 \mathrm{~mm} \mathrm{Hg}$ at $25 \mathrm{~min}$. postburn. This quick exchange of water between the IF and the blood circulation is much stronger than that due to the classically known capillary leakage. Such a leakage was thought to be an imbalance of the transcapillary hydrostatic pressure $(\mathrm{P})$, colloid osmotic pressure (COP) and capillary filtration coefficient (CFC), a theory established before 
1980s. After a series of investigations [199] [200], inflammatory edema was considered to originate from the sudden drop (as observed in the burn experiment) of IFP due to interaction of the dermal fibroblasts with the connective tissues, leading to contraction of the IF gel via the integrins, and a new one $\left(\alpha_{11} \beta_{1}\right)$ was identified to be involved by 2009 [201]. Treatment on edema was suggested to develop inhibitors of the integrin(s) involved. We shall not discuss the mechanism of the integrin mediated edema here, leaving it to topics on specific diseases related to edema. It suffices to note that inflammation of organs often leads to edema, manifesting as a pathological state in some parts of the fascia. Of course, the noninvasive measure is to drain the stagnant IF via the lymphatic vessels. We would also note that it is well-known that chemo-therapy medicine cannot reach the tumor site because the IFP is high around the tumor.

\subsection{From a Half-Century Puzzle on Protein Folding to the Debate on Thermal Stability of the Collagen Triple Helices below and above Body Temperature}

A proper process of unfolding and refolding of collagen proteins process must be at work in catering homeostasis of the fascia for survival-understanding this process is crucial to develop therapeutic measures for treating many diseases. We shall briefly list below some lines of thought on the search of the half-century puzzle-why and how a peptide can fold up into the same native three-dimensional conformation, despite there being trillions of choices.

First, mRNA transcription gives only a peptide chain. How does such a chain fold up spontaneously to a three-dimension configuration with extremely high conformation specificity has been a mystery for half a century because there are ways, of astronomical order in number, to fold up this chain. In physics, a photon finds the shortest way to go from one point to another, following the principle of least action. A similar, but more complicated, principle must be at work also in the formation of a protein, for survival, because any deviation of the structure has a similar consequence of a gene mutation, leading to pathology state(s). Note also that when the protein is denatured to become a random coil, it can refold back into the same conformation. After decades of research, in short, experts propose several principles/routes that could lead a peptide to follow, ending up with the same structure every time it folds. We will only list a few below as examples because there are other models. (i) The peptide follows the easiest path (also the quickest) towards a state with the lowest "local free energy"-this route is called the kinetic principle/control. (ii) The peptide "finds" among all the possible paths that also lead towards the lowest possible energy minimum state, but that state pertains to the highest degree of stability (of the native protein with respect to the protein environment in vivo) thermodynamically-reaching thermodynamical equilibrium. Both models (i) and (ii) are said to follow the energy landscape [202]. (iii) A protein is built of cooperative unfolding-refolding units called foldons (each with 15 - 35 residues) so that the folding is separated into some defined discrete steps; each step-wise process, 
however, has to include also the energy landscape of (i) or/and (ii). Each foldon remains part of the folded native protein configuration [203]. While intensive research on this big puzzle continues, we have to reconsider the issue of thermal stability of collagen fibrils within the context of this paper.

In Section (5), we have presented only three pieces of experimental evidence on folding and unfolding of collagen tropocollagen molecules. Results discussed in Sections (5.1) and (5.2) are in line, contrasting the result of Section (5.3) which is only one example of other in vitro experiments showing evidence of unfolding of collagen fibrils as temperature is raised, in general, below and above body temperature. Daily experience tells us that a person practicing long run, gymnastic exercise, playing a full football match would have core body temperature a few degrees higher than $37^{\circ} \mathrm{C}$. If the result of Section (5.3) occurs in vivo, we should expect that a person, after a relatively long period of exercise, would have very loose skin, would have lost the ability for basic locomotion because parts of the tendons/ligaments would have been denatured and degraded significantly by MMPs. This is not what we experience. Moreover, as explained in Section (4.4), the ${ }^{14} \mathrm{C}$ dating examination of the 28 forensic specimens of Achille tendon gives strong support to the fact that the tendon core is formed at about 17 years of age, without further significant renewal [116]. However, degradation and replacement of the collagen fibrils by new tropocollagen/fibrils outside the core tendon have been taking place all the time.

The continuous collagen fibril structure, with the end of one fibril connecting another fibril in mouse tendon modelled, has recently been revealed [204]. We infer that collagen fibrils, either newly synthesized or resulting from MMP digestion, can elongate to join other fibrils during the repair process.

We would also emphasize that in the investigation of thermal stability of collagen molecules, the parts played by the proteoglycans and glycoproteins are usually difficult to be incorporated in the specimens of in vitro experiments. As demonstrated in atomic force and scanning electron microscopy examination of rat's Achille tendon, the SEM micrograph of Fig. 2A of [205] revealed that the collagen fibrils were interwoven with glycosaminoglycan filament structure. Such inter-fibrillar weaving structure is a factor of keeping the collagen fibrils and hence the triple helices in a tight structure even when the temperature is above body temperature in vivo. In view of the analysis stated in this sub-section, we put forth the notion that tropocollagen fibrils will spontaneously fold in a range of temperature $\left(35^{\circ} \mathrm{C}-42^{\circ} \mathrm{C}\right)$ and the denatured collagen molecules, e.g., triple helices with unfolded regions, tend to refold via a mechanism satisfying one of the principles still under research briefly mentioned above in this section. There is not enough evidence at present for us to draw a concrete conclusion as to which mechanism is at work for this puzzle, but a collagen system needs to climb through an energy barrier to refold. Understanding more about the nature of the mechanism will help in taking measures to refold fibrils when collagen homeostasis or more collagen fibrils are needed in a certain part of the fascia. On 
the other hand, counter-measures may be developed in case pathological fibrosis occurs.

\subsection{Limitations of This Paper}

We have provided some basic material of different constituents/components of the fascia, so that disorders in certain domains of the fascia can be related to the type of disease analyzed in each paper of the series. The reviewed basics in Sections (1) - (3) are by no means exhaustive. We have not analyzed on the special roles played by the elastic and reticular fibers, because elastin fibers amount to only $1 \%-2 \%$ by weight of the tendon [4] [162], and the fine reticular fibers play a role mainly in supporting the integrity of various internal organs [5], but there is no information, so far, that they are involved in the pathogenesis of the tendon. We have analyzed only very briefly the functions of the proteoglycans and glycoproteins with respect to diseases of the tendons. For diseases of the knee, for instance, we will analyze the very special roles of proteoglycans in the pathogenesis involved. In other words, more basic material of the fascia will be supplemented as needed for discussion on the manifestation of pathological states in the fascia for the type of diseases concerned in the future.

\section{Concluding Remarks}

All organ cells need (i) oxygen, (ii) nutrients, (iii) peptides/proteins (such as hormones) from other cells to perform their physiological duties. All (i)-(ii) are carried by the blood stream before they can be used by organs. However, (i)-(iii) are transported by the IF fluid to the organ cells. The CT of various structures enclose all organs, even the small vessels, to maintain the organs' integrity and to provide a platform of communication and durotaxis of cells. The CT must be synthesized and maintained by resident cells (fibroblasts, fibroblast-like cells and stem cells). These cells, together with different CTIF domains, form the largest communication network and organ of the body. To further appreciate the extensivity of this organ, we present in Figure 14 a simplified painting based on the SEM (Figure 2(C) of [206]) of the three-dimensional collagen network forming the endomysium embracing human cardiomyocytes.

Genetic mutation of collagen and other proteins can lead to disorders in the structure of the CT. A pathological state of the CTIF of a certain domain occurs when there is an imbalance of the digestion and synthesis of collagen triple helices in the CT. Such disorders also affect the function of organ cells. Hence the pathological states of numerous diseases manifest in the fascia.

Tendinopathy is initiated by inflammation due to overuse or blockage of the IF, developed by a complex display between the extrinsic and intrinsic compartments, the mechanisms of which are still under research. Development of different groups on plausible treatments of this disease is in process.

Pathological states of inflammation often manifest as edema in certain parts of the fascia. Serological biomarkers (P1NP, Pro-C3, Pro-C5, Pro-C6) have been 


\section{Schematic painting representation of the SEM of three-dimensional collagen} network embracing human cardiomyocytes according to Fig. 2(c) of [206]

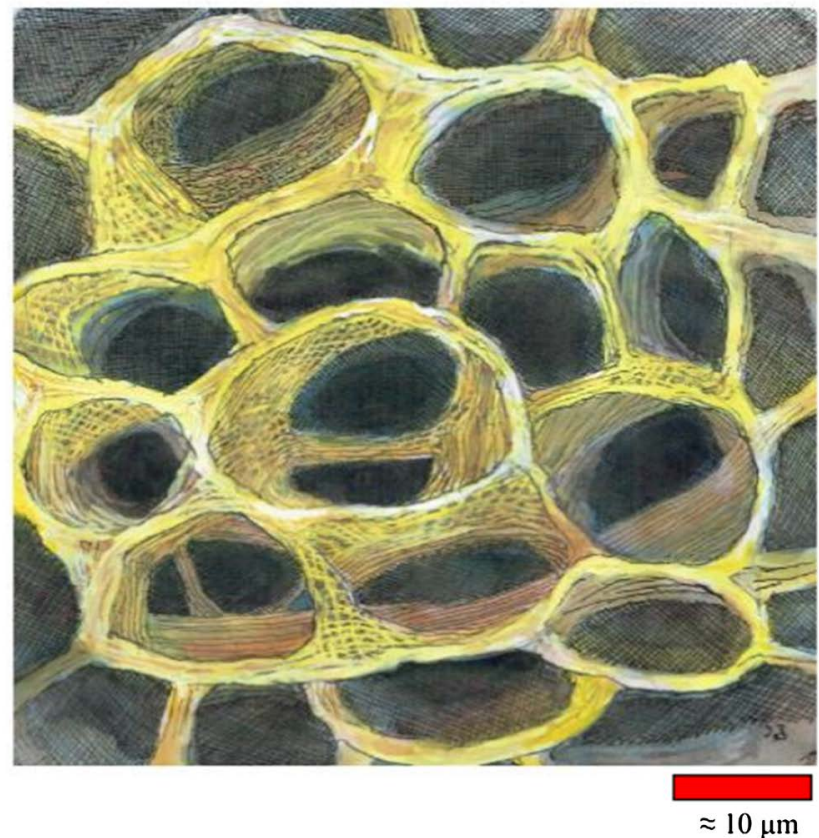

Figure 14. A collagen network forming the endomysium connects human cardiomyocytes was reported in the SEM (Figure 2(C) of [206]). The collagen fibrils grow in multi-directions, allowing movement of the heart cells with three degrees of freedom. The "caves" hold the cardiomyocytes in vivo. This diagram is a hand-painted diagram by author PCWF based on the stated SEM micrograph.

found for the Crohn's disase, targeting disorders of collagen V. Another practical example is the recent usage of the "flash glucose monitoring system" (attached to the upper arm) to detect sugar concentration in the IF any time at the wish of the subject (particular for diabetic patient), rather than basing on blood test. We hypothesize other biomarkers related to the fascia are to be found in the future. Since nerve fibers are also inside the fascia, stimulating the sensory nerves would lead to profound biomedical consequences as explained in [207].

\section{Acknowledgements}

The authors wish to express their gratitude to Mr. Benjamin Fung, brother of PCWF, for his unfailing assistance during the preparation of the manuscript. PCWF wishes to dedicate his work of this series of studies to his late parents Mr. Joseph Wah Hei Fung and Mrs. Helen Woi Suet Lau Fung. All diagrams have been hand-painted by author PCWF.

\section{Conflicts of Interest}

The authors declare no conflicts of interest regarding the publication of this paper.

\section{References}

[1] Ingber, D.E. (1997) Tensegrity: The Architectural Basis of Cellular Mechanotrans- 
duction. Annual Review of Physics, 59, 575-599.

https://doi.org/10.1146/annurev.physiol.59.1.575

[2] Fung, P.C.W. (2009) Probing the Mystery of Chinese Medicine Meridian Channels with Special Emphasis on the Connective Tissue Interstitial Fluid System, Mechanotransduction, Cells Durotaxis and Mast Cell Degranulation. Chinese Medicine, 4, 10. https://doi.org/10.1186/1749-8546-4-10

[3] Fung, P.C.W. (2013) Chapter 5. Plausible Biomedical Consequences of Acupuncture Applied at Sites Characteristic of Acupoints in the Connective-Tissue-Interstitial-Fluid System. In: Chen, L.L. and Cheng, T.O., Eds., Acupuncture in Modern Medicine, IntechOpen, Rijeka, 95-131. https://doi.org/10.5772/53901

[4] Liu, X., Zhao, Y., Gao J, Pawlyk, B., Starcher, B., Spemcer, J.A., Yanagisawa, H., Zuo, J. and Li, T. (2004) Elastic fiber Homeostasis Requires Lysyl Oxidase-Like 1 Protein. Nature Genetics, 36, 178-182. https://doi.org/10.1038/ng1297

[5] Ushiki, T. (2002) Collagen Fibers, Reticular Fibers and Elastic Fibers. A Comprehensive Understanding from a Morphological Viewpoint. Archives of Histology and Cytology, 65, 109-126.

[6] Page, K.E. (1952) The Role of the Fascia in the Maintenance of Structural Integrity Newark. Academy of Applied Osteopathy Yearbook, Newark, 70.

[7] Yuan, L., Yao, D.W., Tang, L., Huang, W.H., Jiao, P.F., Lu, Y.T., Dai, J.X., Zhang, H., He, Z.Q. and Zhong, S.Z. (2004) A Study on Morphological Basis of Chinese Acupuncture and Moxibustion from Digital Human Body. Acta Anatomica Sinica, 35, 337-343.

[8] Ross, R. (1975) Connective Tissue Cells, Cell Proliferation and Synthesis of Extracellular Matrix-A Review. Philosophical Transactions of the Royal Society of London. Series B, 271, 247-259. https://doi.org/10.1098/rstb.1975.0049

[9] Wilke, J., Schleip, R., Yucesoy, C.A. and Banzer, W. (2017) Not Merely a Protective Packing Organ? A Review of Fascia and Its Force Transmission Capacity. Journal of Applied Physiology, 124, 234-244. https://doi.org/10.1152/japplphysiol.00565.2017

[10] Lo, C.M., Wang, H.B., Dembo, M. and Wang, Y.L. (2000) Cell Movement Is Guided by the Rigidity of the Substrate. Biophysical Journal, 79, 144-152. https://doi.org/10.1016/S0006-3495(00)76279-5

[11] Fung, P.C.W. and Kong, R.K.C. (2016) The Integrative Five-Fluid Circulation System in the Human Body. Open Journal of Molecular and Integrative Physiology, 6 , 45-97. https://doi.org/10.4236/ojmip.2016.64005

[12] Sastry, S.K. and Burridge, K. (2000) Focal Adhesions: A Nexus for Intracellular Signaling and Cytoskeletal Dynamics. Experimental Cell Research, 261, 25-36. https://doi.org/10.1006/excr.2000.5043

[13] Katsum, A., Naoe, T., Matsushita, T., Kaibuchi, K. and Schwartz, M.A. (2006) Integrin Activation and Matrix Binding Mediate Cellular Responses to Mechanical Stretch. The Journal of Biological Chemistry, 280, 16546-16549. https://doi.org/10.1074/jbc.C400455200

[14] Wang, N., Tytell, J.D. and Ingber, D.E. (2009) Mechanotransduction at a Distance: Mechanically Coupling the Extracellular Matrix with the Nucleus. Nature Reviews/Molecular Cell Biology, 10, 75-82. https://doi.org/10.1038/nrm2594

[15] Bershadsky, A.D., Balaban, N.Q. and Geiger, B. (2003) Adhesion-Dependent Cell Mechanosensitivity. Annual Review of Cell \& Development Biology, 19, 677-695. https://doi.org/10.1146/annurev.cellbio.19.111301.153011

[16] Nicholson, B.J. (2003) Gap Junctions-From Cell to Molecule. Journal of Cell 
Science, 116, 4479-4481. https://doi.org/10.1242/jcs.00821

[17] Kumar, N.M. and Gilula, N.B. (1996) The Gap Junction Communication. Cell, 84, 381-388. https://doi.org/10.1016/S0092-8674(00)81282-9

[18] Delma, M., Coombs, W., Sorgen, P., Duffy, H.S. and Taffet, S.M. (2004) Structural Bases for the Chemical Regulation of Connexin43 Channels. Cardiovascular Research, 62, 268-275. https://doi.org/10.1016/j.cardiores.2003.12.030

[19] Boot-Handford, R.P. and Tuckwell, D.S. (2003) Fibrillar Collagen: The Key to Vertebrate Evolution? A Tale of Molecular Incest. BioEssays, 25, 142-151. https://doi.org/10.1002/bies.10230

[20] Exposito, J.Y., Cluzel, C., Garrone, R. and Lethias, C. (2002) Evolution of Collagens. The Anatomical Record, 268, 302-316. https://doi.org/10.1002/ar.10162

[21] Aumailley, M. and Gayraud, B. (1998) Structure and Biological Activity of the Extracellular Matrix. Journal of Molecular Medicine, 76, 253-265. https://doi.org/10.1007/s001090050215

[22] Linsenmayer, T.F. (1987) Collagen. In: Hay, E.D., Ed., Cell Biology of the ExtracelIular Matrix, 2nd Edition, Plenum Press, New York, 7-44.

[23] Wilson, S.L., Guilbert, M., Sulé-Suso, J., Torbet, J., Jeansson, P., Sockalingum, G.D. and Yang, Y. (2012) The Effect of Collagen-Ageing on Its Structure and Cellular Behavior. Proceedings of SPIE, 8222, Article ID: 822210.

https://doi.org/10.1117/12.908749

[24] Kuhn, K. (1987) The Classical Collagens: Types I, II and III. In: Mayne, R. and Burgeson, R.E., Eds., Structure and Function of Collagen Types, Academic Press, Orlando, 1-42. https://doi.org/10.1016/B978-0-12-481280-2.50005-2

[25] Kielty, C.M. and Grant, M.E. (2003) Chapter 2. The Collagen Family: Structure, Assembly, and Organization in the Extracellular Matrix. In: Royce, P.M. and Steinmann, B., Eds., Connective Tissue and Its Heritable Disorders, Wiley, New York, 159-221.

[26] Fung, P.C.W. and Kong, R.K.C. (2017) The Heat Shock Protein Story-From Taking mTORC1,2 and Heat Shock Protein Inhibitors as Therapeutic Measures for Treating Cancers to Development of Cancer Vaccines. Journal of Cancer Therapy, 8, 962-1029. https://doi.org/10.4236/jct.2017.811086

[27] Buevich, A.V., Silva, T., Brodsky, B. and Baum, J. (2004) Transformation of the Mechanism of Triple-Helix Peptide Folding in the Absence of a C-Terminal Nucleation Domain and Its Implications for Mutations in Collagen Disorders. The Journal of Biochemistry, 279, 46890-46895.

[28] Nagata, K. (1996) Hsp47: A Collagen-Specific Molecular Chaperone. Trends in Biochemical Sciences, 21, 23-26. https://doi.org/10.1016/S0968-0004(06)80023-X

[29] Silver, F.H. (2009) The Importance of Collagen Fibers in Vertebrate Biology. Journal of Engineered Fibers and Fabrics, 4, 9-17. https://doi.org/10.1177/155892500900400203

[30] Veis, A. and Yuan, L. (1975) Structure of the Collagen Microfibril. A Four-Strand Overlap Model. Biopolymers, 14, 895-900. https://doi.org/10.1002/bip.1975.360140418

[31] Liu, J-.F. and He, J.-H. (2010) Hierarchical Structure and Fractal Dimensions of Tendon. Materials Science and Technology, 26, 1317-1319. https://doi.org/10.1179/026708310X12798718274232

[32] Werner, S. and Grose, R. (2003) Regulation of Wound Healing by Growth Factors and Cytokines. Physiological Reviews, 83, 835-870. 
https://doi.org/10.1152/physrev.2003.83.3.835

[33] Ge, Z., Goh, J.C.H. and Lee, E.H. (2005) The Effects of Bone Marrow-Derived Mesenchymal Stem Cells and Fascia Wrap Application to Anterior Cruciate Ligament Tissue Engineering. Cell Transplantation, 14, 763-773. https://doi.org/10.3727/000000005783982486

[34] Mistriotis, P. and Andreadis, S.T. (2013) Hair Follicle: A Novel Source of Multipotent Stem Cells for Tissue Engineering and Regenerative Medicine. Tissue Engineering Part B: Reviews,19, 265-278. https://doi.org/10.1089/ten.teb.2012.0422

[35] Gattazzo, F., Urciuolo, A. and Bonaldo, P. (2014) Extracellular Matrix: A Dynamic Microenvironment for Stem Cell Niche. Biochimica et Biophysica Acta (BBA)-General Subjects, 1840, 2506-2519. https://doi.org/10.1016/j.bbagen.2014.01.010

[36] http://www.histology.leeds.ac.uk/bone/cartilage.php

[37] Seeman, E. (2006) Chapter 13. Bone Structure and Strength. In: Seibel, M.J., Robins, S.P. and Bilezikian, J.P., Eds., Dynamics of Bone and Cartilage Metabolism: Principles and Clinical Applications, 2nd Edition, Academic Press, London, 213-220.

[38] Histology Guide @ Faculty of Biological Sciences, University of Leeds. http://www.mhhe.com/biosci/ap/histology_mh/cartilag.html

[39] Pittenger, M.F., Mackay, A.M., Beck, S.C., Jaiswal, R.K., Douglas, R., Mosca, J.D., Moorman, M.A., Simonetti, D.W., Craig, S. and Marshak, D.R. (1999) Multilineage Potential of Adult Human Mesenchymal Stem Cells. Science, 284, 143-147. https://doi.org/10.1126/science.284.5411.143

[40] Arana-Chavez, V.E., Soares, A.M. and Katchburian, E. (1995) Junctions between Early Developing Osteoblasts of Rat Calvaria as Revealed by Freeze-Fracture and Ultrathin Section Electron Microscopy. Archives of Histology and Cytology, 58, 285-292.

[41] Blair, H.C., Sun, L. and Kohanski, R.A. (2007) Balanced Regulation of Proliferation, Growth, Differentiation, and Degradation in Skeletal Cells. Annals of the New York Academy of Sciences, 1116, 165-173. https://doi.org/10.1196/annals.1402.029

[42] Gurish, M.F., Tao, H., Abonia, J.P., Arya, A., Friend, D.S., Parker, C.M. and Austen, K.F. (2001) Intestinal Mast Cell Progenitors Require CD49d $\beta 7$ ( $\alpha 4 \beta 7$ Integrin) for Tissue-Specific Homing. The Journal of Experimental Medicine, 194, 1243-1252. https://doi.org/10.1084/jem.194.9.1243

[43] Rodewald, H.R., Dessing, M., Dvorak, A.M. and Galli, S.J. (1996) Identification of a Committed Precursor for the Mast Cell Lineage. Science, 271, 818-822. https://doi.org/10.1126/science.271.5250.818

[44] Metcalfe, D.D., Baram, D. and Mekori, Y.A. (1997) Mast Cells. Physiological Reviews, 77, 1033-1079. https://doi.org/10.1152/physrev.1997.77.4.1033

[45] Artuc, M., Steckelings, U.M. and Henz, B.M. (2002) Mast Cell-Fibroblast Interactions: Human Mast Cells as Source and Inducers of Fibroblast and Epithelial Growth Factors. Journal of Investigative Dermatology, 118, 391-395. https://doi.org/10.1046/j.0022-202x.2001.01705.x

[46] Dioguardi, N., Grizzi, F., Bossi, P. and Roncalli, M. (1999) Fractal and Spectral Dimension Analysis of Liver Fibrosis in Needle Biopsy Specimens. Analytical and Quantitative Cytology and Histology, 21, 262-266.

[47] Magnusson, S.P., Qvortrup, K., Larsen, J.O., Rosager, S., Hanson, P., Aagaard, P., Krogsgaard, M. and Kjaer, M. (2002) Collagen Fibril Size and Crimp Morphology in Ruptured and Intact Achilles Tendons. Matrix Biology, 21, 369-377. https://doi.org/10.1016/S0945-053X(02)00011-2 
[48] Silver, F.H., Freeman, J.W. and Gwinder, P.S. (2003) Collagen Self-Assembly and the Development of Tendon Mechanical Properties. Journal of Biomechanics, 36, 1529-1553. https://doi.org/10.1016/S0021-9290(03)00135-0

[49] Ho, M.W. and Saunders, P.T. (1994) Liquid Crystalline Mesophases in Living Organisms. In: Ho, M.W., Popp, F.A. and Warnke, U., Eds., Bioelectrodynamcis and Biocommunications, World Scientific, Singapore, 213-227.

https://doi.org/10.1142/9789814503822_0008

[50] Martin, R., Farjanel, J., Eichenberger, D., Colige, A., Kessler, E., Hulmes, D.J.S. and Giraud-Guille, M.M. (2000) Liquid Crystalline Ordering of Procollagen as a Determinant of Three-Dimensional Extracellular Matrix Architecture. Journal of Molecular Biology, 301, 11-17. https://doi.org/10.1006/jmbi.2000.3855

[51] Snedeker, J.G. and Foolen, J. (2017) Tendon Injury and Repair-A Perspective on the Basic Mechanisms of Tendon Disease and Future Clinical Therapy. Acta Biomaterialia, 63, 18-36. https://doi.org/10.1016/j.actbio.2017.08.032

[52] Guilak, F., Cohen, D.M., Estes, B.T., Gimble, J.M., Liedtke, W. and Chen, C.S. (2009) Control of Stem Cell Fate by Physical Interactions with the Extracellular Matrix. Cell Stem Cell, 5, 17-26. https://doi.org/10.1016/j.stem.2009.06.016

[53] Itoh, M., Lin, Y., Yang, Z., Nguyen, J., Liang, F., Morris, R.J. and Cotsarelis, G. (2005) Stem Cells in the Hair Follicle Bulge Contribute to Wound Repair but Not to Homeostasis of the Epidermis. Nature Medicine, 11, 1351-1354. https://doi.org/10.1038/nm1328

[54] Liu, C.-F., Aschbacher-Smith, L., Barthelery, N.J., Dyment, N., Butler, D. and Wylie, C. (2011) What We Should Know before Using Tissue Engineering Techniques to Repair Injured Tendons: A Developmental Biology Perspective. Tissue Engineering Part B: Reviews, 17, 165-176. https://doi.org/10.1089/ten.teb.2010.0662

[55] Ackermann, P.W., Franklin, S.L., Dean, B.J., Carr, A.J., Salo, P.T. and Hart, D.A. (2014) Neuronal Pathways in Tendon Healing and Tendinopathy-Update. Frontiers in Bioscience (Landmark Ed), 19, 1251-1278. https://doi.org/10.2741/4280

[56] Ackermann, P.W., Salo, P. and Hart, D.A. (2016) Tendon Innervation. In: Ackermann, P. and Hart, D., Eds., Metabolic Influences on Risk for Tendon Disorders. Advances in Experimental Medicine and Biology, Vol. 920, Springer, Cham, 35-51. https://doi.org/10.1007/978-3-319-33943-6_4

[57] Franchi, M., Fini, M., Quaranta, M., Pasquale, V.D., Raspanti, M., Giavaresi, G., Ottani, V. and Ruggeri, A. (2007) Crimp Morphology in Relaxed and Stretched Rat Achilles Tendon. Journal of Anatomy, 210, 1-7. https://doi.org/10.1111/j.1469-7580.2006.00666.x

[58] Franchi, M., Ottani, V., Stagni, R. and Ruggeri, A. (2010) Tendon and Ligament Fibrillar Crimps Give Rise to Left-Handed Helices of Collagen Fibrils in Both Planar and Helical Crimps. Journal of Anatomy, 216, 301-309. https://doi.org/10.1111/j.1469-7580.2009.01188.x

[59] Icardo, J.M., Elvira Colvee, E. and Revuelta, J.M. (2013) Structural Analysis of Chordae Tendineae in Degenerative Disease of the Mitral Valve. International Journal of Cardiology, 167, 1603-1609. https://doi.org/10.1016/j.ijcard.2012.04.092

[60] Xu, J., Rodriguez, D., Petitclerc, E., Kim, J.J., Hangai, M., Yuen, S.M., Davis, G.E. and Brooks, P.C. (2001) Proteolytic Exposure of a Cryptic Site within Collagen Type IV Is Required for Angiogenesis and tumor Growth in Vivo. The Journal of Cell Biology, 154, 1069-1079. https://doi.org/10.1083/jcb.200103111

[61] MMP1 Matrix Metallopeptidase 1 [Homo Sapiens (Human)], Gene ID: 4312, updated on 25-Nov-2018, Full Report, NCBI. 
[62] MMP2 Matrix Metallopeptidase 2 [Homo Sapiens (Human)], Gene ID: 4313, updated on 2-Dec-2018, Full Report, NCBI.

[63] MMP3 Matrix Metallopeptidase 2 [Homo Sapiens (Human)], Gene ID: 4314, updated on 22-Nov-2018, Full Report, NCBI.

[64] MMP8 Matrix Metallopeptidase 8 [Homo Sapiens (Human)], Gene ID: 4317, updated on 22-Nov-2018, Full Report, NCBI.

[65] MMP9 Matrix Metallopeptidase 9 [Homo Sapiens (Human)], Gene ID: 4318, updated on 2-Dec-2018, Full Report, NCBI.

[66] MMP10 Matrix Metallopeptidase 10 [Homo Sapiens (Human)], Gene ID: 4319, updated on 22-Nov-2018, Full Report, NCBI.

[67] MMP13 Matrix Metallopeptidase 13 [Homo Sapiens (Human)], Gene ID: 4322, updated on 24-Nov-2018, Full Report, NCBI.

[68] MMP14 Matrix Metallopeptidase 14 [Homo Sapiens (Human)], Gene ID: 4323, updated on 24-Nov-2018, Full Report, NCBI.

[69] Itoh, Y. (2015) Membrane-Type Matrix Metalloproteinases: Their Functions and Regulations. Matrix Biology, 44-46, 207-223. https://doi.org/10.1016/j.matbio.2015.03.004

[70] MMP15 Matrix Metallopeptidase 15 [Homo Sapiens (Human)], Gene ID: 4324, updated on 22-Nov-2018, Full Report, NCBI.

[71] Ramachandran, G.N. and Kartha, G. (1955) Structure of Collagen. Nature, 176, 593-595. https://doi.org/10.1038/176593a0

[72] Orgel, J.P., Irving, T.C., Miller, A. and Wess, T.J. (2006) Microfibrillar Structure of Type I Collagen in Situ. Proceedings of the National Academy of Sciences of the United States of America, 103, 9001-9005. https://doi.org/10.1073/pnas.0502718103

[73] Overall, C.M. (2002) Molecular Determinants of Metalloproteinase Substrate Specificity: Matrix Metalloproteinase Substrate Binding Domains, Modules, and Exosites. Molecular Biotechnology, 22, 51-86. https://doi.org/10.1385/MB:22:1:051

[74] Rosenblum, G., Van den Steen, P.E., Cohen, S.R., Bitler, A., Brand, D.D., Opdenakker, G. and Sagi, I. (2010) Direct Visualization of Protease Action on Collagen Triple Helical Structure. PLOS ONE, 5, e11043.

https://doi.org/10.1371/journal.pone.0011043

[75] Ohuchi, E., Imai, K., Fujii, Y., Sato, H., Seiki, M. and Okada, Y. (1997) Membrane Type 1 Matrix Metalloproteinase Digests Interstitial Collagens and Other Extracellular Matrix Macromolecules. The Journal of Biological Chemistry, 272, 2446-2451. https://doi.org/10.1074/jbc.272.4.2446

[76] Li, J., Brick, P., O’Hare, M.C., Skarzynski, T., Lloyd, L.F., Curry, V.A., Clark, I.M., Bigg, H.F., Hazleman, B.L., Cawston, T.E. and Blow, D.M. (1995) Structure of Full-Length Porcine Synovial Collagenase Reveals a C-Terminal Domain Containing a Calcium-Linked, Four-Bladed $\beta$-Propeller. Structure, 3, 541-549. https://doi.org/10.1016/S0969-2126(01)00188-5

[77] Murphy, G. and Nagase, H. (2011) Localizing Matrix Metalloproteinase Activities in the Pericellular Environment. The FEBS Journal, 278, 2-15. https://doi.org/10.1111/j.1742-4658.2010.07918.x

[78] Manka, S.W., Carafoli, F., Visse, R., Bihan, D., Raynal, N., Farndale, R.W., Murphy, G., Enghild, J.J., Hohenester, E. and Nagase, H. (2012) Structural Insights into Triple-Helical Collagen Cleavage by Matrix Metalloproteinase 1. Proceedings of the National Academy of Sciences of the United States of America, 109, 12461-12466. https://doi.org/10.1073/pnas.1204991109 
[79] Welgus, H.G., Stricklin, G.P., Eisen, A.Z., Bauer, E.A., Cooney, R.V. and Jeffrey, J.J. (1979) A Specific Inhibitor of Vertebrate Collagenase Produced by Human Skin Fibroblasts. The Journal of Biological Chemistry, 254, 1938-1943.

[80] Vater, C.A., Mainardi, C.L. and Harris, E.D. (1979) Inhibitor of Human Collagenase from Cultures of Human Tendon. Journal of Biological Chemistry, 254, 3045-3053.

[81] TIMP1 TIMP Metallopeptidase Inhibitor 1 [Homo Sapiens (Human)], Gene ID: 7076, updated on 7-Dec-2018, Full Report, NCBI.

[82] Taraboletti, G., Morbidelli, L., Donnini, S., Parenti, A., Granger, H.J., Giavazzi, R. and Ziche, M. (2000) The Heparin Binding $25 \mathrm{kDa}$ Fragment of Thrombospondin-1 Promotes Angiogenesis and Modulates Gelatinase and TIMP2 Production in Endothelial Cells. The FASEB Journal, 14, 1674-1676. https://doi.org/10.1096/fj.99-0931fje

[83] TIMP2 TIMP Metallopeptidase Inhibitor 2 [Homo Sapiens (Human)], Gene ID: 7077, updated on 7-Dec-2018, Full Report, NCBI.

[84] Arris, C.E., Bevitt, D.J., Mohamed, J., Li, Z., Langton, K.P., Barker, M.D., Clarke, M.P. and McKie, N. (2003) Expression of Mutant and Wild-Type TIMP3 in Primary Gingival Fibroblasts from Sorsby's Fundus Dystrophy Patients. Biochimica et Biophysica Acta (BBA)-Molecular Basis of Disease, 1638, 20-28. https://doi.org/10.1016/S0925-4439(03)00036-X

[85] Thomas Fréour, T., Jarry, A., Bach-Ngohou, K., Dejoie, T., Bou-Hanna, C., Denis, M.G., Mosnier, J.F., Laboisse, C.L. and Masson, D. (2009) TACE Inhibition Amplifies TNF- $\alpha$-Mediated Colonic Epithelial Barrier Disruption. International Journal of Molecular Medicine, 23, 41-48.

[86] Qi, J.H., Ebrahem, Q., Moore, N., Murphy, G., Claesson-Welsh, L., Bond, M., Andrew Baker, A. and Anand-Apte, B. (2003) A Novel Function for Tissue Inhibitor of Metalloproteinases-3 (TIMP3): Inhibition of Angiogenesis by Blockage of VEGF Binding to VEGF Receptor-2. Nature Medicine, 9, 407-415. https://doi.org/10.1038/nm846

[87] TIMP3 TIMP Metallopeptidase Inhibitor 3 [Homo Sapiens (Human)], Gene ID: 7078, updated on 8-Dec-2018, Full Report, NCBI.

[88] Casagrande, V., Mauriello, A., Bischetti, S., Mavilio, M., Federici, M. and Menghin, R. (2017) Hepatocyte Specific TIMP3 Expression Prevents Diet Dependent Fatty Liver Disease and Hepatocellular Carcinoma. Scientific Reports, 7, Article No. 6747. https://doi.org/10.1038/s41598-017-06439-x

[89] TIMP4 TIMP Metallopeptidase Inhibitor 4 [Homo Sapiens (Human)], Gene ID: 7079, updated on 7-Dec-2018, Summary, NCBI.

[90] Lizarraga, F., Espinosa, M., Ceballos-Cancino, G., Vazquez-Santillan, K., Bahena-Ocampo, I., Schwarz-Cruzy Celis, A., Vega-Gordillo, M., Garcia Lopez, P., Maldonado, V. and Melendez-Zajgla, J. (2016) Tissue Inhibitor of Metalloproteinases-4 (TIMP-4) Regulates Stemness in Cervical Cancer Cells. Molecular Carcinogenesis, 55, 1952-1961. https://doi.org/10.1002/mc.22442

[91] Lizarraga, F., Ceballos-Cancino, G., Espinosa, M., Vazquez-Santillan, K., Maldonado, V. and Melendez-Zajgla, J. (2015) Tissue Inhibitor of Metalloproteinase-4 Triggers Apoptosis in Cervical Cancer Cells. PLoS ONE, 10, e0135929. https://doi.org/10.1371/journal.pone.0135929

[92] Haerian, B.S., Sha'ari, H.M., Fong, C.Y., Tan, H.J., Wong, S.W., Ong, L.C., Raymond, A.A., Tan, C.T. and Mohamed, Z. (2015) Contribution of TIMP4 rs3755724 Polymorphism to Susceptibility to Focal Epilepsy in Malaysian Chinese. Journal of Neuroimmunology, 278, 137-143. https://doi.org/10.1016/j.jneuroim.2014.12.016 
[93] Groft, L.L., Muzik, H., Rewcastle, N.B., Johnston, R.N., Knäuper, V., Lafleur, M.A., Forsyth, P.A. and Edwards, D.R. (2001) Differential Expression and Localization of TIMP-1 and TIMP-4 in Human Gliomas. British Journal of Cancer, 85, 55-63. https://doi.org/10.1054/bjoc.2001.1854

[94] Kannus, P. and Józsa, L. (1991) Histopathological Changes Preceding Spontaneous Rupture of a Tendon. A Controlled Study of 891 Patients. The Journal of Bone and Joint Surgery, 73, 1507-1525. https://doi.org/10.2106/00004623-199173100-00009

[95] Veres, S.P. and Lee, J.M. (2012) Designed to Fail: A Novel Mode of Collagen Fibril Disruption and Its Relevance to Tissue Toughness. Biophysical Journal, 102, 28762884. https://doi.org/10.1016/j.bpj.2012.05.022

[96] Veres, S.P., Harrison, J.M. and Lee, J.M. (2014) Mechanically Overloading Collagen Fibrils Uncoils Collagen Molecules, Placing Them in a Stable, Denatured State. Matrix Biology, 33, 54-59. https://doi.org/10.1016/j.matbio.2013.07.003

[97] Baldwin, S.J., Kreplak, L. and Lee, J.M. (2016) Characterization via Atomic Force Microscopy of Discrete Plasticity in Collagen Fibrils from Mechanically Overloaded Tendons: Nano-Scale Structural Changes Mimic Rope Failure. Journal of the Mechanical Behavior of Biomedical Materials, 60, 356-366.

https://doi.org/10.1016/j.jmbbm.2016.02.004

[98] Medalia, O. and Geiger, B. (2010) Frontiers of Microscopy-Based Research into Cell-Matrix Adhesions. Current Opinion in Cell Biology, 22, 659-668. https://doi.org/10.1016/j.ceb.2010.08.006

[99] Knight, D.P. and Vollrath, F. (2002) Biological Liquid Crystal Elastomers. Philosophical Transactions of the Royal Society B, 357, 155-163.

https://doi.org/10.1098/rstb.2001.1030

[100] Hulmes, D.J.S. (2002) Building Collagen Molecules, Fibrils, and Suprafibrillar Structures. Journal of Structural Biology, 137, 2-10. https://doi.org/10.1006/jsbi.2002.4450

[101] Hamley, I.W. (2010) Liquid Crystal Phase Formation by Biopolymers. Soft Matter, 6, 1863-1871. https://doi.org/10.1039/b923942a

[102] Diamant, J., Keller, A., Baer, E., Litt, M. and Arridge, R.G. (1972) Collagen; Ultrastructure and Its Relation to Mechanical Properties as a Function of Ageing. Proceedings of the Royal Society B: Biological Sciences, 180, 293-315. https://doi.org/10.1098/rspb.1972.0019

[103] Järvinen, T.A., Järvinen, T.L., Kannus, P., Józsa, L. and Järvinen, M. (2004) Collagen Fibres of the Spontaneously Ruptured Human Tendons Display Decreased Thickness and Crimp Angle. Journal of Orthopaedic Research, 22, 1303-1309. https://doi.org/10.1016/j.orthres.2004.04.003

[104] Bass, E.C., Wistrom, E.V., Diederich, C.J., Nau, W.H., Pellegrino, R., Ruberti, J. and Lotz, J.C. (2004) Heat Induced Changes in Porcine Annulus Fibrosus Biomechanics. Journal of Biomechanics, 37, 233-240. https://doi.org/10.1016/j.jbiomech.2003.07.002

[105] Nabeshima, Y., Grood, E.S., Sakurai, A. and Herman, J.H. (1996) Uniaxial Tension Inhibits Tendon Collagen Degradation by Collagenase in Vitro. Journal of Orthopaedic Research, 14, 123-130. https://doi.org/10.1002/jor.1100140120

[106] Ruberti, J.W. and Hallab, N.J. (2005) Strain-Controlled Enzymatic Cleavage of Collagen in Loaded Matrix. Biochemical and Biophysical Research Communications, 336, 483-489. https://doi.org/10.1016/j.bbrc.2005.08.128

[107] Wyatt, K.E., Bourne, J.W. and Torzilli, P.A. (2009) Deformation-Dependent En- 
zyme Mechanokinetic Cleavage of Type I Collagen. Journal of Biomechanical Engineering, 131, Article ID: 051004. https://doi.org/10.1115/1.3078177

[108] Bhole, A.P., Flynn, B.P., Liles, M., Saeidi, N., Dimarzio, C.A. and Ruberti, J.W. (2009) Mechanical Strain Enhances Survivability of Collagen Micronetworks in the Presence of Collagenase: Implications for Load-Bearing Matrix Growth and Stability. Philosophical Transactions of the Royal Society A: Mathematical, Physical and Engineering Sciences, 367, 3339-3362. https://doi.org/10.1098/rsta.2009.0093

[109] Flynn, B.P., Bhole, A.P., Saeidi, N., Liles, M., DiMarzio, C.A. and Ruberti, J.W. (2010) Mechanical Strain Stabilizes Reconstituted Collagen Fibrils against Enzymatic Degradation by Mammalian Collagenase Matrix Metalloproteinase 8 (MMP-8). PLoS ONE, 5, e12337. https://doi.org/10.1371/journal.pone.0012337

[110] Wu, H., Byrne, M.H., Stacey, A., Goldring, M.B., Birkhead, J.R., Jaenisch, R. and Krane, S.M. (1990) Generation of Collagenase-Resistant Collagen by Site-Directed Mutagenesis of Murine Pro Alpha 1(I) Collagen Gene. Proceedings of the National Academy of Sciences of the United States of America, 87, 5888-5892. https://doi.org/10.1073/pnas.87.15.5888

[111] Flynn, B.P., Tilburey, G.E. and Ruberti, J.W. (2013) Highly Sensitive Single-Fibril Erosion Assay Demonstrates Mechanochemical Switch in Native Collagen Fibrils. Biomechanics and Modeling in Mechanobiology, 12, 291-300. https://doi.org/10.1007/s10237-012-0399-2

[112] Welgus, H.G., Jeffrey, J.J., Stricklin, G.P., Roswit, W.T. and Eisen, A.Z. (1980) Characteristics of the Action of Human Skin Fibroblast Collagenase on Fibrillar Collagen. The Journal of Biological Chemistry, 255, 6808-6813.

[113] Toledano, M., Aguilera, F.S., Yamauti, M., Ruiz-Requena, M.E. and Osorio, R. (2013) In Vitro Load-Induced Dentin Collagen-Stabilization against MMPs Degradation. Journal of the Mechanical Behavior of Biomedical Materials, 27, 10-18. https://doi.org/10.1016/j.jmbbm.2013.06.002

[114] Tonge, T.K., Ruberti, J.W. and Nguyen, T.D. (2015) Micromechanical Modeling Study of Mechanical Inhibition of Enzymatic Degradation of Collagen Tissues. Biophysical Journal, 109, 2689-2700. https://doi.org/10.1016/j.bpj.2015.10.051

[115] Chithra, P., Sajithlal, G.B. and Chandrakasan, G. (1998) Influence of Aloe vera on Collagen Characteristics in Healing Dermal Wounds in Rats. Molecular and Cellular Biochemistry, 181, 71-76. https://doi.org/10.1023/A:1006813510959

[116] Heinemeier, K.M., Schjerling, P., Heinemeier, J., Magnusson, S.P. and Kjaer, M. (2013) Lack of Tissue Renewal in Human Adult Achille Tendon Is Revealed by Nuclear Bomb ${ }^{14} \mathrm{C}$. The FASEB Journal, 27, 2074-2079. https://doi.org/10.1096/fj.12-225599

[117] Leikina, E., Mertts, M.V., Kuznetsova, N. and Leikin, S. (2002) Type I Collagen Is Thermally Unstable at Body Temperature. Proceedings of the National Academy of Sciences of the United States of America, 99, 1314-1318. https://doi.org/10.1073/pnas.032307099

[118] Bruckner, P. and Eikenberry, E.F. (1984) Procollagen Is More Stable in Cellulo than in Vitro. European Journal of Biochemistry, 140, 397-399. https://doi.org/10.1111/j.1432-1033.1984.tb08115.x

[119] Steinmann, B., Bruckner, P. and Superti-Furga, A. (1991) Cyclosporin A Slows Collagen Triple-Helix Formation in Vivo: Indirect Evidence for a Physiologic Role of Peptidyl-Prolyl Cis-Trans-Isomerase. The Journal of Biological Chemistry, 266, 1299-1303.

[120] Kadler, K.E., Hojima, Y. and Prockop, D.J. (1988) Assembly of Type I Collagen Fi- 
brils de Novo. Between 37 and 41 Degrees C the Process Is Limited by Micro-Unfolding of Monomers. Journal of Biological Chemistry, 263, 10517-10523.

[121] Bell, M.L. and Engvall, E. (1982) The Specific Detection of Collagenous Proteins after Electrophoresis Using Enzyme-Conjugated Collagen-Binding Fibronectin Fragments. Analytical Biochemistry, 123, 329-335. https://doi.org/10.1016/0003-2697(82)90454-7

[122] Bachinger, H.P., Bruckner, P., Timpl, R., Prockop, D.J. and Engel, J. (1980) Folding Mechanism of the Triple Helix in Type-III Collagen and Type-III pN-Collagen: Role of Disulfide Bridges and Peptide Bond Isomerization. The FEBS Journal, 106, 619-632. https://doi.org/10.1111/j.1432-1033.1980.tb04610.x

[123] Bruckner, P. and Prockop, D.J. (1981) Proteolytic Enzymes as Probes for the Triple-Helical Conformation of Procollagen. Analytical Biochemistry, 110, 360-368. https://doi.org/10.1016/0003-2697(81)90204-9

[124] Davis, J.M. and Bachinger, H.P. (1993) Hysteresis in the Triple Helix-Coil Transition of Type III. The Journal of Biological Chemistry, 268, 25965-25972.

[125] Nerenberg, P.S. and Stultz, C.M. (2008) Differential Unfolding of $\alpha 1$ and $\alpha 2$ Chains in Type I Collagen and Collagenolysis. Journal of Molecular Biology, 382, 246-256. https://doi.org/10.1016/j.jmb.2008.07.009

[126] Miles, C.A., Sims, T.J., Camacho, N.P. and Bailey, A.J. (2002) The Role of $\alpha 2$ Chain in the Stabilization of the Collagen Type I Heterotrimer: A Study of the Type I Homotrimer in oim Mouse Tissues. Journal of Molecular Biology, 321, 797-805. https://doi.org/10.1016/S0022-2836(02)00703-9

[127] Han, S., Makareeva, E., Kuznetsova, N.V., DeRidder, A.M., Sutter, M.B., Losert, W., Phillips, C.L., Visse, R., Nagase, H. and Leikin, S. (2010) Molecular Mechanism of Type I Collagen Homotrimer Resistance to Mammalian Collagenases. The Journal of Biological Chemistry, 285, 22276-22281. https://doi.org/10.1074/jbc.M110.102079

[128] Makareeva, E., Han, S., Vera, J.C., Sackett, D.L., Holmbeck, K., Phillips, C.L., Visse, R., Nagase, H. and Leikin, S. (2010) Carcinomas Contain a Matrix Metalloproteinase-Resistant Isoform of Type I Collagen Exerting Selective Support to Invasion. Cancer Research, 70, 4366-4374. https://doi.org/10.1158/0008-5472.CAN-09-4057

[129] Huang, K.A., Yi, B.R. and Choi, K.C. (2011) Molecular Mechanisms and in Vivo Mouse Models of Skin Aging Associated with Dermal Alterations. Laboratory Animal Research, 27, 1-8. https://doi.org/10.5625/lar.2011.27.1.1

[130] Hakala, M., Risteli, L., Manelius, J., Nieminen, P. and Risteli, J. (1993) Increased Type I Collagen Degradation Correlates with Disease Severity in Rheumatoid Arthritis. Annals of the Rheumatic Diseases, 52, 866-869. https://doi.org/10.1136/ard.52.12.866

[131] González, A., López, B., Querejeta, R. and Díez, J. (2002) Regulation of Myocardial Fibrillar Collagen by Angiotensin II. A Role in Hypertensive Heart Disease? Journal of Molecular and Cellular Cardiology, 34, 1585-1593. https://doi.org/10.1006/jmcc.2002.2081

[132] Lombardi, R., Betocchi, S., Losi, M.A., Tocchetti, C.G., Aversa, M., Miranda, M., Alessandro, G.D., Cacace, A., Ciampi, Q. and Chiariello, M. (2003) Collagen Turnover in Hypertrophic Cardiomyopathy. Circulation, 108, 1455-1460. https://doi.org/10.1161/01.CIR.0000090687.97972.10

[133] Misof, K., Landis, W.J., Klaushofer, K. and Fratzl, P. (1997) Collagen from the Osteogenesis Imperfecta Mouse Model (oim) Shows Reduced Resistance against Tensile Stress. Journal of Clinical Investigation, 100, 40-45. 
https://doi.org/10.1172/JCI119519

[134] McBride, D.J., Choe, V., Shapiro, J.R. and Brodsky, B. (1997) Altered Collagen Structure in Mouse Tail Tendon Lacking the $\alpha 2(\mathrm{I})$ Chain. Journal of Molecular Biology, 270, 275-284. https://doi.org/10.1006/jmbi.1997.1106

[135] Phillips, C.L., Pfeiffer, B.J., Luger, A.M. and Franklin, C.L. (2002) Novel Collagen Glomerulopathy in a Homotrimeric Type I Collagen Mouse (oim). Kidney International, 62, 383-391. https://doi.org/10.1046/j.1523-1755.2002.00451.x

[136] Gay, S., Vijanto, J., Raekallio, J. and Penttinen, R. (1978) Collagen Types in Early Phases of Wound Healing in Children. Acta Chirurgica Scandinavica, 144, 205-211.

[137] Wooley, P.H., Luthra, H.S., Stuart, J.M. and David, C.S. (1981) Type II Collagen-Induced Arthritis in Mice. I. Major Histocompatibility Complex (I Region) Linkage and Antibody Correlates. The Journal of Experimental Medicine, 154, 688700. https://doi.org/10.1084/jem.154.3.688

[138] Maroudas, A., Palla, G. and Gilav, E. (1992) Racemization of Aspartic Acid in Human Articular Cartilage. Connective Tissue Research, 28, 161-169. https://doi.org/10.3109/03008209209015033

[139] Maffulli, N., Khan, K.M. and Puddu, G. (1998) Overuse Tendon Conditions: Time to Change a Confusing Terminology. Arthroscopy, 14, 840-843. https://doi.org/10.1016/S0749-8063(98)70021-0

[140] Xu, Y. and Murrell, G.A. (2008) The Basic Science of Tendinopathy. Clinical Orthopaedics and Related Research, 466, 1528-1538. https://doi.org/10.1007/s11999-008-0286-4

[141] Khan, K., Cook, J., Kannus, P., Maffulli, N. and Bonar, S. (2002) Time to Abandon the "Tendinitis" Myth: Painful, Overuse Tendon Conditions Have a Non-Inflammatory Pathology. BMJ, 324, 626-627. https://doi.org/10.1136/bmj.324.7338.626

[142] Riley, G. (2005) Chronic Tendon Pathology: Molecular Basis and Therapeutic Implications. Expert Reviews in Molecular Medicine, 7, 1-25. https://doi.org/10.1017/S1462399405008963

[143] Sharma, P. and Maffulli, N. (2005) Tendon Injury and Tendinopathy: Healing and Repair. The Journal of Bone and Joint Surgery, 87, 187-202.

[144] Ralphs, J.R. (2002) Cell Biology of Tendons. European Cells \& Materials Journal, 4, 39-40.

[145] Wall, M.E., Otey, C., Qi, J. and Banes, A.J. (2006) Connexin 43 Is Localized with Actin in Tenocytes. Cell Motility, 64, 121-130. https://doi.org/10.1002/cm.20170

[146] Maeda, E., Pian, H. and Ohashi, T. (2017) Temporal Regulation of Gap Junctional Communication between Tenocytes Subjected to Static Tensile Strain with Physiological and Nonphysiological Amplitudes. Biochemical and Biophysical Research Communications, 482, 1170-1175. https://doi.org/10.1016/j.bbrc.2016.12.007

[147] Wenstrup, R.J., Florer, J.B., Brunskill, E.W., Bell, S.M., Chervoneva, I. and Birk, D.E. (2004) Type V Collagen Controls the Initiation of Collagen Fibril Assembly. The Journal of Biological Chemistry, 279, 53331-53337. https://doi.org/10.1074/jbc.M409622200

[148] da Silva, M.L., Caplan, A.I. and Nardi, N.B. (2008). In Search of the in Vivo Identity of Mesenchymal Stem Cells. Stem Cells, 26, 2287-2299. https://doi.org/10.1634/stemcells.2007-1122

[149] Kalamajski, S. and Oldberg, Å. (2010) The Role of Small Leucine-Rich Proteoglycans in Collagen Fibrillogenesis. Matrix Biology, 29, 248-253.

https://doi.org/10.1016/j.matbio.2010.01.001 
[150] Perryman, S.V. and Sylvester, K.G. (2006) Repair and Regeneration: Opportunities for Carcinogenesis from Tissue Stem Cells. Journal of Cellular and Molecular Medicine, 10, 292-308. https://doi.org/10.1111/j.1582-4934.2006.tb00400.x

[151] Smith, A.A., Li, J., Liu, B., Hunter, D., Pyles, M., Gilletle, M., Dhamdhere, G.R., Abo, A., Oro, A., Helms, J.A. (2016) Activating Hair Follicle Stem Cells via R-spondin2 to Stimulate Hair Growth, J. Investigative Dermatology, 136(8):1549-1558. https://doi.org/10.1016/j.jid.2016.01.041

[152] Donnelly, E., Ascenzi, M.G. and Farnum, C. (2010) Primary Cilia Are Highly Oriented with Respect to Collagen Direction and Long Axis of Extensor Tendon. Journal of Orthopaedic Research, 28, 77-82.

[153] Matthews, T.J.W., Hand, G.C., Rees, J.L., Athanasou, N.A. and Carr, A.J. (2006) Pathology of the Torn Rotator Cuff Tendon, Reduction in Potential for Repair as Tear Size Increases. The Bone and Joint Journal, 88, 489-495.

[154] Archambault, J., Tsuzaki, M., Herzog, W. and Banes, A.J. (2006) Stretch and Interleukin- $1 \beta$ Induce Matrix Metalloproteinases in Rabbit Tendon Cells in Vitro. Journal of Orthopaedic Research, 20, 36-39. https://doi.org/10.1016/S0736-0266(01)00075-4

[155] Tsuzaki, M., Guyton, G., Garrett, W., Archambault, J.M., Herzog, W., Almekinders, L., Bynum, D., Yang, X. and Banes, A.J. (2003) IL-1 $\beta$ Induces COX2, MMP-1, -3 and -13, ADAMTS-4, IL-1 $\beta$ and IL-6 in Human Tendon Cells. Journal of Orthopaedic Research, 21, 256-264. https://doi.org/10.1016/S0736-0266(02)00141-9

[156] Millar, N.L., Wei, A.Q., Molloy, T.J., Bonar, F. and Murrell, G.A. (2009) Cytokines and Apoptosis in Supraspinatus Tendinopathy. The Bone \& Joint Journal, 91B, 417-424. https://doi.org/10.1302/0301-620X.91B3.21652

[157] Schoenenberger, A.D., Foolen, J., Moor, P., Silvan, U., Jess, G. and Snedeker, J.G. (2018) Substrate Fiber Alignment Mediates Tendon Cell Response to Inflammatory Signalling. Acta Biomaterialia, 71, 306-317.

https://doi.org/10.1016/j.actbio.2018.03.004

[158] Phelan, K. and May, K.M. (2015) Basic Techniques in Mammalian Cell Tissue Culture. Current Protocols in Cell Biology, 66, 1.1.1-1.1.22.

[159] Zajac, E., Schweighofer, B., Kupriyanova, T.A., Juncker-Jensen, A., Minder, P., Quigley, J.P. and Deryugina, E.I. (2013) Angiogenic Capacity of M1- and M2-Polarized Macrophages Is Determined by the Levels of TIMP-1 Complexed with Their Secreted proMMP-9. Blood, 122, 4054-4067. https://doi.org/10.1182/blood-2013-05-501494

[160] Zhang, B., Luo, Q., Sun, J., Xu, B., Ju, Y., Yang, L. and Song, G. (2015) MGF Enhances Tenocyte Invasion through MMP-2 Activity via the FAK-ERK1/2 Pathway. Wound Repair and Regeneration, 23, 394-402. https://doi.org/10.1111/wrr.12293

[161] Grant, T.M., Thompson, M.S., Urban, J. and Yu, J. (2013) Elastic Fibres Are Broadly Distributed in Tendon and Highly Localized around Tenocytes. Journal of Anatomy, 222, 573-579. https://doi.org/10.1111/joa.12048

[162] Kannus, P. (2000) Structure of the Tendon Connective Tissue. Scandinavian Journal of Medicine \& Science in Sports, 10, 312-320. https://doi.org/10.1034/j.1600-0838.2000.010006312.x

[163] Thorpe, C.T., Peffers, M.J., Simpson, D., Halliwell, E., Screen, H.R.C. and Clegg, P.D. (2016) Anatomical Heterogeneity of Tendon: Fascicular and Interfascicular Tendon Compartments Have Distinct Proteomic Composition. Scientific Reports, 6, Article No. 20455. https://doi.org/10.1038/srep20455 
[164] THBS4 Thrombospondin 4 [Homo Sapiens (Human)], Gene ID: 7060, updated on 7-Dec-2018, Full Report, NCBI.

[165] UniProtKB-P49747 (COMP_HUMAN) 2018.

[166] UniProtKB Q06828 (FMOD_HUMAN) 2018.

[167] DCN Decorin [Homo Sapiens (Human)] Gene ID: 1634, updated on 7-Dec-2018, Full Report, NCBI.

[168] Svensson, R.B., Smith, S.T., Moyer, P.J. and Magnusson, S.P. (2018) Effects of Maturation and Advanced Glycation on Tensile Mechanics of Collagen Fibrils from Rat Tail and Achilles Tendons. Acta Biomaterialia, 70, 270-280. https://doi.org/10.1016/j.actbio.2018.02.005

[169] de Mos, M., van der Windt, A.E., Jahr, H., van Schie, H.T.M., Weinans, H., Verhaar, J.A.N. and van Osch, G.J.V.M. (2008) Can Plateletrich Plasma Enhance Tendon Repair? A Cell Culture Study. The American Journal of Sports Medicine, 36, 11711178. https://doi.org/10.1177/0363546508314430

[170] Giusti, I., Sandra D’Ascenzo, S.D., Mancò, A., Stefano, G.D., Francesco, M.D., Rughetti, A., Mas, A.D., Properzi, G., Calvisi, V. and Dolo, V. (2014) Platelet Concentration in Platelet-Rich Plasma Affects Tenocyte Behavior in Vitro. BioMed Research International, 2014, Article ID: 630870. https://doi.org/10.1155/2014/630870

[171] Lamkanfi, M. and Dixit, V.M. (2009) IL-33 Raises Alarm. Immunity, 31, 5-7. https://doi.org/10.1016/j.immuni.2009.06.011

[172] Bartel, D.P. (2009) MicroRNAs: Target Recognition and Regulatory Functions. Cell, 136, 215-233. https://doi.org/10.1016/j.cell.2009.01.002

[173] Millar, N.L., Gilchrist, D.S., Akbar, M., Reilly, J.H., Kerr, S.C., Campbell, A.L., Murrell, G.A.C., Liew, F.Y., Kurowska-Stolarska, M. and Mclnnes, L.B. (2015) MicroRNA29a Regulates IL-33-Mediated Tissue Remodelling in Tendon Disease. Nature Communications, 6, Article No. 6774.

[174] Millar, N.L., Murrell, G.A.C. and McInnes, I.B. (2017) Inflammatory Mechanisms in Tendinopathy-Towards Translation. Nature Reviews, 13, 110-112. https://doi.org/10.1038/nrrheum.2016.213

[175] Gee, M.D., Lynn, B. and Cotsell, B. (1997) The Relationship between Cutaneous C Fiber Type and Antidromic Vasodilatation in the Rabbit and the Rat. Journal of Physiology, 503, 31-44. https://doi.org/10.1111/j.1469-7793.1997.031bi.x

[176] Lui, S.L., Chan, L.Y., Zhang, X.H., Zhu, W., Chan, T.M., Fung, P.C.W. and Lai, K.N. (2001) Effect of Mycophenolate Mofetil on Nitric Oxide Production and Inducible Nitric Oxide Synthase Gene Expression during Renal Ischaemia-Reperfusion Injury. Nephrology Dialysis Transplantation, 16, 1577-1582. https://doi.org/10.1093/ndt/16.8.1577

[177] Schäffer, M.R., Tantry, U., Gross, S.S., Wasserkrug, H.L. and Barbul, A. (1996) Nitric Oxide Regulates Wound Healing. Journal of Surgical Research, 63, 237-240. https://doi.org/10.1006/jsre.1996.0254

[178] Xia, W., Szomor, Z., Wang, Y. and Murrell, G.A.C. (2006) Nitric Oxide Enhances Collagen Synthesis in Cultured Human Tendon Cells. Journal of Orthopaedic Research, 24, 159-172. https://doi.org/10.1002/jor.20060

[179] Lin, J.H., Wang, M.X., Wei, A., Zhu, W., Diwan, A.D. and Murrell, G.A.C. (2001) Temporal Expression of Nitric Oxide Synthase Isoforms in Healing Achilles Tendon. Journal of Orthopaedic Research, 19, 136-142. https://doi.org/10.1016/S0736-0266(00)00019-X

[180] Murrell, G.A.C. (2007) Using Nitric Oxide to Treat Tendinopathy. British Journal 
of Sports Medicine, 41, 227-231. https://doi.org/10.1136/bjsm.2006.034447

[181] Bokhari, A.R. and Murrell, G.A. (2012) The Role of Nitric Oxide in Tendon Healing. Journal of Shoulder and Elbow Surgery, 21, 238-244.

https://doi.org/10.1016/j.jse.2011.11.001

[182] Menon, A., Pettinari, L., Martinelli, C., Colombo, G., Portinaro, N., Dalle-Donne, I., Agostino, M.C. and Gagliano, N. (2013) New Insights in Extracellular Matrix Remodeling and Collagen Turnover Related Pathways in Cultured Human Tenocytes after Ciprofloxacin Administration. Muscles, Ligaments and Tendons Journal, 3, 122-131.

[183] Brilla, C.G., Matsubara, L.S. and Weber, K.T. (1993) Antifibrotic Effects of Spironolactone in Preventing Myocardial Fibrosis in Systemic Arterial Hypertension. The American Journal of Cardiology, 71, A12-A16.

https://doi.org/10.1016/0002-9149(93)90239-9

[184] Horn, M.A., Graham, H.K., Richards, M.A., Clarke, J.D., Greensmith, D.J., Briston, S.J., Hall, M.C.S., Dibb, K.M. and Trafford, A.W. (2012) Age-Related Divergent Remodeling of the Cardiac Extracellular Matrix in Heart Failure: Collagen Accumulation in the Young and Loss in the Aged. Journal of Molecular and Cellular Cardiology, 53, 82-90. https://doi.org/10.1016/j.yjmcc.2012.03.011

[185] Stickens, D., Behonick, D.J., Ortega, N., Heyer, B., Hartenstein, B., Yu, Y., Fosang, A.J., Schorpp-Kistner, M., Angel, P. and Werb, Z. (2004) Altered Endochondral Bone Development in Matrix Metalloproteinase 13-Deficient Mice. Development, 131, 5883-5895. https://doi.org/10.1242/dev.01461

[186] Bataller, R. and Brenner, D.A. (2005) Liver Fibrosis. Journal of Clinical Investigation, 115, 209-218. https://doi.org/10.1172/JCI24282

[187] Riley, G.P., Harrall, R.L., Watson, P.G., Cawston, T.E. and Hazleman, B.L. (1995) Collagenase (MMP-1) and TIMP-1 in Destructive Corneal Disease Associated with Rheumatoid Arthritis. Eye, 9, 703-718. https://doi.org/10.1038/eye.1995.182

[188] Barnes, M.J. and Farndale, R.W. (1999) Collagens and Atherosclerosis. Experimental Gerontology, 34, 513-525. https://doi.org/10.1016/S0531-5565(99)00038-8

[189] Akiyama, K., Shikata, K., Sugimoto, H., Matsuda, M., Shikata, Y., Fujimoto, N., Obata, K., Matsui, H. and Makino, H. (1997) Changes in Serum Concentrations of Matrix Metalloproteinases, Tissue Inhibitors of Metalloproteinases and Type IV Collagen in Patients with Various Types of Glomerulonephritis. Research Communications in Molecular Pathology and Pharmacology, 95, 115-128.

[190] Van Haaften, W.T., Mortensen, J.H., Karsdal, M.A., Bay-Jensen, A.C., Dijkstra, G. and Olinga, P. (2017) Misbalance in Type III Collagen Formation/Degradation as a Novel Serological Biomarker for Penetrating (Montreal B3) Crohn's Disease. Alimentary Pharmacology \& Therapeutics, 46, 26-39.

https://doi.org/10.1111/apt.14092

[191] Gautieri, A., Uzel, S., Vesentini, S., Redaelli, A. and Buehler, M.J. (2009) Molecular and Mesoscale Mechanisms of Osteogenesis Imperfecta Disease in Collagen Fibrils. Biophysical Journal, 97, 857-865. https://doi.org/10.1016/j.bpj.2009.04.059

[192] Chang, S.W., Shefelbine, S.J. and Buehler, M.L. (2012) Structural and Mechanical Differences between Collagen Homo- and Heterotrimers: Relevance for the Molecular Origin of Brittle Bone Disease. Biophysical Journal, 102, 640-648. https://doi.org/10.1016/j.bpj.2011.11.3999

[193] Lee, J.S., Park, I.S., Park, K.B., Kang, D.H., Lee, C.H. and Hwang, S.H. (2008) Familial Intracranial Aneurysms. Journal of Korean Neurosurgical Society, 44, 136-140. https://doi.org/10.3340/jkns.2008.44.3.136 
[194] Steinmann, B., Royce, P.M. and Superti-Furga, A. (1993) Chapter 9. The Ehlers-Danlos Syndrome. In: Royce, P.M. and Steinmann, B., Eds., Connective Tissue and Its Heritable Disorders, Wiley, New York, 431-523.

[195] Maw, G.J., Mackenzie, I.L. and Taylor, N.A.S. (1995) Redistribution of Body Fluids during Postural Manipulations. Acta Physiologica Scandinavica, 155, 157-163. https://doi.org/10.1111/j.1748-1716.1995.tb09960.x

[196] Husmann, M., Barton, M., Amann-Vesti, B. and Franzock, U.K. (2006) Postural Effects on Interstitial Fluid Pressure in Humans. Journal of Vascular Research, 43, 321-326. https://doi.org/10.1159/000093197

[197] Fung, P.C.W. and Kong, R.K.C. (2018) Relationship among the Meridians, Sinew Channels and Integrative Five Fluid Circulation System. Traditional Chinese Medicine, 7, 74-92. https://doi.org/10.12677/TCM.2018.71013

[198] Lund, T., Wiig, H., Reed, R.K. and Aukland, K. (1987) A “New" Mechanism for Oedema Generation: Strongly Negative Interstitial Fluid Pressure Causes Rapid Fluid Flow into Thermally Injured Skin. Acta Physiologica Scandinavica, 129, 433-435. https://doi.org/10.1111/j.1365-201X.1987.tb10610.x

[199] Wiig, H., Rubin, K. and Reed, R.K. (2003) New and Active Role of the Interstitium in Control of Interstitial Fluid Pressure: Potential Therapeutic Consequences. Acta Anaesthesiologica Scandinavica, 47, 111-121. https://doi.org/10.1034/j.1399-6576.2003.00050.x

[200] Lidén, Å. (2006) Integrin $\alpha_{\mathrm{v}} \beta_{3}$-Directed Contraction by Connective Tissue Cells Role in Control of Interstitial Fluid Pressure and Modulation by Bacterial Proteins. Ph.D. Thesis, Faculty of Medicine, Uppsala University, Uppsala.

[201] Svendsen, Ø.S., Barczyk, M.M., Popova, S.N., Lidén, Å., Gullberg, D. and Wiig, H. (2009) The $\alpha 11 \beta 1$ Integrin Has a Mechanistic Role in Control of Interstitial Fluid Pressure and Edema Formation in Inflammation. Arteriosclerosis, Thrombosis, and Vascular Biology, 29, 1864-1870. https://doi.org/10.1161/ATVBAHA.109.194308

[202] Finkelstein, A.V., Badretdin, A.J., Galzitskaya, O.V., Ivankov, D.N., Bogatyreva, N.S. and Garbuzynskiy, S.O. (2017) There and Back Again: Two Views on the Protein Folding Puzzle. Physics of Life Reviews, 21, 56-71. https://doi.org/10.1016/j.plrev.2017.01.025

[203] Englandera, S.W. and Maynea, L. (2017) The Case for Defined Protein Folding Pathways. Proceedings of the National Academy of Sciences of the United States of America, 114, 8253-8258. https://doi.org/10.1073/pnas.1706196114

[204] Svensson, R.B., Herchenhan, A., Starborg, T., Larsen, M., Kadler, K.E., Qvortrup, K. and Magnusson, S.P. (2017) Evidence of Structurally Continuous Collagen Fibrils in Tendons. Acta Biomaterialia, 50, 293-301. https://doi.org/10.1016/j.actbio.2017.01.006

[205] Raspanti, M., Congiu, T. and Guizzardi, S. (2002) Structural Aspects of the Extracellular Matrix of the Tendon: An Atomic Force and Scanning Electron Microscopy Study. Archives of Histology and Cytology, 65, 37-43. https://doi.org/10.1679/aohc.65.37

[206] Kanzaki. Y., Terasaki, F., Okabe, M., Fujita, S., Katashima, T., Otsuka, K. and Ishizaka, N. (2010) Three-Dimensional Architecture of Cardiomyocytes and Connective Tissue in Human Heart Revealed by Scanning Electron Microscopy. Circulation, 122, 1973-1974. https://doi.org/10.1161/CIRCULATIONAHA.110.979815

[207] Fung, P.C.W. and Kong, R.K.C. (2018) New Insights on Stimulating the Lung Meridian Based on Modern Neurophysiology. Chinese Medicine, Scientific Research, 9 , 75-117. 